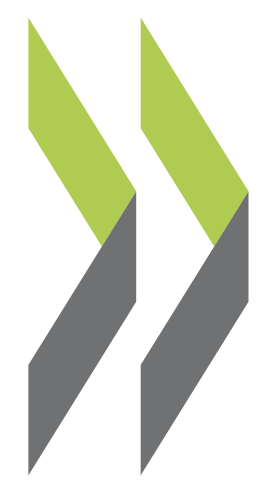

OECD Local Economic and Employment Development (LEED) Papers 2013/07

\title{
Pomorskie Region: Responding to Demographic Transitions Towards 2035
}

\section{Iwona Sagan,}

\section{Cristina Martinez-} Fernandez,

\section{Tamara Weyman}




\section{POMORSKIE REGION: RESPONDING TO DEMOGRAPHIC}

\section{TRANSITIONS TOWARDS 2035}




\section{DISCLAIMER}

This work is published on the responsibility of the Secretary-General of the OECD. The opinions expressed and arguments employed herein do not necessarily reflect the official views of the Organisation or of the governments of its member countries.

This document and any map included herein are without prejudice to the status of or sovereignty over any territory, to the delimitation of international frontiers and boundaries and to the name of any territory, city or area. 


\title{
ABOUT THE OECD
}

The Organisation for Economic Co-operation and Development (OECD) is a unique forum where the governments of 34 market democracies work together to address the economic, social and governance challenges of globalisation as well as to exploit its opportunities. The OECD's way of working consists of a highly effective process that begins with data collection and analysis and moves on to collective discussion of policy, then decision making and implementation. Mutual examination by governments, multi-lateral surveillance and peer pressure to conform or reform are at the heart of the OECD's effectiveness. Much of the material collected and analysed at the OECD is published on paper or online: from press releases and regular compilations of data and projections to one-off publications or monographs on particular issues; from economic surveys of each member country to regular reviews of education systems, science and technology policies or environmental performance. For more information on the OECD, please visit www.oecd.org/about.

The OECD member countries are: Australia, Austria, Belgium, Canada, Chile, the Czech Republic, Denmark, Estonia, Finland, France, Germany, Greece, Hungary, Iceland, Ireland, Israel, Italy, Japan, Korea, Luxembourg, Mexico, the Netherlands, New Zealand, Norway, Poland, Portugal, the Slovak Republic, Slovenia, Spain, Sweden, Switzerland, Turkey, the United Kingdom and the United States. The European Commission takes part in the work of the OECD.

\begin{abstract}
ABOUT LEED
The OECD Programme on Local Economic and Employment Development (LEED) has advised governments and communities since 1982 on how to respond to economic change and tackle complex problems in a fast-changing world. Its mission is to contribute to the creation of more and better quality jobs through more effective policy implementation, innovative practices, stronger capacities and integrated strategies at the local level. LEED draws on a comparative analysis of experience from the five continents in fostering economic growth, employment and inclusion.
\end{abstract}

ISSN 2079-4797 (PDF) OECD Local Economic and Employment Development (LEED) Working Paper Series. This report is part of a series of working papers from the OECD Local Economic and Employment Development (LEED) Programme. The LEED Programme identifies, analyses and disseminates innovative ideas for local development, governance and the social economy. Governments from OECD member and non-member economies look to LEED and work through it to generate innovative guidance on policies to support employment creation and economic development through locally based initiatives. 


\section{ACKNOWLEDGEMENTS}

This paper was prepared by Iwona Sagan, University of Gdańsk, Poland with Cristina Martinez-Fernandez and Tamara Weyman. The paper was prepared under the supervision of Dr Cristina Martinez (OECD LEED Programme). Dr Tamara Weyman (consultant) provided research and editorial assistance. The paper has been reviewed by Naoko Kubo (consultant) and Antonella Noya (OECD LEED Programme). Ms Melissa Telford edited and formatted the paper for publication. Ms Elisa Campestrin and Mr Francois Iglesias provided technical support.

The paper has benefited from the valuable contribution of Dr Grzegorz Masik, University of Gdańsk and comments from Przemysław Herman and Michał Sułkowski from the Ministry of Regional Development under the supervision of Mr Pawel Chorazy, Director, Department for European Social Fund Management. Thanks also to the significant inputs and workshop recommendations made by the international experts participating in the OECD study mission to Gdańsk in March 2012: Dr Jasper Van Loo (CEDEFOP), Mr Aldert de Vries (Ministry of Interior and Kingdom Relations of the Netherlands), Robert Strauss (European Commission), Naoko Kubo and Antonella Noya (OECD LEED Programme).

Special thanks should be given to the representatives and officers of the Marshall's Office of the Pomorskie Voivodeship, and to the other provincial and local authorities and institutions who participated in meetings, workshops and study visits, and who provided documentation and comments critical to the production of the paper.

This Working Paper is part of a series of studies of the Organisation for Economic Co-operation and Development (OECD) Local Economic and Employment Development (LEED) Programme on "Local Scenarios of Demographic Change". This study is conducted in collaboration with project partners Ministry of Regional Development, Poland and the Pomorskie Regional Government. 
TABLE OF CONTENTS

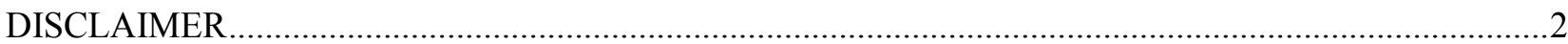

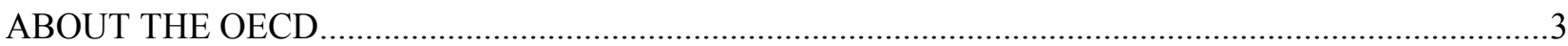

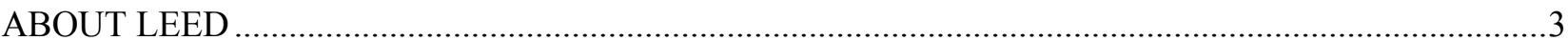

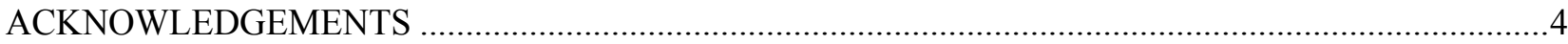

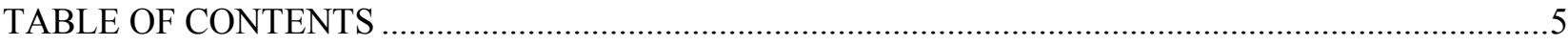

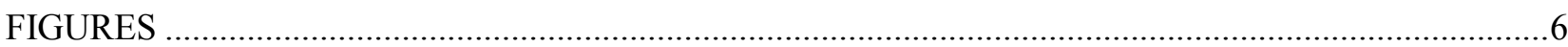

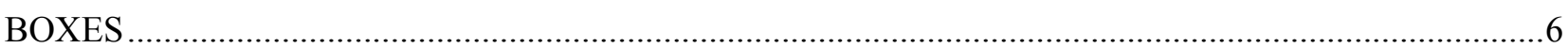

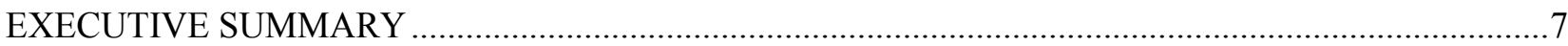

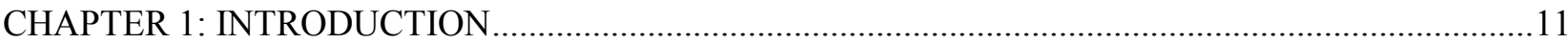

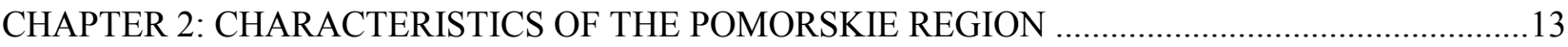

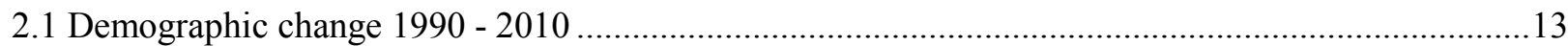

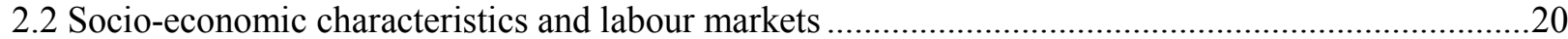

CHAPTER 3: OLDER WORKERS: SILVER ECONOMY AND WHITE ECONOMY ..........................29

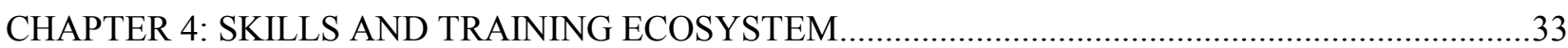

CHAPTER 5: HEALTH SERVICES FOR SOCIAL TRANSFORMATION AND INCLUSION ...............36

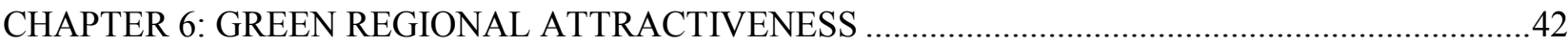

CHAPTER 7: REGIONAL/LOCAL INITIATIVES AND POLICY ISSUES …......................................46

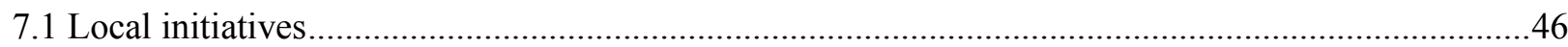

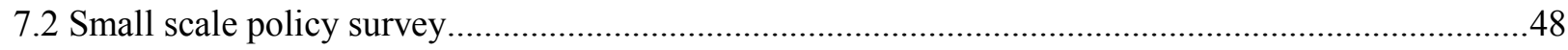

CHAPTER 8: KEY CONCLUSIONS AND RECOMMENDATIONS FOR POMORSKIE......................50

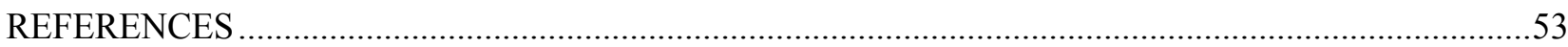

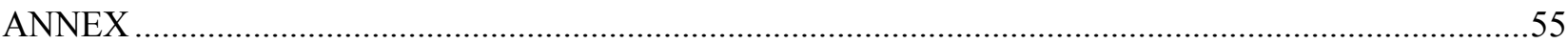




\section{FIGURES}

Figure 1 Pomorskie voivodeship

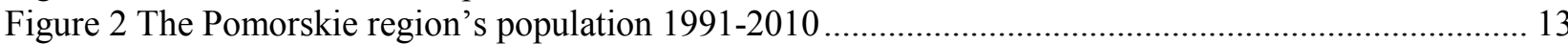

Figure 3 Average inter-LAU 1 migrations of the Pomorskie Region, 2002- 2010 ................................... 14

Figure 4 Population density changes in LAU 1 of the Pomorskie region, 2002-2010 _............................. 15

Figure 5 People over 65 years in LAU 1 of the Pomorskie region, 2010 ................................................ 16

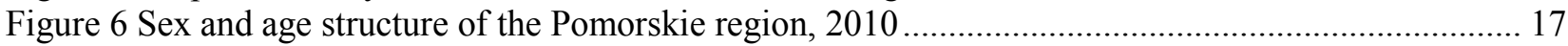

Figure 7 Fertility rate in the Pomorskie region, 1991-2009 ................................................................... 18

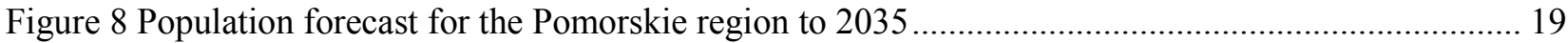

Figure 9 People aged 50+ forecast for the Pomorskie region to 2035................................................... 19

Figure 10 Changes in gross value added by branches of the economy, 1995-2008 .................................. 21

Figure 11 Population by working age categories in the Pomorskie region, $1995-2010 \ldots \ldots \ldots \ldots \ldots \ldots \ldots \ldots \ldots . . . . . .22$

Figure 12 Employment and employment rate in the Pomorskie region, 1999-2010 ................................ 23

Figure 13 Employment rate by age groups in the Pomorskie region, 1999-2010 ..................................... 24

Figure 14 The employment structure in Pomorskie, 1998-2007 …...................................................... 25

Figure 15 Unemployment rates in the Pomorskie region, 1999-2010 _....................................................... 26

Figure 16 Unemployment of people over the age of 55 in LAU 1 of the Pomorskie region, 2010 ............ 27

Figure 17 Changes in unemployment rates for people 55+ in LAU 1 of the Pomorskie region, 2002-201028

Figure 18 Population forecast by working-age groups for the Pomorskie region to 2035 ......................... 29

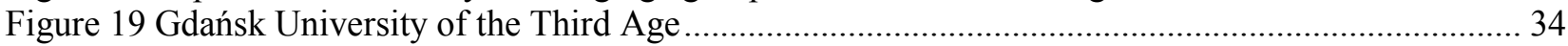

Figure 20 Physicians in LAU 1 of the Pomorskie Region, 2010 ........................................................... 37

Figure 21 Changes in the number of physicians in LAU 1 of the Pomorskie region, 2006-2010.............. 37

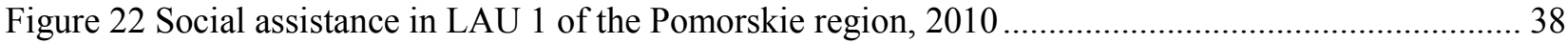

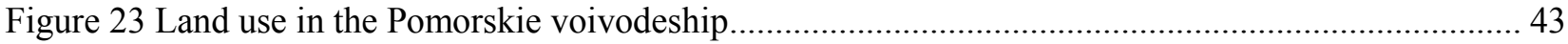

Figure 24 Publicly accessible green spaces indicator in LAU 1 of the Pomorskie region, 2010 ............... 44

Figure 25 The evaluation and level of importance of specific areas of the OLWOF index in Pomorskie... 48

Figure 26 The evaluation of specific areas of the ELFRI index in Pomorskie........................................... 49

\section{BOXES}

Box 1 I work - I develop competence. An innovative model of support for workers 50+. ..................... 30

Box 2 "Make Use of Us! 45 + Employees in Your Enterprise" ................................................................ 31

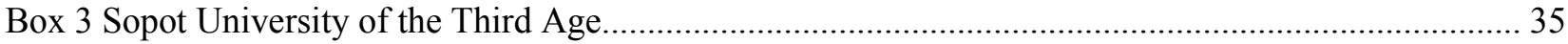

Box 4 Baltic Centre for Biotechnology and Innovative Diagnostics BioBaltica ....................................... 47 


\section{EXECUTIVE SUMMARY}

Demographic change is one of the key challenges today for local development; strategic solutions must consider the interplay of elements within a particular local area of development. At the same time, there are opportunities to be fostered, such as the development of the silver economy of older entrepreneurs, the white economy for medical services for the elderly population, and the green economy.

This paper outlines the findings of the Poland case study for the Pomorskie region for the international project Local scenarios of demographic change. The project is conducted by the Organisation of Economic Development and Co-operation (OECD) Local Economic and Employment Development (LEED) Programme with the support of the European Commission DG Employment, Social Affairs and Inclusion. The analysis in Poland was conducted in partnership with the Ministry of Regional Development and the regions of Pomorskie, Łódzkie and Małopolska.

The Pomorskie voivodeship is experiencing population growth, with both a natural increase and a net migration yielding a positive value in the region. Compared to the rest of the country, Pomorskie has a relatively young age structure and a low dependency ratio. However, there is a growing share of elderly people in the social structure of the region and the number of people at the pre-working age is decreasing. Therefore, respective local and regional policies must be applied in order to manage the problems that will originate from these new demographic trends.

The findings of the study highlight the following issues:

- The region has been experiencing population growth since the $1990 \mathrm{~s}$, and the majority $(68 \%)$ of the population lives in the cities. The region's immigration attractiveness is its labour market, however, there has been notable shrinkage in the Gdańsk agglomeration population as a result of urban sprawl. There have been attempts made to slow down the processes of urban sprawl, with the implementation of compact city ideals.

- The socio-economic development related to spatial diversity within the region is a significant aspect to consider in any policy development. While the metropolitan suburban areas have the highest demographic potential (due to intensive suburbanisation, younger age structure, positive net migration and natural increase) the western and south-eastern parts, which are located far from urban centres, suffer from limited access to labour markets and education services.

- The changing age structure is becoming a noticeable issue, with a significant decrease in the number of young people and increasing number of working and post-working age groups. However, the region is currently in the initial phase of population ageing. Along with rising life expectancies (especially men) and a declining fertility rate, which is below replacement levels, the ageing population structure will impact on the region's labour market, economy and social assistance systems before long. The impact on the labour market has been met with initiatives (funded/co-funded by European Social Funds) designed to activate older workers, improve skills, focus on age management and combat ageing stereotyping.

- The ageing population also opens up opportunities in the silver and white economies, which are all about meeting older people's needs. However, there are several issues related to the white economy that need to be assessed, such as funding, long-term care, geriatric and rehabilitation services, psychological support, and the increasing number of older foreign tourists seeking medical services. The opportunities in the silver economy are related to meeting consumption demands of older customers, services to occupy free time (education, tourism and recreation), and care services (cleaning, shopping, transportation, etc). Another growing economic potential is 
linking of the silver and white economies' (health and beauty) care services. The location of the region (coastal) also provides favourable conditions for silver economy development, especially for small and medium enterprises which is an advantage not to be overlooked.

- Together with population ageing, social welfare expenditure is increasing. Within the Pomorskie region, the distribution of social assistance is spatially diverse; stimulating socio-economic activity within a given territorial area is one solution to problems relating to social exclusion. The increasing elderly population also contributes to the growing number of non-government organisations (NGOs), some specialising in social assistance and training activities. An effective method of counteracting social exclusion is building a knowledge-based society, investing in computer equipment and broadband internet access.

- The number of people employed in the region increased by 9\% from 1999 to 2010. However, the actual employment rate has declined, which indicates a labour market that is not able to absorb the labour force resources. Overall, the employment structure within the region has undergone significant change (1998-2007), with declines in agriculture, fishery and forestry, but increases in: mining and utilities; finance, real estate and entrepreneurial activities; and public sector employment.

- Youth unemployment has fluctuated significantly between 1999 and 2010, with the 2010 figure reaching $21 \%$. This fluctuation has been caused by the economic crisis and declining employment opportunities, which mostly impact young people. The percentage of unemployed people aged over 55 has increased, especially within the cities of the Gdańsk agglomeration, where, despite the large labour market, older persons are unable to find employment due to their poor qualifications. Unemployment is a developmental barrier for the region, and so counteracting significant inequalities in the labour market is a challenge for regional policy.

- Pomorskie is a strong educational centre, with key state universities, and the TriCity agglomeration leading the field of secondary education and attracting the best students from across the country. However, the region is unable to keep the most talented students, who prefer to study in the major educational centres, such as Warsaw or Kraków, or decide to study abroad. The report also identified that the preschool education system is not meeting parents' needs in terms of accessibility and forms of service. According to a recent study, the majority of households (members aged over 16) do not continue education as a lifelong learning (LLL) process. LLL plays a crucial role in forming skills and training ecosystems and should be highlighted as a key regional strategy. A successful example of local policy in this area is the functioning of the six Universities of the Third Age; the popularity of these universities illustrates the desire of older people to develop knowledge.

- The location of Pomorskie within the Baltic Sea region also opens up new development opportunities for economic growth, in areas such as recreation, silver and white economies. To make the most of this potential requires an active participation in the Baltic Sea's organisations, institutions and initiatives.

The results of two regional questionnaires indicated 'under average' scores for Pomorskie as an Elderly Friendly Place to Live (ELFRI) and Older Worker Friendly Place to Work (OLWOF). The ELFRI had below average results for all areas: outdoor spaces and building; transport; housing (public and private); social participation; respect and social inclusion; civic participation and employment; communication and information; and community support and health services. The OLWOF also had below average results for all areas: recruitment; work culture and opportunities; training and skills development opportunities; and organisational health and benefits. However, participants did note the importance of having friendly places to work for older workers, thus highlighting a policy gap.

Local and regional authorities are well aware of changing demographic conditions, especially population ageing. Actions include initiatives to stimulate and prolong the older population's participation 
in the labour market; encouraging LLL aimed at developing skills and competencies; adjusting health and social care systems; and recognising the high priority of family-focused policy. Territorial diversification is the most challenging issue for local and regional policies, thereby placing increasing importance on having a cohesive policy and regional strategy whilst taking inner regional differences into consideration. A systemic approach is necessary to manage the demographic transition. The most important elements for policy design should be focused on the development of a regional strategy whereby diagnosis and prognosis of demographic change is analysed.

Key elements for policy development are:

- Governance - identification of the correct level of intervention by government. Currently, there are both overlapping policies, and policy gaps, an example of which is the health system whereby the state regulates and provides funding, while infrastructure development is the responsibility of all levels of governance. Territorial diversification also requires policy devolution, enabling true local and regional investigation and tailor-made policy solutions. The partnership approach is also necessary (building a coalition of stakeholders), involving regional entrepreneurial sectors and social organisations, and bottom-up community led initiatives.

- Regional consideration - regional policy should not be developed in geographic isolation. Interpretation of problems in the national as well international perspective is necessary, especially concerning migration movements. Opportunities and challenges should be examined in the context of the area being in the Baltic Sea region.

- Ageing population - the rapidly decreasing number of people of pre-working age and an increasingly ageing population is and will place pressures on the economic and social structure of the region. The ageing population requires large investments in different types of infrastructure and services. Accessibility to social services and healthcare is a region-wide challenge. The ongoing healthcare reform and shrinking number of medical staff and facilities make improving the healthcare service difficult. The limited influence that regional policy has over the centrally-funded system is an obstacle, thus, more emphasis should be placed on the importance of policy improvements to governance.

- Economic structure - protect positive economic trends from the negative demographic changes on the labour market. The post-industrial type of economy creates a solid foundation for future dynamic development and domination of the service sector. The service sector provides opportunities for older workers and women, therefore, creating favourable conditions in which to carry out workforce-ageing-related policy are needed.

- Silver and green economy - the potential of the silver economy should not be under-estimated and requires legislative adjustment, flexible institution embeddedness and changing cultural/social attitudes. The location of the region is ideal for offering innovative solutions in the development of the green economy. Both the environmental conditions and life science services provide developmental opportunities for the silver and green economies. This requires long-term policy development and investment, and the protection of environmental assets.

- Skill ecosystem - development of a policy to instil LLL attitudes among inhabitants, which is a pre-requisite for socio-economic transformation in light of population ageing challenges. Promoting the importance of preschool and primary school education is crucial in the formation of LLL-oriented attitudes and a willingness to undertake self-education. Across the entire education system, the development of generic skills is vitally important as a basis from which to instil entrepreneurial and innovative attitudes.

- Family policy - promotion of change within the working culture, social and institutional organisations and the legislative systems are needed, in order to allow better support for families and the family unit. Unconventional solutions to assist the family in its caring role should be explored. Changes in the family care system, from hands-on care to managing care arrangements opens up new possibilities for service development and new ways to assist families to function. 
- Socio-economic diversity - the significant differences between urbanised metropolitan areas and rural peripheral areas need to be recognised in order to effectively develop and implement different strategies to tackle the demographic challenges occurring in each area. 


\section{CHAPTER 1: INTRODUCTION}

The Pomorskie region is situated in the northern part of Poland, on the coast of the Baltic Sea (Figure 1). The present borders of the Pomorskie voivodeship ${ }^{1}$ were established on 1 January 1999 when the administrative reform of the country took place. The region occupies 18000 square kilometres (5.9\% of the country's total territory) and is divided into 20 districts and 123 municipalities among which there are 25 urban municipalities, 17 urban-rural and 81 rural municipalities. The Pomorskie region has 2230000 inhabitants, which constitutes $5.8 \%$ of the country's population (CSO, 2012).

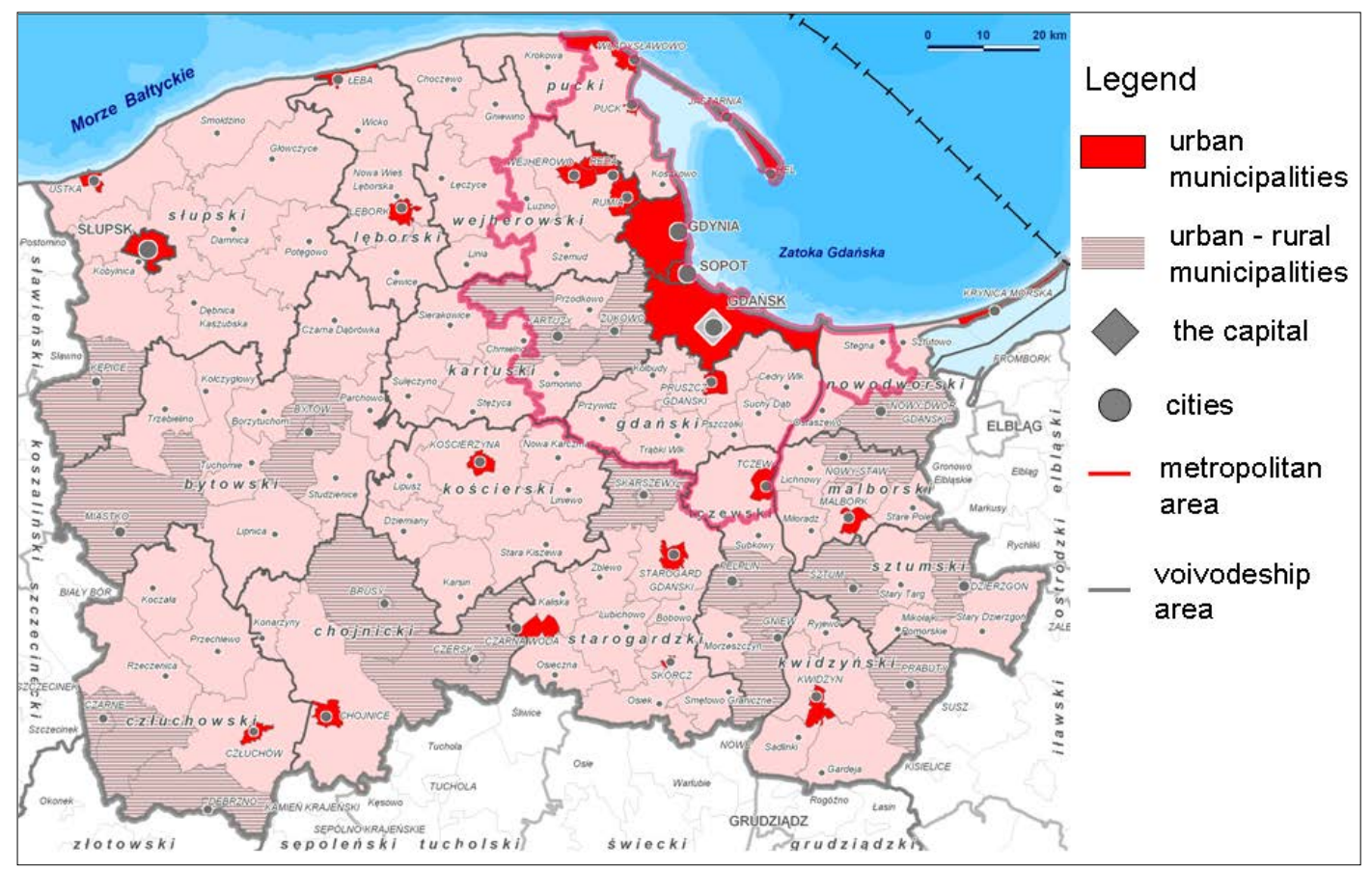

Figure 1 Pomorskie voivodeship

Source: Marshall's Office of the Pomorskie Voivodeship

The average population density is 122 people per square Kilometre (sq. $\mathrm{km}$ ), which is the same as the Polish average. The Pomorskie voivodeship is among the few regions that have observed population growth, due both to a natural increase in the population, and a positive net migration. Compared to the rest of the country, Pomorskie has a relatively young age structure and a low dependency ratio (CSO, 2012).

\footnotetext{
${ }^{1}$ The voivodeship, as the administrative name for the region, will be used as a synonym.
} 
Sixty-eight per cent of the Pomorskie region's population lives in the cities. The voivodeship ranked fourth among the most urbanised regions in the country. Forty per cent of the region's population live in the three largest neighbouring cities of Gdańsk, Sopot and Gdynia, which form a single metropolitan area (CSO, 2012).

The paper discusses the demographic changes that took place in the Pomorskie region during the last decade. The ongoing changes are analysed in the context of the region's social and economic structures' transformations, focusing on the issues of labour markets, silver and white economies, systems of skills and training, and green regional attractiveness. The response of the regional and local authorities to these ongoing processes is also presented. As it is mainly the highly urbanised areas that are affected by the consequences of population ageing, urban policy plays a vital role in the new approach to demographic change processes. The findings from the field studies, and direct discussions with different social groups' representatives, which took place during the workshop, are presented within the report (see Annex 8). The small-scale policy survey results are then discussed, followed by key conclusions and implications for future practices and policy development in the Pomorskie region. 


\section{CHAPTER 2: \\ CHARACTERISTICS OF THE POMORSKIE REGION}

\subsection{Demographic change 1990 - 2010}

During the 1990s and the first decade of the $21^{\text {st }}$ century, the number of inhabitants within the Pomorskie voivodeship increased. In the years 1991-2010, the population grew from 2120000 to 2240000 , although in the first years of the $21^{\text {st }}$ century, a slight decrease was observed (Figure 2). The most populated cities are Gdańsk (457 000 inhabitants) and Gdynia (247 000). Some 1.3 million people live in the Gdańsk metropolitan area (CSO, 2012).

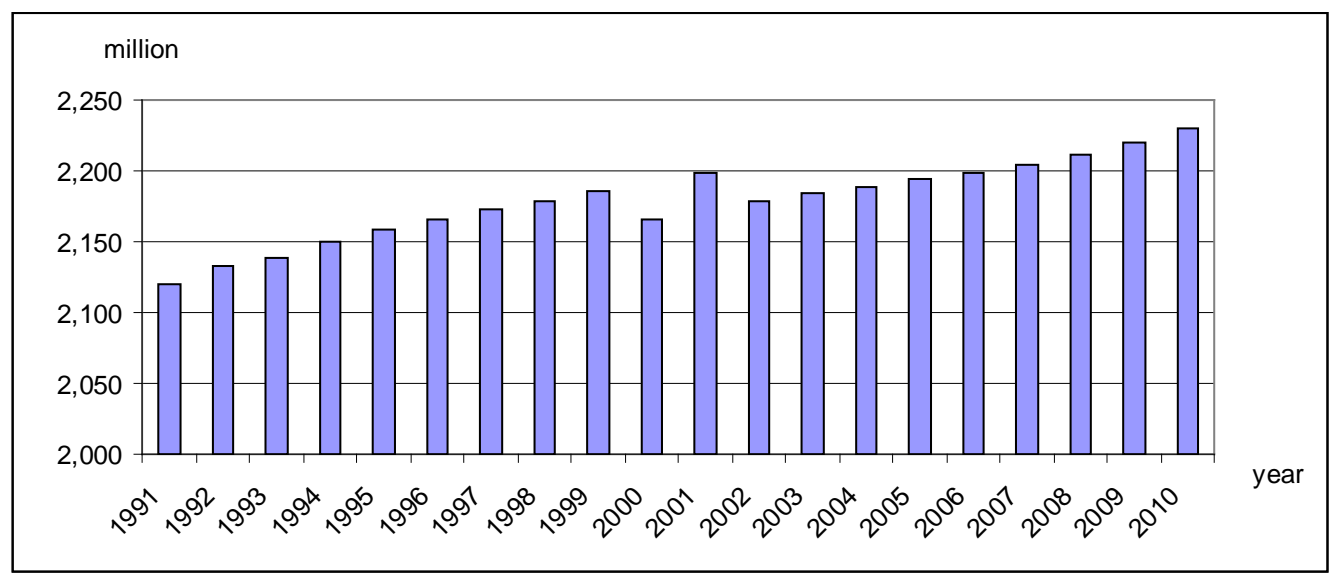

Figure 2 The Pomorskie region's population 1991-2010

Source: graph produced from Eurostat data, 2012

The region's immigration attractiveness includes its relatively large labour market, Gdańsk's attraction as an urban centre, and the favourable natural environment. All of these factors have led to the growth in the region's population. In the years 2000-2007, immigration from the other voivodeships rose from 6900 people per year to 8800 per year, a 29\% increase, which indicates that Pomorskie has proven to be more attractive than many other regions of Poland. At the same time, the number of people who permanently left the region also grew, from 5200 to 6200 per year, which was a 20\% increase (Eurostat, 2012). The accession to the EU and the opening up of the Western European labour markets to Polish workers were the main drivers of this rise in emigration rates.

In general, the net migration per 1000 inhabitants in the 2001-2010 period increased from 0.2 to 1.3 (while the figures for the rest of the country were -0.1 to -0.9 respectively). The inter-LAU ${ }^{1} 1$ migration analysis indicates that the largest population growth took place in the municipalities surrounding the Gdańsk agglomeration (over 0.5\%), while the polarisation of the migration processes between the

\footnotetext{
${ }^{1}$ LAU stands for Local Administrative Units of the first level (LAU 1), formerly known as NUTS 4.
} 
agglomeration and its surroundings in the 2002-2010 period increased (see Annex 1 and Annex 2). The average net migration rates for the 2002-2010 years indicate that the voivodeship's most peripheral eastern and western districts, as well as the Gdańsk agglomeration, registered the highest migration outflow rates (Figure 3). The shrinking Gdańsk agglomeration population is a result of the increasing suburban sprawl. The net migration rate strongly influences the intensity of the population ageing phenomena (CSO, 2012).

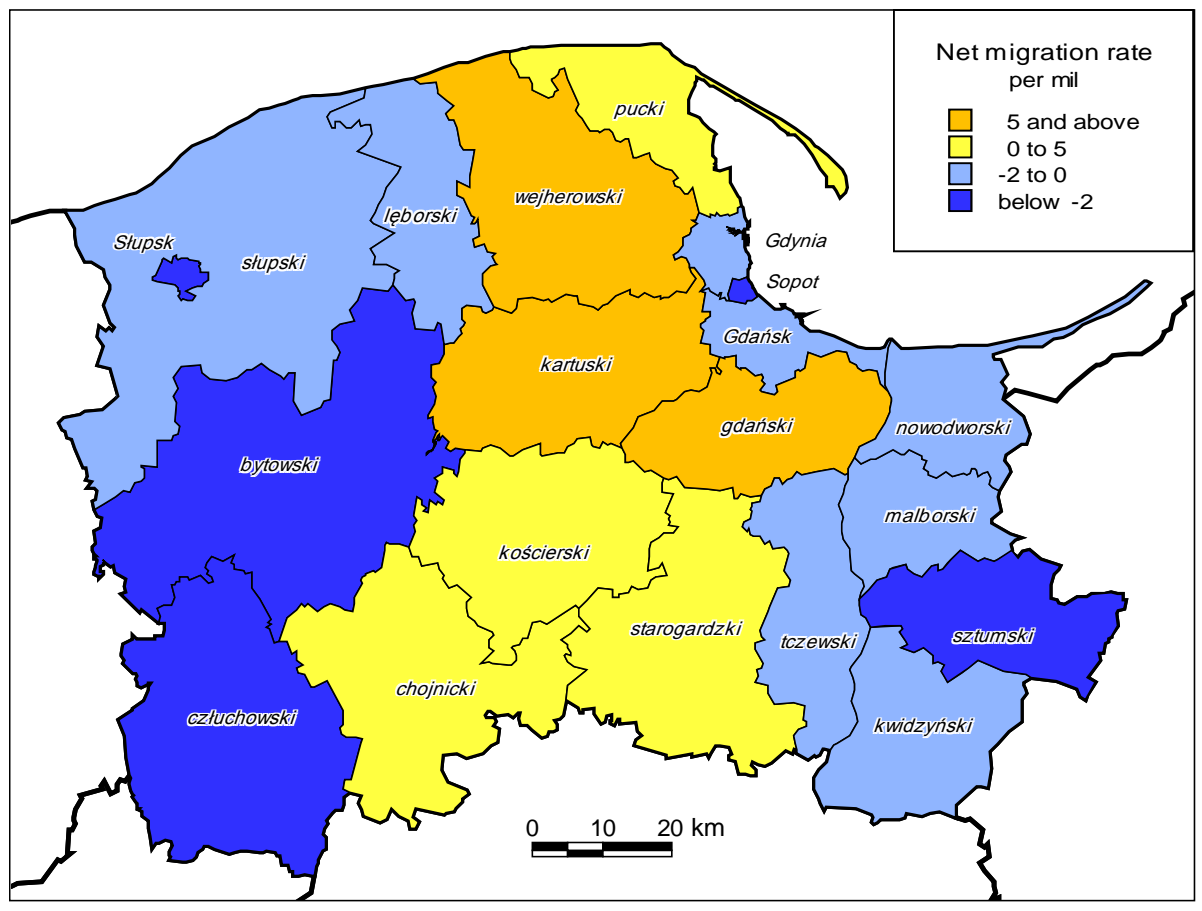

Figure 3 Average inter-LAU 1 migrations of the Pomorskie Region, 2002- 2010

Source: map produced from the Local Data Bank, CSO, 2012

In the years 1991-2010, population density in the Pomorskie voivodeship grew from 116 to 122 people per sq. km, as opposed to the decrease (from 123 to 122) that occurred in the rest of Poland in the same period. The most densely populated cities are Słupsk and Sopot (over 2200 people/sq. $\mathrm{km}$ ), followed by Gdynia (over 1 800) and Gdańsk (1700). The least densely populated districts are those situated further from the Gdańsk agglomeration, which have population densities of less than 40 people per sq. $\mathrm{km}$ (Annex 3 ). These are mainly rural areas, lacking major urban centres. In recent years, the population, and consequently the population density, have been falling both in the larger cities and in districts situated east of the Gdańsk agglomeration (Figure 4). These districts also suffer from a faster population ageing rate, a relatively high structural unemployment rate, and a larger number of people employed in agriculture. Compared to the districts that are situated west and south of the agglomeration, the eastern districts have poor transportation accessibility, in spite of their geographical proximity to Gdańsk (Local Data Bank, CSO, 2012). 


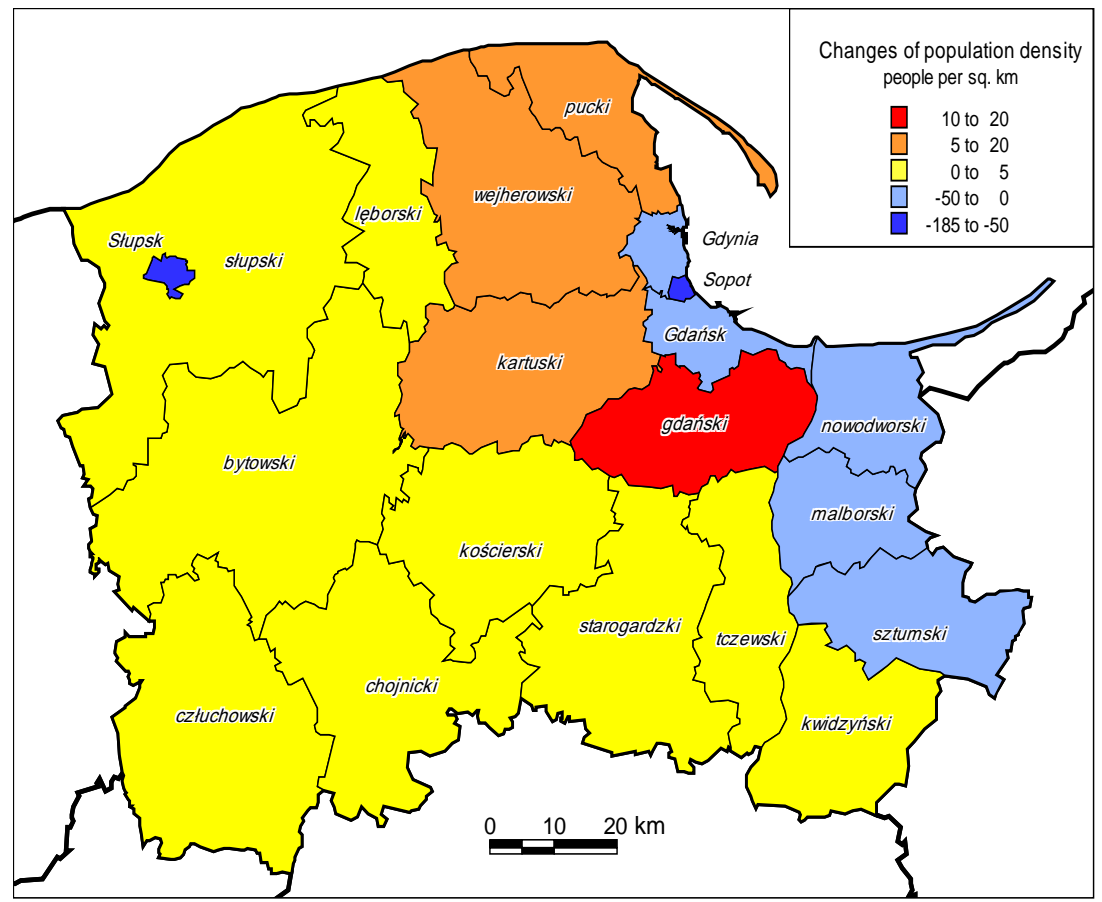

Figure 4 Population density changes in LAU 1 of the Pomorskie region, 2002-2010 Source: map produced from Local Data Bank, CSO, 2012

According to OECD data (2012), in 1991, the age structure of the region was as follows: the 0-14 age group constituted $26 \%$ of the population; the $15-64$ group $65 \%$; and the 65 and above age group accounted for less than $9 \%$ of the region's population. By 2009, the population ratios in the abovementioned age groups shifted to $17 \%, 71 \%$, and $12 \%$ respectively. During this period, there was a significant decrease in the number of young people, while the number of persons of working and postworking age grew.

Many regions of Poland face population ageing. The Pomorskie voivodeship is among the few regions in which this process is still in its initial phase. Pomorskie has a positive net migration, is experiencing population growth, and has a relatively young age structure, with a comparatively high share of the working age population within what is considered the mobility group i.e. 18-44 years, therefore, the percentage of elderly people is rather low. In 2010, people in the post-working age ${ }^{2}$ group constituted $15 \%$ of the population (an increase from the 1995 rate of 12\%), while the Polish average was $17 \%$. However, the number of people of pre-working age (17 years old and less) is decreasing rapidly - shifting from $29 \%$ to $20 \%$ in the years $1995-2010$. The number of people in the working age ${ }^{3}$ group grew from $59 \%$ to $64 \%$. In 2010, the largest elderly populations (65 years and above) were observed in the cities of the Gdańsk agglomeration (Figure 5). In Gdańsk, this amounted to $15 \%$ of the population, in Gdynia it was $16 \%$, and in Sopot, 21\%. The fastest elderly population growth occurs in Gdynia and Słupsk (over 2 percentage points in the years 2002-2010), as well as in Gdańsk and Sopot (Local Data Bank, CSO, 2012). As mentioned previously, migration outflow has intensified the population ageing processes in urban areas.

\footnotetext{
${ }^{2}$ Calculated in accordance with the Polish methodology, i.e. including women aged 60 and older, and men aged 65 and older.

${ }^{3}$ Calculated in accordance with the Polish methodology, i.e. including women aged 18-59 and men aged 18-64.
} 


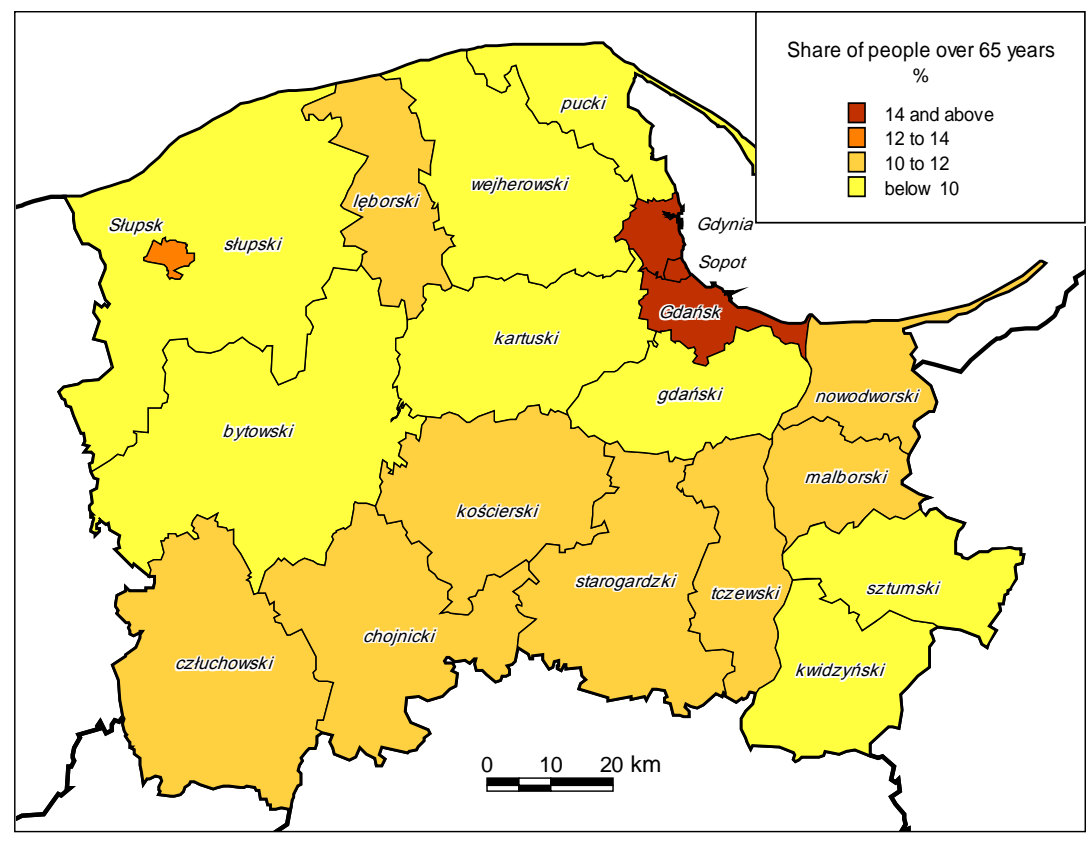

Figure 5 People over 65 years in LAU 1 of the Pomorskie region, 2010 Source: map produced from Local Data Bank, CSO, 2012

According to OECD data (2012), in 1991, women formed 49\% of 0-14 age group, 50\% of 15-64 age group, and $62.5 \%$ of the 65 and above age group. In 2009, these levels were as follows: less than $48.5 \% ; 50.5 \%$; and $61 \%$ respectively. In the period studied, the percentage of women in the oldest age group fell, which could be related to the increased life expectancy of men in that age group. Thanks to the improvement in living and work standards, men's life expectancy is growing faster than that of women. In 2010, the region's average life expectancy for men was 72.97, while the Polish average was 72.10 (Demographic Data Base, CSO, 2012). During the last three years, the average life expectancy periods for men have been extended by almost three years (in 2007 it was only 70.7). Pomorskie is among the top four Polish regions with the highest men's life expectancy rates. This demonstrates a high and constantly growing level of quality of life, represented among others by employment security, growing income levels of households, housing opportunities, health care and a healthier style of life.

The Pomorskie voivodeship has a relatively high birth rate, compared to the rest of Poland. Between 2000 and 2010, the number of births per 1000 inhabitants increased from 10.8 to 12.1 (compared to 9.8 to 10.8 in the rest of the country). In the same period, the mortality rate increased from 8.3 to 8.7 per 1000 inhabitants, which is lower than the Polish average of 9.6 to 9.9 respectively. The region's natural increase rate during this period grew from 2.5 to 3.4 and was significantly higher than the average in the rest of the country ( 0.3 to 0.9 respectively) (Eurostat, 2012). The growth in the natural increase rate is well reflected in the pyramid of age and sex (Figure 6). The pyramid also clearly illustrates the rapid growth of the regions' population aged 50+, with a notable domination of women in the older age groups. As was previously mentioned, however, the strong disproportion in life expectancy between men and women is rapidly reducing. 


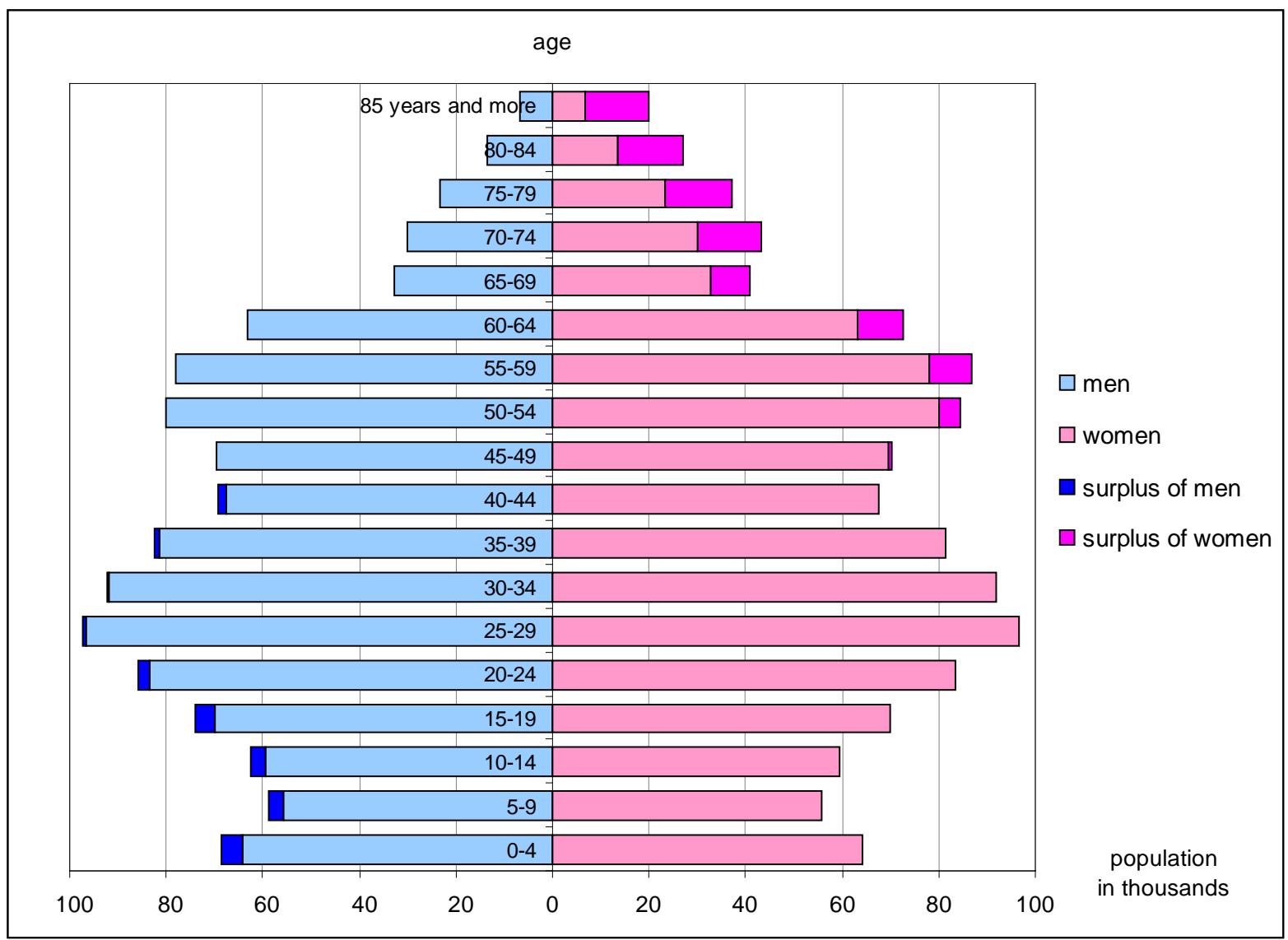

Figure 6 Sex and age structure of the Pomorskie region, 2010 Source: graph produced from CSO data, 2012

Thanks to improvements in health care and better equipped hospitals, in the years 1995-2010, the infant mortality rate in the Pomorskie voivodeship dropped from 13.9 to 4.5. In the same period, in the rest of the country, infant mortality rates decreased from 13.6 to 5.0 per 1000 births. This indicates that the progress in the field of medical care was more effective in the Pomorskie region than in the rest of Poland (Local Data Bank, CSO, 2012).

The fertility rate in the region decreased from 2.12 in 1991 to 1.54 in 2009 (Figure 7). However, it should be noted that, in more recent years, the rate has been increasing slightly since dropping down to its lowest figure of 1.32 in 2002 . The highest fertility rate is observed in the sub-region that directly neighbours onto the Gdańsk agglomeration - in 2010, this area surpassed 1.74. This phenomenon can be associated with the processes of suburbanisation. The Gdańsk sub-region attracts young people of working age, who settle in the agglomeration's suburbs. However, the cities of the agglomeration - Gdańsk, Gdynia and Sopot (the TriCity sub-region) - are also experiencing a similar growth, with the fertility rate rising from 1.06 in 2002 to 1.28 in 2010 . The observed present growth rate is associated with the demographic echo effect of the baby boom of the 1980s. The outflow of the core cities' inhabitants to suburban areas is primarily responsible for the shrinking population in the cities. To slow down this process, attempts to implement the concept of the compact city are being undertaken in the urban development policy of the TriCity sub-region. 


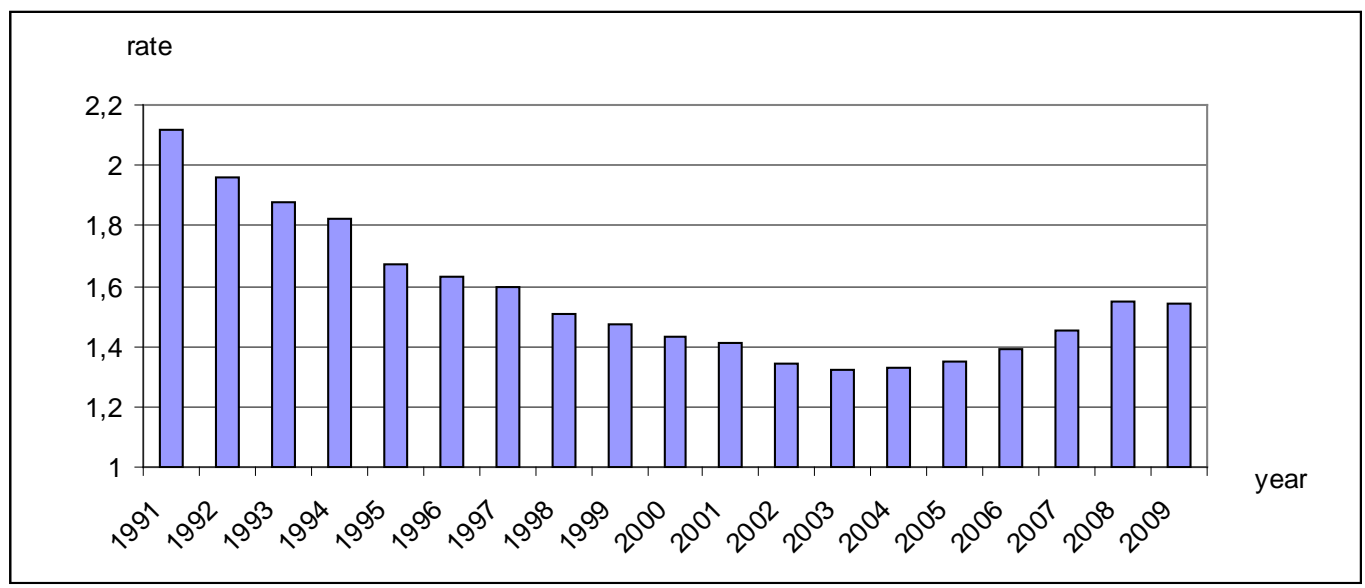

Figure 7 Fertility rate in the Pomorskie region, 1991-2009

Source: graph produced from Eurostat data, 2012

In the years 2001-2009, the number of women undertaking higher education increased from 46000 to 65000 in the Pomorskie voivodeship, which was a $41 \%$ increase (compared to $21 \%$ across Poland as a whole). Among the total number of women studying in the Pomorskie region, the percentage of these participating in higher education rose from 16 to $25 \%$ (in comparison to 20 up to $28 \%$ in Poland) (Eurostat, 2012). It can be anticipated that, without a well planned state family policy, this tendency may impact negatively upon the region's fertility rate. The current positive growth trend may collapse, and there may be a significant shift towards the lifestyle associated with professional career-oriented women. Thus, the incentives that encourage combining a professional career with raising children, play a crucial role in the policy supporting the growth of the fertility rate.

The analysis of demographic processes in the last decade proves that the region currently has one of the highest demographic potentials in the country. Compared to other regions, Pomorskie has the highest natural increase rate and the third largest positive net migration. The combination of these two factors results in the country's highest real increase of inhabitants. The population is also relatively young compared to the rest of Poland, which significantly influences the labour market. Nevertheless, the process of population ageing has already begun, a reality that is clearly reflected in demographic forecasts prepared for the region to the year 2035 (Figure 8 and Figure 9). 


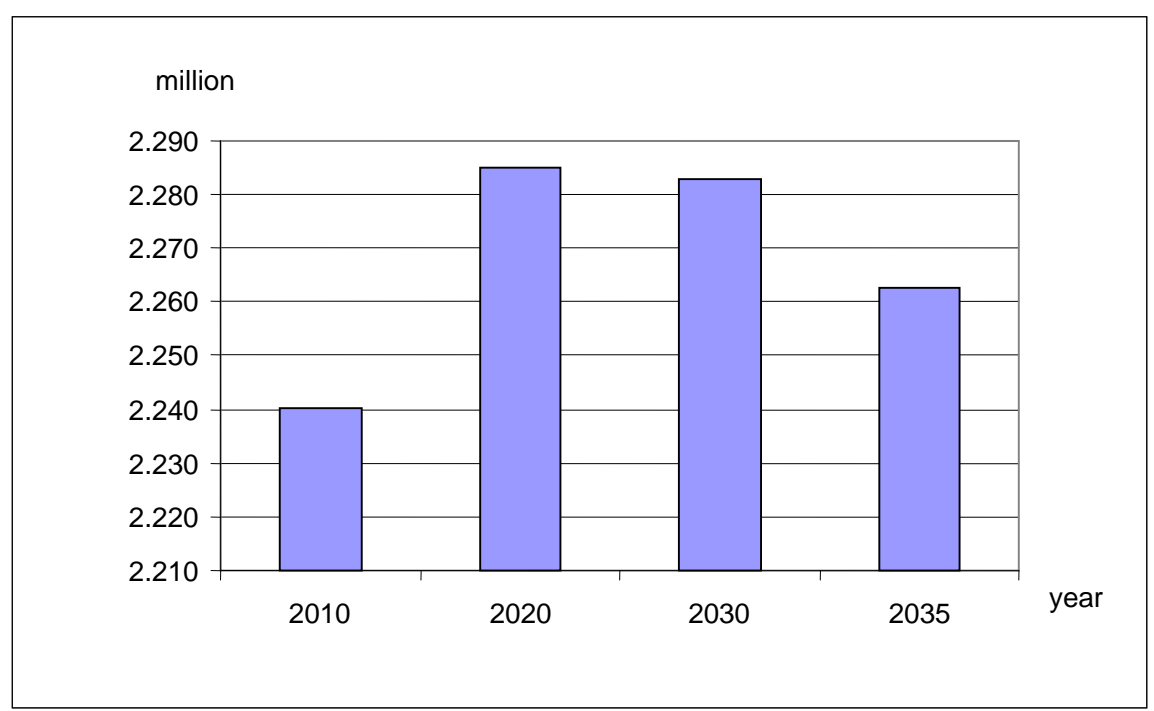

Figure 8 Population forecast for the Pomorskie region to 2035 Source: graph produced from CSO data, 2012

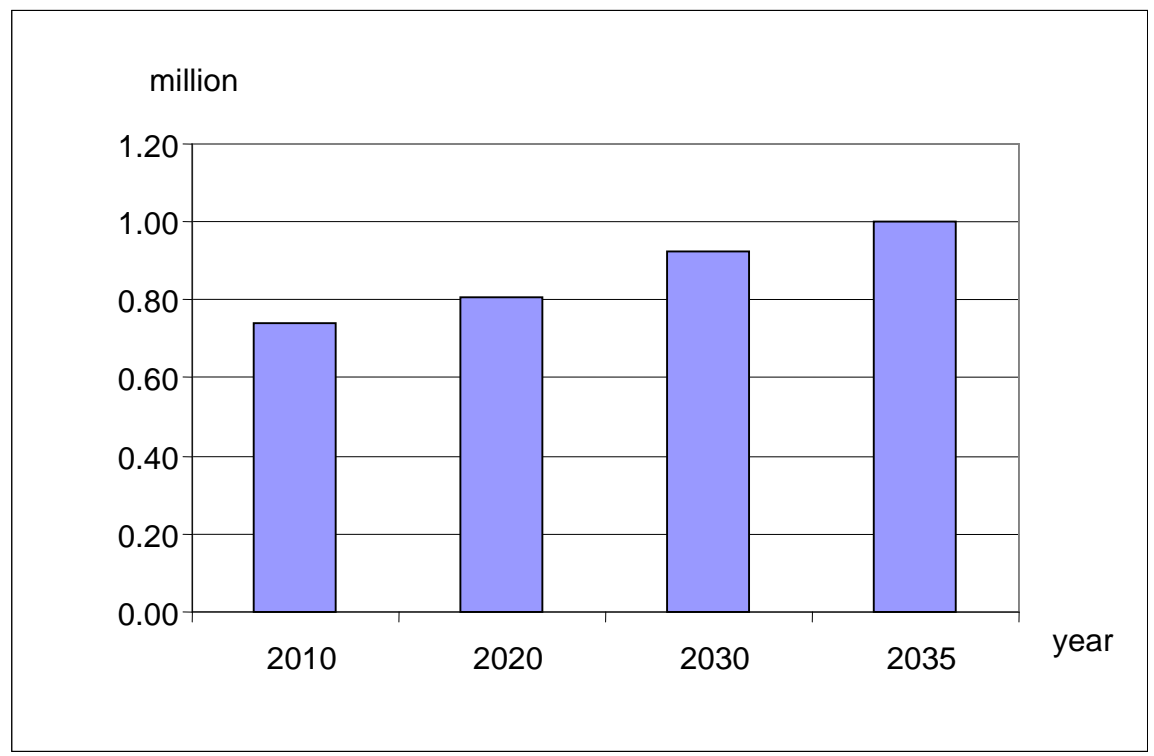

Figure 9 People aged 50+ forecast for the Pomorskie region to 2035 Source: graph produced from CSO data, 2012

The effects of the expected decrease in the population will be augmented by a significant growth in the population aged 50+. As a consequence, the share of elderly inhabitants in the region's age structure will grow rapidly. The constant growth of the older population is a process that has already started. Therefore, adjusting labour markets, the region's economy, and social assistance systems to meet the new challenges that stem from this demographic transformation is a strategic task for the region's authorities.

One of the most salient features of the region, from a public intervention perspective, is the disadvantageous spatial diversity, which is strongly entrenched and difficult to counter in terms of socioeconomic development. Demographic structures are also inextricably linked to the highly diversified socioeconomic potential of the territorial units. The differences between municipalities originate mainly from the net migration rate. The metropolitan suburban area with the highest demographic potential as a result of intensive suburbanisation processes, has a demographic structure that is dominated by younger age groups, 
experiences a positive net migration rate, and a positive natural increase. The western and south-eastern parts of the region, which are far from the urban centres, possess the least favourable demographic rates. Their peripheral situation limits accessibility to labour markets and higher education services, which are the main factors behind the inhabitant's decisions to emigrate. Counteracting strong and undesired demographic polarisation of the region should definitely be one of the fundamental tasks for local and regional policies.

\subsection{Socio-economic characteristics and labour markets}

The Pomorskie region is usually classified fifth in national economic rankings. Since 1989, the region's economic structure has been characterised by a visible growth in the service sector, even though the production sector still constitutes the core of economic activities in the region, with its basis in shipbuilding, petrochemicals, chemical industries, food processing, electronics, telecommunications, IT engineering, cosmetics, pharmaceuticals and print industries. However, there are strong differences in economic potential within the region, a fact that is reflected in the population's distribution according to market availability. About $60 \%$ of the region's population is concentrated in the metropolitan area, which covers about 29\% of the region's territory (Marshall's Office of the Pomorskie Voivodeship, 2010).

One of the basic indicators of the region's economic performance is its share in the country's gross domestic product (GDP). In 1995, the Pomorskie voivodeship generated as much as $5.7 \%$ of the Polish GDP, and 5.5\% in 2008. And, as the 2009 Ministry of Regional Development's report shows, the dynamics of Pomorskie's development, represented by the level and growth rate of GDP, place the region among the fastest developing regions in the country (OECD, 2012).

In 1995, the GDP of Pomorskie voivodeship equalled \$5.1 billion (current purchasing power parity (PPP), current prices), while in 2008, it amounted to $\$ 10.4$ billion - a $102 \%$ rise. Taking inflation into account (constant PPP, constant real prices from the year 2000), the region's GDP equalled \$5.6 billion in 1995 and $\$ 8.8$ billion in 2008 - a 58\% rise. The Pomorskie region ranks fourth among the regions, but has the highest share of services generating gross value added (67.1\% in 2009). Nevertheless, the economy in Pomorskie grew at slower rate than it did in the rest of the country (63\%). In 1995, Pomorskie's GDP per capita equalled \$2 380 (compared to \$2 340 in Poland), but by 2008, it was approximately $\$ 4700$ in comparison to $\$ 4930$ in Poland (current PPP, current prices) (OECD, 2012).

Economic growth varied noticeably across different branches of the region's economy. The measure of economic growth is the change in gross value added (GVA). This stands for the value of goods and services produced in an area, minus the costs of their production. In the 1995-2008 period, the GVA, expressed in constant prices, dropped by $10 \%$ in agriculture, forestry and fishery, while other branches experienced the following growth rates: mining and utilities $-80 \%$; construction $-48 \%$; wholesale and retail, vehicle and other goods' repairs, hotels and restaurants, transport, storage of goods and communication $-55 \%$; finance, real estate and entrepreneurial activities $-61 \%$; public service $-20 \%$. In the years 1995 to 2009, the Pomorskie voivodeship's overall GVA grew by $53.5 \%$, compared to $58.5 \%$ in Poland (Figure 10) (OECD, 2012). 


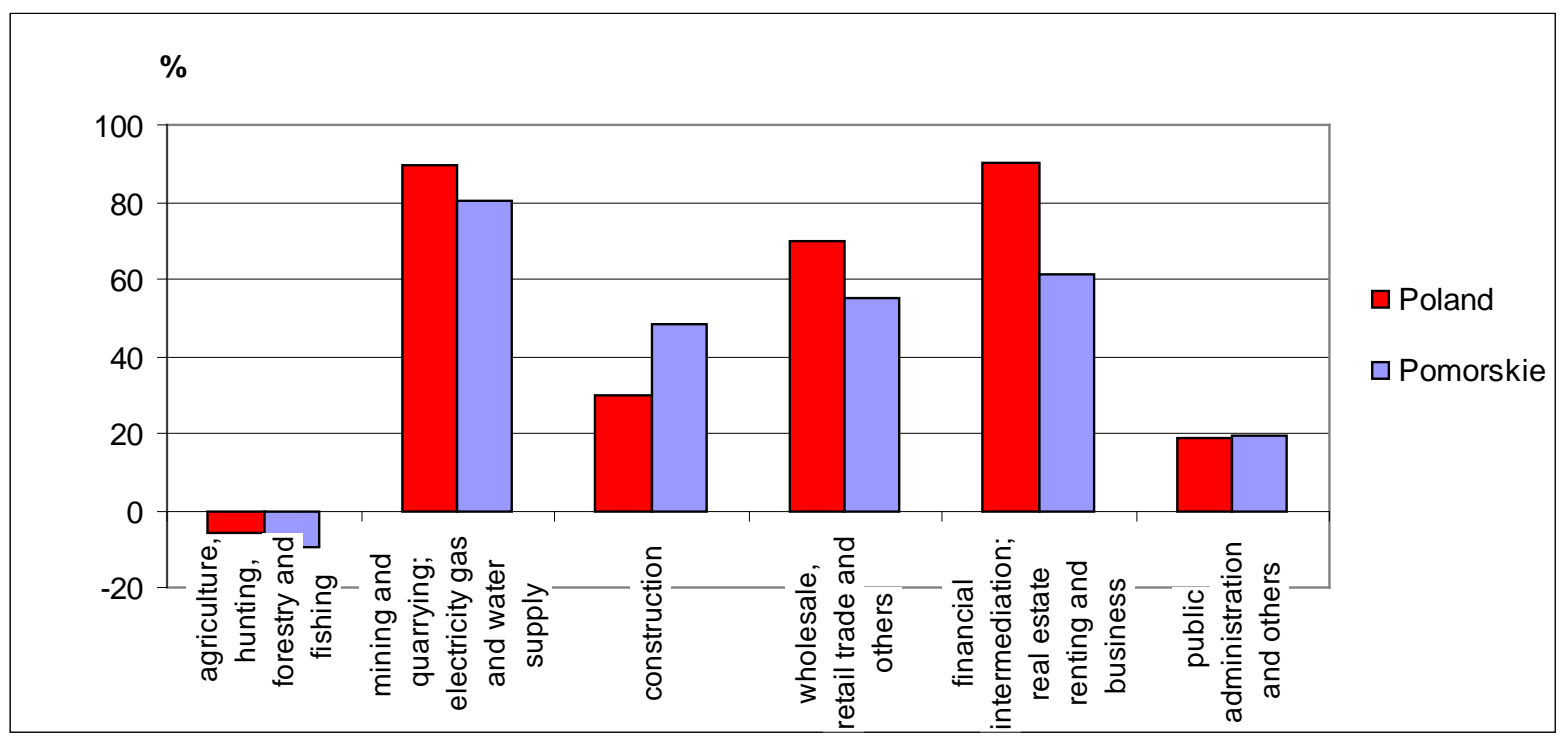

Figure 10 Changes in gross value added by branches of the economy, 1995-2008

Source: graph produced from OECD data, 2012

Between 1995 and 2009, the actual (constant PPP, constant real prices) primary income of private households in the region grew by $47 \%$. In the same period, the disposable income of private households grew by $44 \%$. The decrease in the disposable income was caused by an increase in tax rates. In the period discussed, in Poland, both primary as well as disposable income grew by some $40 \%$ (due to the country's GDP growth rate being higher).

Expenditure on research and development (R\&D) is a measure of the economy's innovativeness. Growth in this area of expenditure influences the rate of modernisation. In the Pomorskie voivodeship in the years 2000-2007, the expenditure on R\&D in the business sector grew by $135 \%$, while the Polish average was only $13 \%$ (current USD PPP). R\&D expenditure within the public sector increased by $57 \%$ (49\% in Poland) and higher education by $16 \%$ (46\% in Poland). Overall, expenditure on R\&D in the Pomorskie region, in the period being discussed, grew by $62 \%$ (up to $\$ U S 180$ million), in contrast to the Polish average of $35 \%$. This demonstrates a higher rate of modernisation in the voivodeship's economy than the Polish average, especially considering the significant growth of expenditure in the business sector. Nevertheless, it is important to note that in 2007 , expenditure on R\&D constituted only $0.51 \%$ of the voivodeship's GDP (compared to $0.57 \%$ in Poland). In terms of absolute value of R\&D expenditure, as well as the proportionate share in this expenditure, the Pomorskie region ranked only $7^{\text {th }}$ out of 16 in the country. However, since the year 2000, the region's share in R\&D expenditure has grown slightly, whereas it has generally been decreasing across the rest of the country. Employment in R\&D in the business sector grew in the period under discussion by $8 \%$, while in Poland overall it dropped by $23 \%$. In the public sector, R\&D employment grew by $2 \%$, whereas in higher education it decreased by $7 \%$. In the period 2000-2007, in the Pomorskie voivodeship, the overall employment in R\&D dropped by $4 \%$ (compared to $3 \%$ in the rest of the country) and constituted only $0.86 \%$ of total employment in the region (OECD, 2012).

The level of a country's development can be measured, among other things, by employment levels in highly advanced sectors of the economy. In Pomorskie, in the 2004-2007 period, employment in high and medium-high level technological manufacturing grew by $42 \%$ ( $25 \%$ in Poland), whereas in knowledge intensive services it only grew by $26 \%$ (13\% in Poland). In 2007, the share of employees in the high and medium-high technology manufacturing arena constituted $38 \%$ of the total number of employees in manufacturing. The share of employees in the knowledge intensive services constituted $48 \%$, and when 
compared to 2004 levels, there has been only a small percentage growth. In comparison to the Polish average, it is worth noting that in Pomorskie, the percentage share of employees in these services was $12 \%$ higher in the first case and $2 \%$ higher in the latter.

One measure of innovativeness is the number of patent applications lodged. Low expenditure on $R \& D$ is reflected in the region's poor ranking based on number of patents. The region is $13^{\text {th }}$ out of 16 voivodeships. In the 1990s, in the Pomorskie voivodeship, the number of applications fluctuated between 0.2 and 1.6 per 1 million inhabitants. In the year 2000, it reached 2.7. In the 2000-2007 period, it ranged from 2.0 to 3.1. In other parts of Poland, it oscillated between 2.8 and 4.2. No patents from nanotechnologies and green technologies sectors have been registered in Pomorskie; there are also very few applications from the biotechnology sector and few more from the information and communication technologies sector (OECD, 2012).

Labour force resources condition the development of local economies. The growing, economically active population in turn stimulates economic growth. Economic growth, on the other hand, intensifies the inflow of labour forces into the region, initiating a spiral of regional labour market growth. In 2010 in Pomorskie, the number of economically active people surpassed 917 000, which was a 7\% increase since 1999 whereas the Polish average was 3.5\% (Figure 11). Compared to 1999 figures, the number of economically active women rose by $8.5 \%$ and the number of men by $6 \%$. The share of women in the economically active population reached $45 \%$ in 2010 (44\% in 1999). In Pomorskie, in the 1999-2009

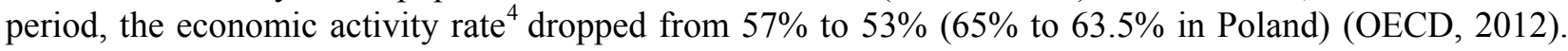
This decrease, in spite of the growth in the economically active population and the working age population growth, indicates the overall decline in the number of working or actively job seeking people within the working age population. This negative tendency is visible in both the regional and national labour markets.

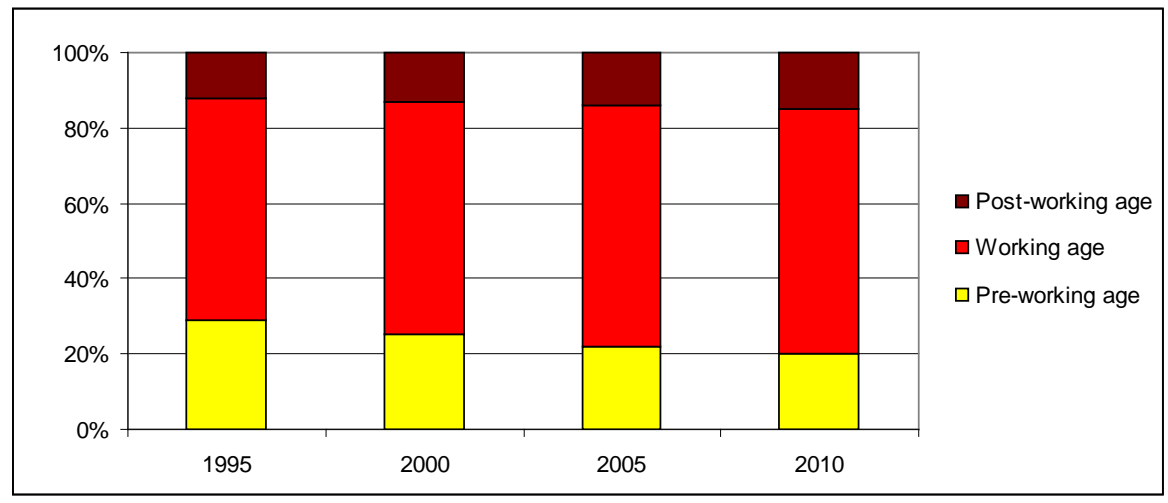

Figure 11 Population by working age categories in the Pomorskie region, 1995 - 2010

Source: graph produced from CSO data, 2012

In the 1999-2010 period, within the Pomorskie region, the employed population grew by $9 \%$ to reach 832000 in 2010 (Figure 12). In this period, the number of both working women and men rose (11\% and $8 \%$ respectively). Around the same period (1999-2009), the employment rate ${ }^{5}$ dropped from 51\% to 50\% (while in Poland overall it rose from 57\% to 58.5\%). Among women, this rate decreased from $44.5 \%$ to $44 \%$ (OECD, 2012). This decline, together with the growth of the employed population, indicates that the number of people of working age was growing faster than the number of available workplaces. The labour

\footnotetext{
${ }^{4}$ The labour force participation rate is defined as the ratio of the labour force to the working age population, expressed in percentages

${ }^{5}$ Persons in employment divided by the population. Data refer to the working age population (15-64) and are expressed in percentages.
} 
market was not able to absorb the labour force resources. These negative trends have not been observed in the rest of the country.

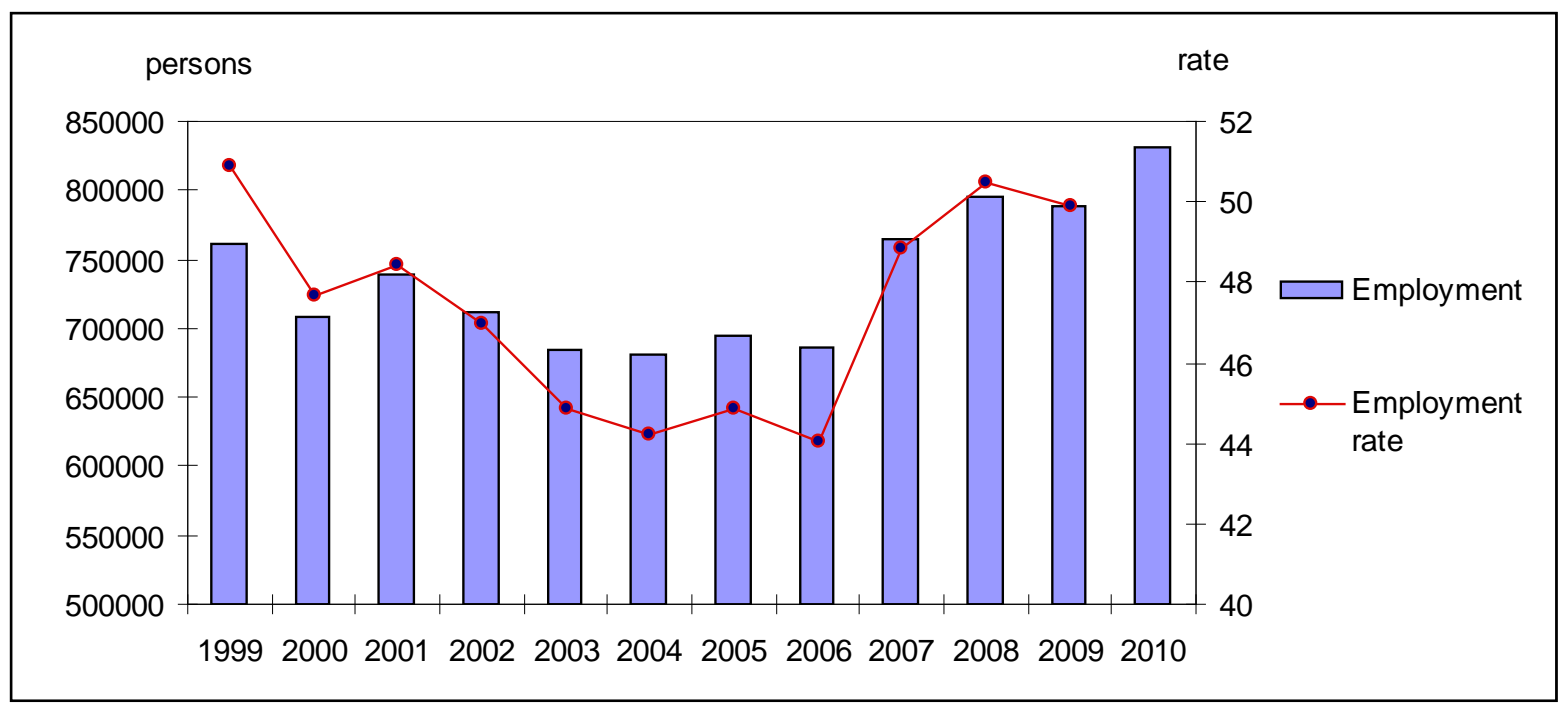

Figure 12 Employment and employment rate in the Pomorskie region, 1999-2010

Source: graph produced from OECD data, 2012

The employment rate is a measure that allows evaluation of the population's activity on the labour market and workplace supply. It is the ratio of the number of working persons to the overall population in a given age group. The employment rate in the Pomorskie voivodeship among the 15-24 age group rose from 25\% in 1999 to $28.5 \%$ in 2010 (from $24 \%$ to $26 \%$ in Poland). This rate increased for men from $27 \%$ to $31 \%$ and was slightly lower for women, increasing from $23 \%$ to $26 \%$ respectively. In the same period, among the population aged $25-34$, the employment rate rose from $70 \%$ to $75 \%$ (from $73 \%$ to $77 \%$ in Poland). For men, this rate dropped from $85 \%$ to $84 \%$ (while it rose in Poland), and for women it increased from $55 \%$ to $67 \%$. The highest rates of employment for Pomorskie's population were among the $35-44$ age group, which rose from $78 \%$ to $80 \%$ (78\% to $82 \%$ in Poland). For men, the rate rose from $81 \%$ to $86 \%$ and for women it dropped from $76 \%$ to $74 \%$. Among the $45-54$ age group, the employment rate was lower, but it too rose during the period being discussed - overall it rose from $70 \%$ to $72 \%$ (70\% to $73 \%$ in Poland), for men the rate dropped from $79 \%$ to $78 \%$, but for women it rose from $59 \%$ to $66 \%$. Among the population aged 55-64, the employment rate also increased - from 34\% in 1999 to $38 \%$ in 2010 (33\% to $34 \%$ across Poland as a whole). For men, the rate rose from $41 \%$ to $51 \%$, while for women it dropped from $28 \%$ to $27 \%$. For all age groups, the employment rate was decreasing through to the half of the first decade of the $21^{\text {st }}$ century, at which time it started increasing. The increase was especially visible among older age groups (Eurostat, 2012) (Figure 13). 


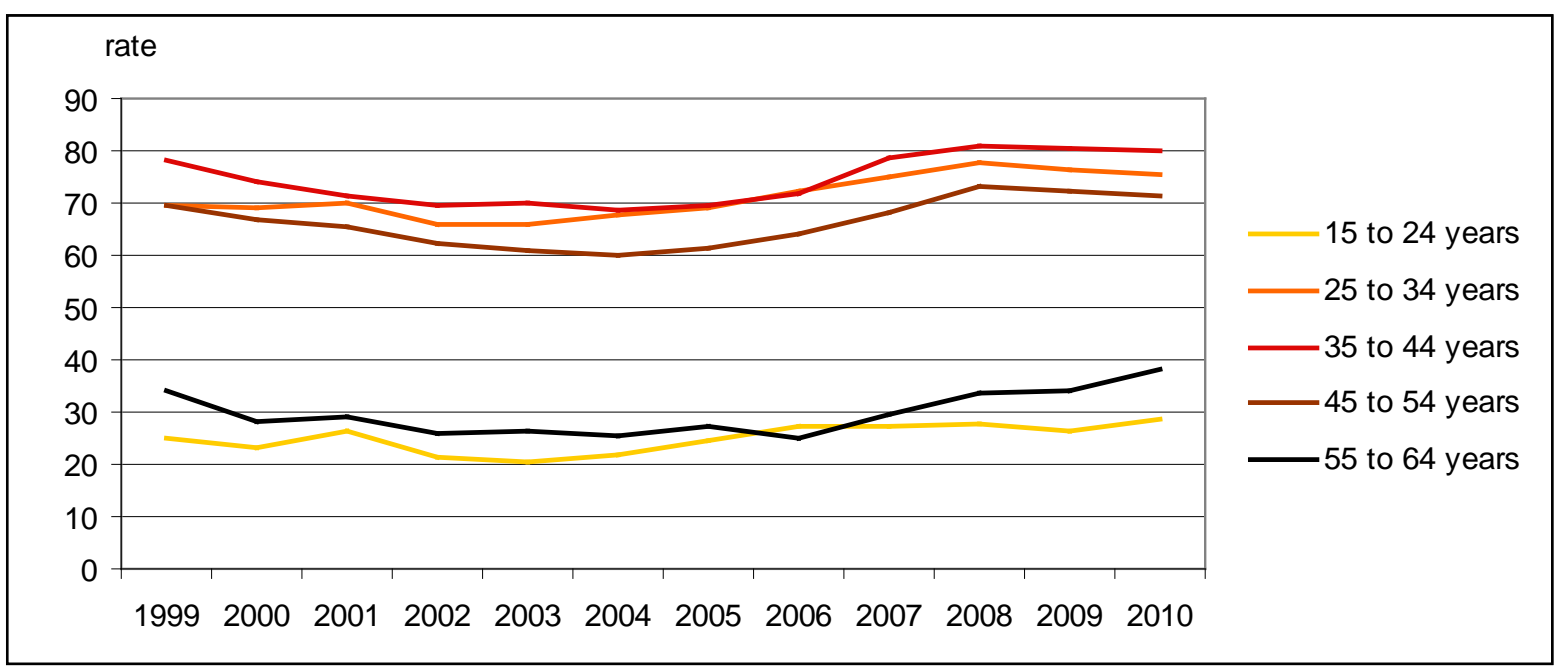

Figure 13 Employment rate by age groups in the Pomorskie region, 1999-2010

Source: graph produced from Eurostat data, 2012

In 2010, the percentage share of women in the overall employed population ranged between $45 \%$ and $47 \%$ in the 15-54 age group. Older women who, unlike men, had access to earlier retirement, amounted to $37 \%$ of the total for their age group. Between 1999 and 2010, the share of working women in the 15-24 age group remained at $46 \%$; in the $25-34$ age group it rose from $40 \%$ to $45 \%$; in the $35-44$ age group it dropped from $49 \%$ to $46 \%$; and in the $45-54$ age group it rose from $41 \%$ to $47 \%$; while in the 55 64 age group it dropped from $45 \%$ to $30 \%$ in 2005 , and then rose to $37 \%$ in 2010 . The average Polish rates did not differ significantly (Eurostat, 2012).

Considering the economic transformations that were taking place across Poland, including within the Pomorskie voivodeship, and the increased share of the population employed in the service sector, the growth in the share of women within the overall employed population is noticeable. In Pomorskie, this share gradually grew from 46\% in 1995 to $49 \%$ in 2010 (Local Data Bank, CSO, 2012). This tendency is especially visible in Sopot, where women find employment in specialised higher level services. It should also be noted that the highest shares of working women are observed in the districts where employment in agriculture predominates (Annex 4). On the other hand, the share of women decreases in the fasturbanising districts situated near the Gdańsk agglomeration. This trend could be connected to the fact that, in these districts, construction is the fastest developing economic sector, which is a sector that generally employs men. Additionally, the percentage share of working women is decreasing more rapidly in the depopulating districts, as they are the first ones to emigrate to the agglomeration cities, among other options, in search of a job (Annex 5).

The level of education has a crucial influence on the quality of the labour force resources. The share of the economically active population with a higher education background (as a percentage of the labour force) in the Pomorskie region amounted to $23 \%$ in 2008 (a significant growth from $14 \%$ in 1999), while the population with secondary education skills amounted to $69 \%$ (a drop from $71 \%$ ), and $8 \%$ for those with low education only (a drop from 15\%). Similar changes and rates were observed in the rest of the country (Eurostat, 2012). The approximately $10 \%$ growth in the economically active population with a higher level of education reflects the significant improvement in the quality of labour force resources in the region.

In the years 1998-2007, the employment structure in Pomorskie, by economic sectors, underwent considerable changes (Figure 14). 


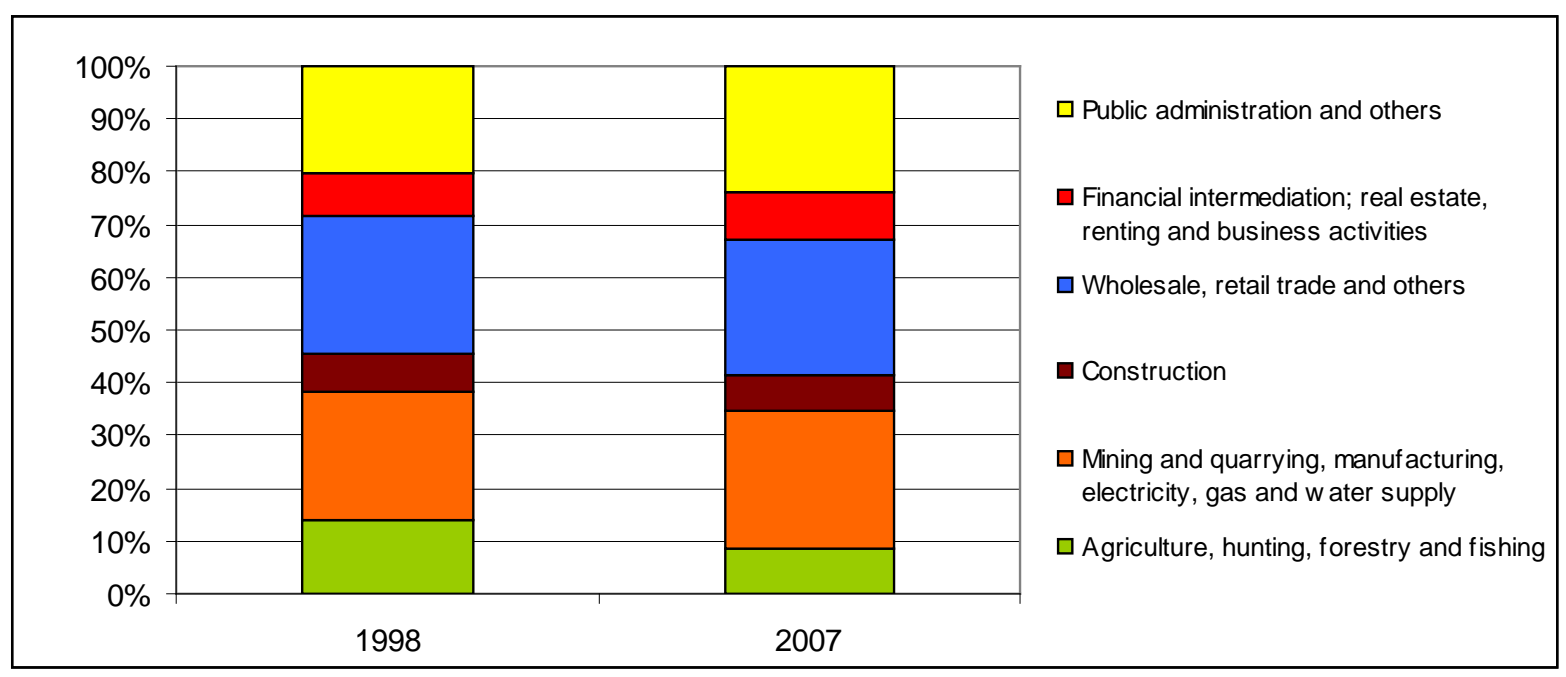

Figure 14 The employment structure in Pomorskie, 1998-2007

Source: graph produced from OECD data, 2012

During this period, the shares of those employed in the different sectors have changed in the following manner: decline in agriculture, fishery and forestry from $14 \%$ to $9 \%$; increase in mining and utilities from $24 \%$ to $26 \%$; remained stable in construction $7 \%$; also remained stable in wholesale and retail, vehicle and other goods' repairs, hotels and restaurants, transport, storage of goods and communication $(26 \%)$; increase in the finance, real estate and entrepreneurial activities sector from 8 to $9 \%$; and an increase in the public sector up from $20 \%$ to $23.5 \%$. Compared to the rest of the country, the Pomorskie voivodeship has a relatively low employment share in the agricultural sector (in Poland, in 2007, over 15\% of all employees were working in this sector), whereas the shares in all the other sectors are somewhat higher (OECD, 2012). The domination of the service sector in the region's economy is also reflected in the number of establishments by sectors of the economy. In 2007, the highest numbers were in the wholesale and retail trade, together with motor vehicle repair and household goods activities sectors (over 33000 establishments); in real estate, renting and business there were approximately 19000 establishments; in construction more than 14 000; and in transport, storage and communications activities, almost 10000 . In addition, the hotels and restaurants services were relatively high, exceeding 5500 establishments. In all other forms of economic activity, the number of establishments was significantly smaller (OECD, 2012).

The unemployment rate reflects the unused potential of the labour force. Calculated in accordance with Eurostat methodology, the unemployment rate in the Pomorskie voivodeship in 2010 slightly exceeded $9 \%$, and was lower than the rate for the rest of the country, which was $9.5 \%$ (Figure 15). Between 1999 and 2010, the unemployment rate ranged from 11\% (1999) to 21\% (2002), then dropped to $5.5 \%$ in 2008 , but in recent years has gradually been increasing again. In the period under discussion, the unemployment rate corresponded to the national average. 


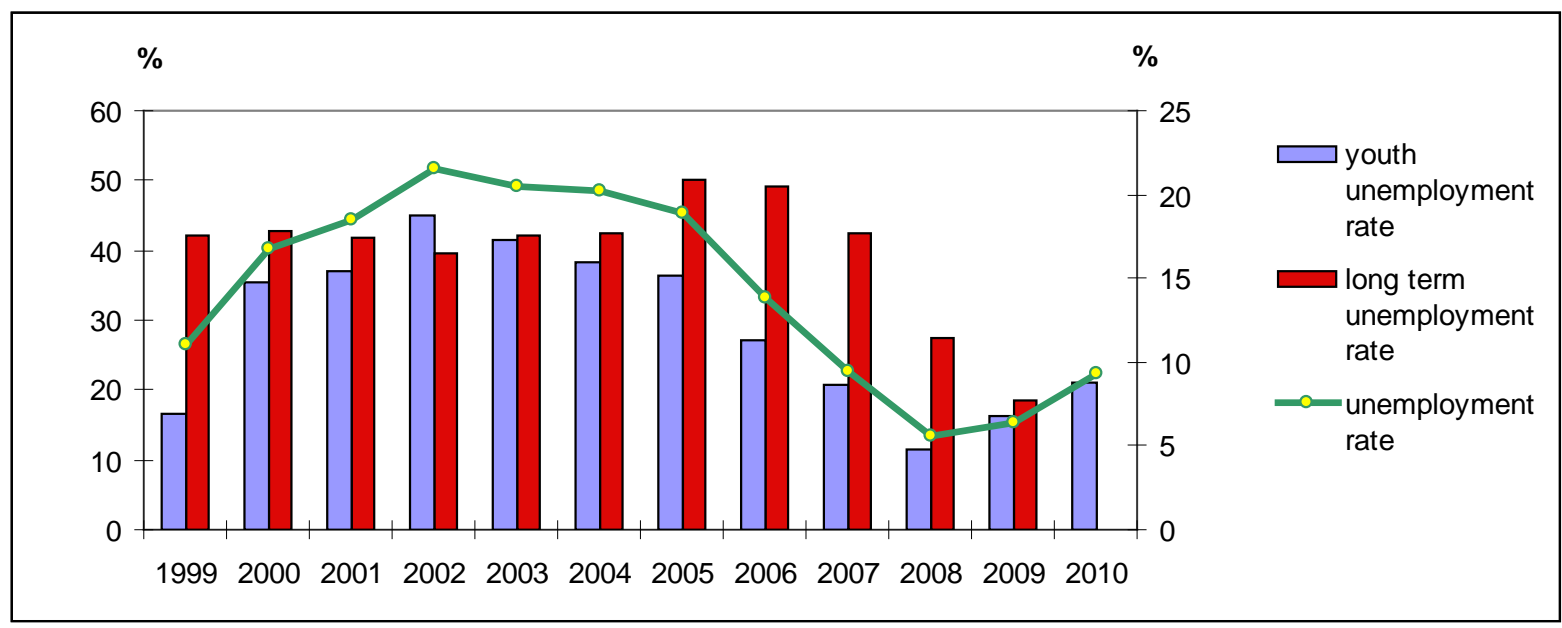

Figure 15 Unemployment rates in the Pomorskie region, 1999-2010

Source: graph produced from Eurostats data, 2012

For the years 1999-2005, the percentage share of long-term unemployed ${ }^{6}$ people increased from $42 \%$ to $50 \%$ of the entire recorded population of unemployed people, and then decreased to below $19 \%$ in 2009 , where the national average share is $30 \%$. The share of young people ${ }^{7}$ among the unemployed rate grew from $16 \%$ in 1999 to $45 \%$ in 2002 , dropping to $11 \%$, but then growing again, reaching $21 \%$ in 2010 . In the rest of the country, the share of younger age groups in the unemployed population is generally a few percent higher than in the Pomorskie region. The negative trend of growing youth unemployment rate is a trend observed not only in Poland, but also in most European countries. Economic crises and shrinking employment opportunities primarily affect young people as the most vulnerable group in the labour market. It is for this reason that employers should be encouraged to employ younger people, via a range of incentives targeted specifically at first employment opportunities.

The share of women among the unemployed is decreasing. Between the years 2000-2010, it decreased from $57 \%$ to $53 \%$. The comparatively low share of unemployed women can be observed in the districts of Gdańsk, Sopot and Puck, where many women find jobs in services industries, including tourism (Annex 6). The biggest decrease in the percentage share of women in the unemployment rate was observed in the agglomeration cities where, in the 2003-2010 period, it dropped to 5 percentage points (Annex 7). The development of service-based industries in regional economies is positively correlated with the increase of women's employment rates. In the Pomorskie region, the growing number of establishments in the tourism and recreational services creates favourable labour market conditions for women.

When analysed by age group, people aged 25-34 form a significantly large group among the unemployed. In the years 2000-2010, the share of unemployed aged 24 and less decreased (from $29 \%$ to $23 \%$ ), while the percentage of unemployed aged 55 and above rose from $2 \%$ to $10 \%$ (Local Data Bank, CSO, 2012). Two decades of uninterrupted economic growth permitted the creation of many workplaces in Poland, mainly in the services and high-technology industries, which historically employ primarily young people. The highest share of unemployed aged 55 and above was observed in the cities of the Gdańsk agglomeration (Figure 16). This corresponds to a relatively high share of elderly people within these cities. Also, within these cities, the growth in unemployed percentage share among people aged 55 and above is much more pronounced than in other areas. In the years 2002-2010, this growth surpassed 10 percentage

\footnotetext{
${ }^{6}$ Persons unemployed for 12 months or more as a percentage of total unemployed

${ }^{7}$ Data refer to persons aged 15 to 24 years and are expressed in percentages
} 
points (Figure 17). In spite of the existence of large labour markets in Gdynia and Gdańsk, the more elderly population is unable to find employment, as their qualifications do not meet the needs of employers and labour market requirements (CSO, 2012). Among the most common constraints for 55+ workers are:

- job insecurity, intensified today by highly flexible labour markets;

- work skills, and ever growing individual performance efficiency expectations;

- spatial and professional mobility required in the labour market; and

- health limitations of older age.

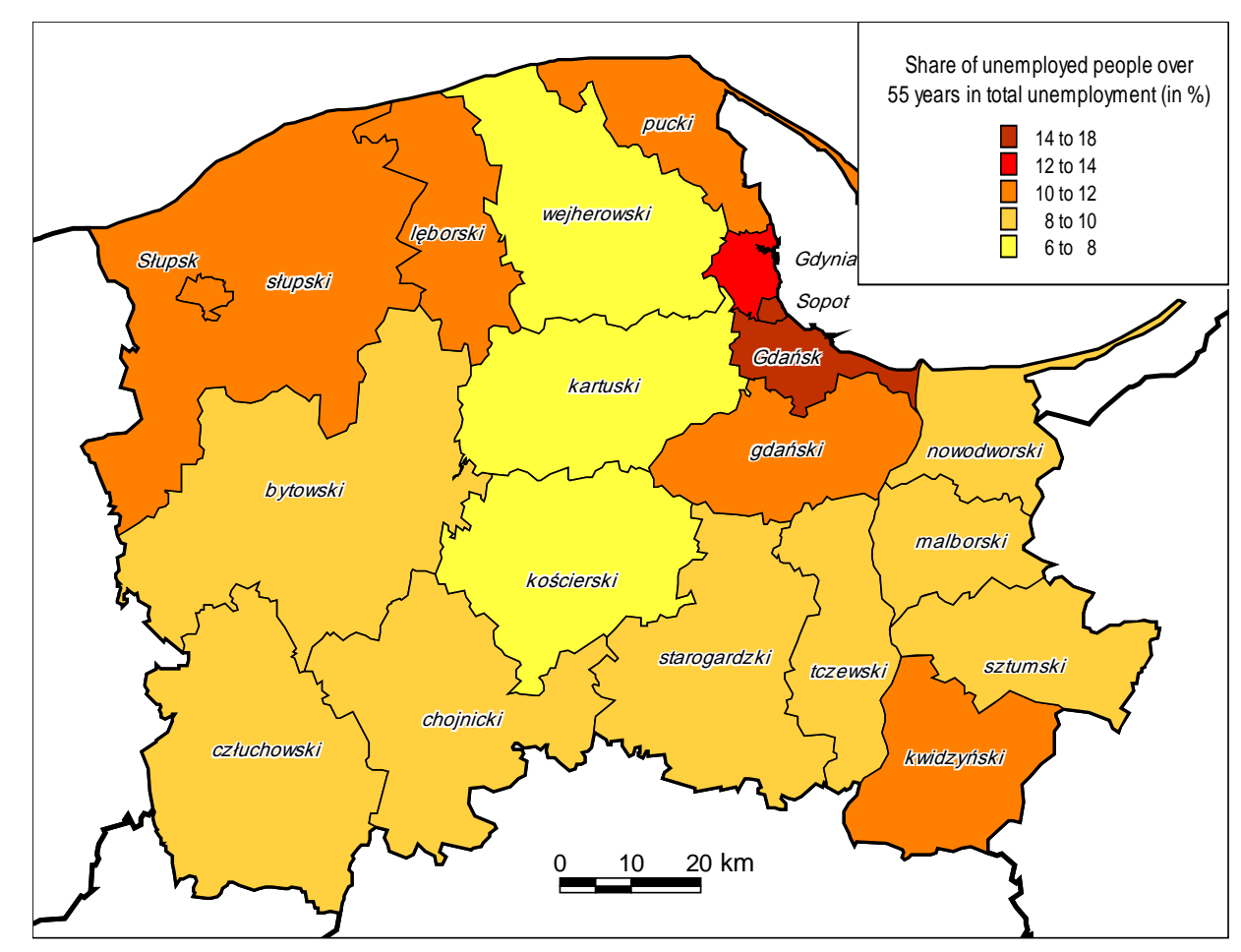

Figure 16 Unemployment of people over the age of 55 in LAU 1 of the Pomorskie region, 2010

Source: map produced from Local Data Bank, CSO, 2012 


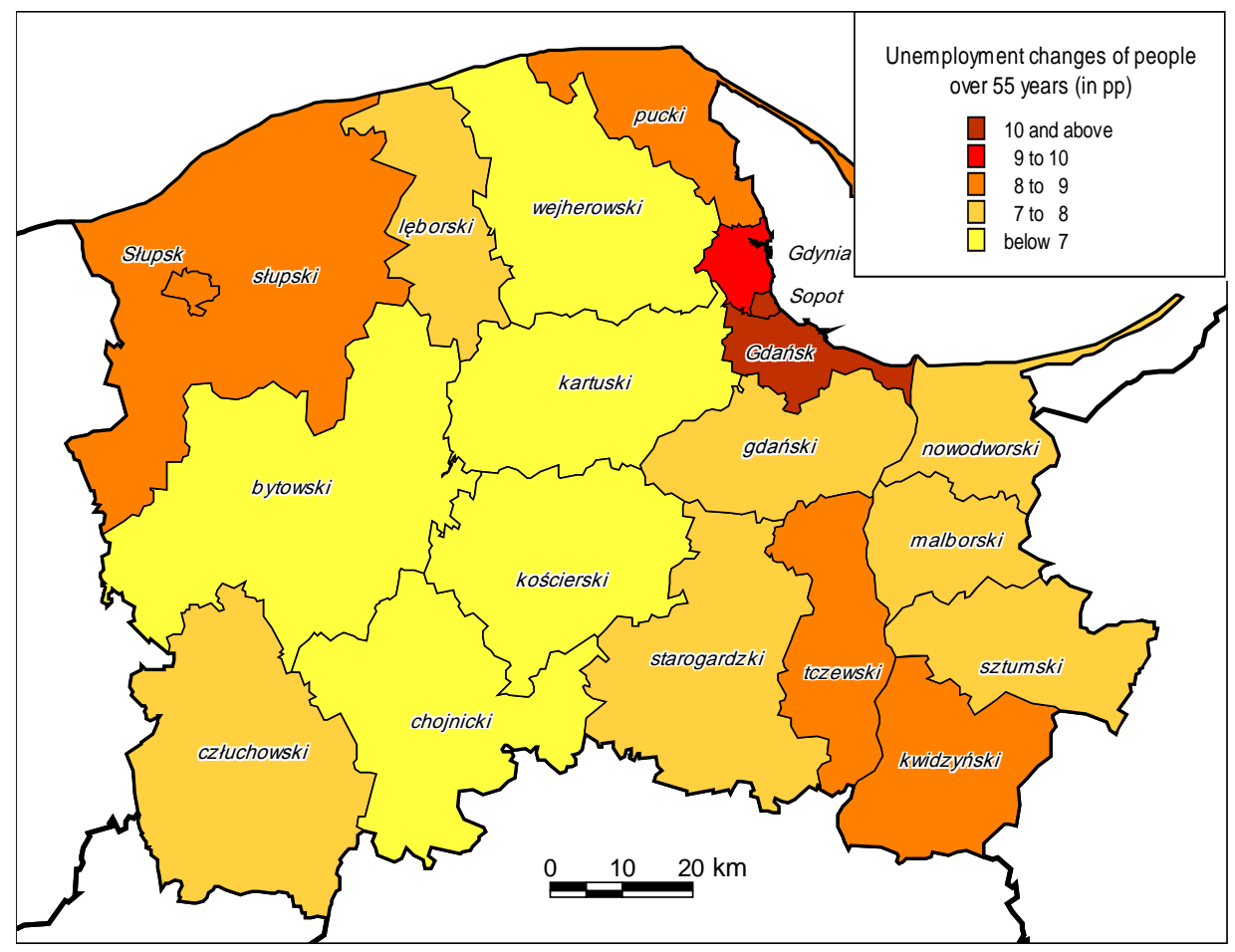

Figure 17 Changes in unemployment rates for people 55+ in LAU 1 of the Pomorskie region, 2002-2010

Source: map produced from Local Data Bank, CSO, 2012

Although unemployed people are predominately women, this disproportion between the sexes is most noticeable in younger age groups. This disparity is especially evident in the 25-34 age group, and stems from the fact that most employers expect that women will want to start families at this age. Since employers often lack a flexible approach to working hours, many women who are raising children decide to remain unemployed, and only take odd jobs from time to time.

This high unemployment rate among the inhabitants is a developmental barrier for the region. Counteracting strong inequalities in the labour markets within the region is a challenge for regional policy. Gdańsk, Sopot and Gdynia (the TriCities) possess the most attractive labour markets and a lower general level of unemployment. In contrast, the situation is most difficult in peripheral areas along the region's borders. However, this picture changes when investigating the unemployment rate among the older population. It is in the metropolitan areas that the share of unemployed aged 55+ is highest, which is caused by concentrations of older people in urban zones. The metropolitan area thus will not only be the first to be affected by population-ageing-related problems, but it will also suffer the most. However, on the plus side, the metropolitan environment creates the most advantageous conditions for the development of advanced system of skills and training for older workers. The engagement of employers in the educational training of their workers is an essential part of this process. The growing flexibility of labour markets may also work favourably for the employment of elderly people. Project-oriented forms of employment are especially sensitive to qualifications, skills and experience within the working force, which places the experienced older workers in a much more promising position. 


\section{CHAPTER 3: \\ OLDER WORKERS: SILVER ECONOMY AND WHITE ECONOMY}

In the years 1999-2010, the Pomorskie region's population grew by some $5 \%$, while the population aged $55-59$ increased by $61 \%$ (44\% in Poland). The number of women grew slightly more than the number of men. The age group of $60-64$ grew at a slower rate; $33 \%$ (15\% in Poland). The number of men in this age group increased more than the number of women. The share of both age groups rose from ca. $5 \%$ to ca. $7 \%$ of the population in the period mentioned (Eurostat, 2012). The significant increase in the elderly population is the consequence of the significant increase in life expectancy rates in Poland and the Pomorskie region.

The demographic forecasts clearly indicate that the problem of employment of older people will continue to increase significantly (Figure 18).

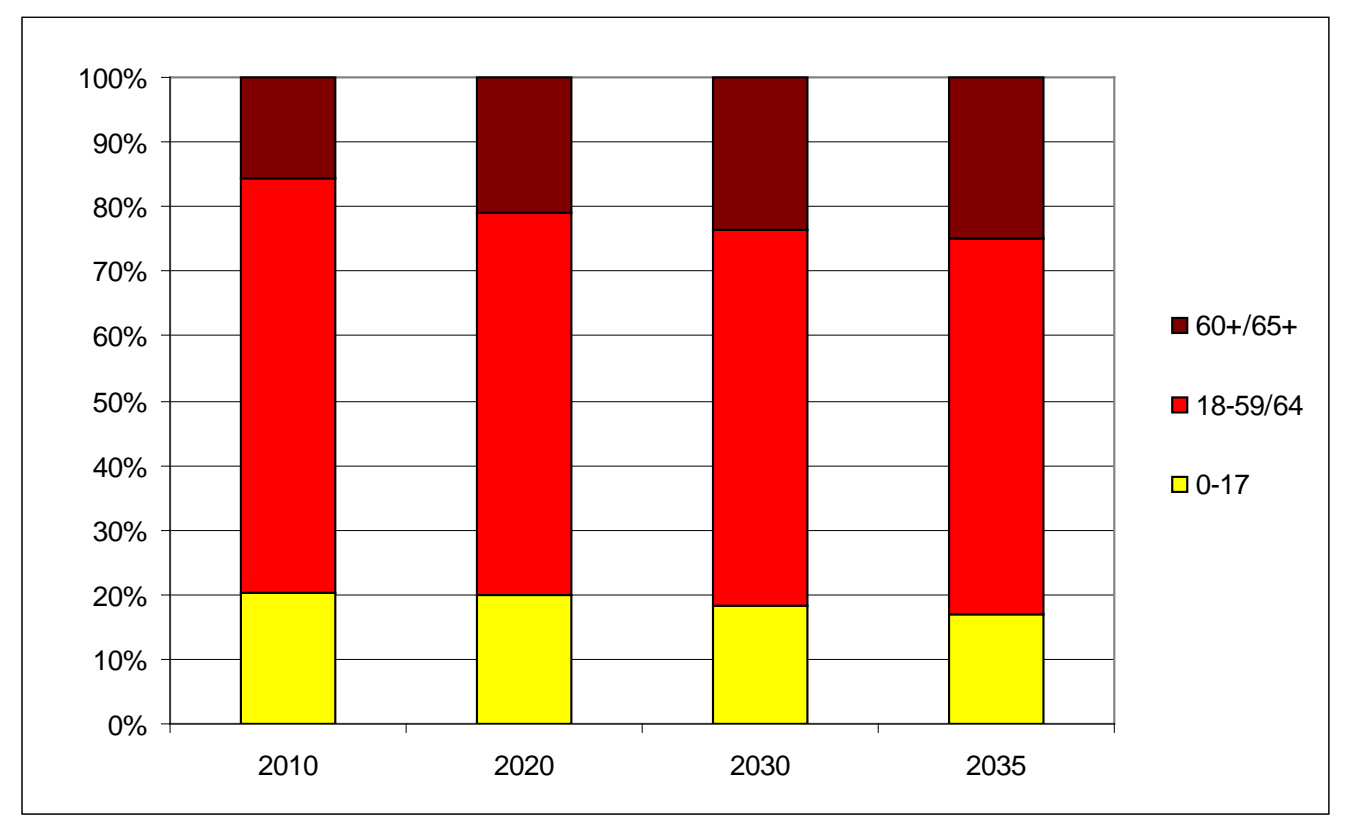

Figure 18 Population forecast by working-age groups for the Pomorskie region to 2035

Source: graph produced from CSO data, 2012

In comparing the forecasts that predict a constant growth of post-production aged population with the expected gradual subsiding of the real population increase (cf. figure 53 and 54), a substantial and constant growth in the share of elder age groups in the population's structure is indicated. Therefore, undertaking actions aimed at adjusting the labour market to meet the new demographic transition of the ageing population) is required. 
One successful initiative that has been taken to adjust labour markets to meet the challenges being evoked by the process of population ageing is the implementation of the "I work - I develop competence. An innovative model of support for workers 50+" project (Box 1). The project has been funded from regional European Social Fund sources.

\section{Box 1 I work - I develop competence. An innovative model of support for workers 50+.}

In 2010-2012, PBS DGA implemented one of the first innovative age-related worker projects in the Pomorskie region. The project was targeted at particular groups, among which were:

- User Groups: representatives of local and regional institutions that lead employment promotion policy or which hold the instruments of implementation for system solutions to economic activity in the labour market; public counsellors (employment offices); and private labour market institutions.

- Groups of customers: workers in the 50+ age group residing in the Pomorskie region, interested in maintaining employment and continuing their professional development. Additionally, this group included human resources (HR) professionals, and HR departments dealing with human resource management, including age management personnel in companies.

The main objective of the project was to increase the activity and the attractiveness of employment of workers in the 50+ age group within the labour market, by developing and testing an innovative model of consulting services and personal development, including: the use of career counselling and assessment of existing levels of competence; participation in training and courses; the use of specialised health-related consulting; and access to legal services related to the functioning of the labour market.

The dimension of innovation in the labour market was targeted at three main areas:

- A new approach to the problem of availability and dissemination of career counselling services for older working people (creation Career Centre $50+$ ).

- Implementation of new methods of vocational guidance; Balance of Competence (including the development of tools to diagnose the potential competence of workers aged $50+$ ).

- Implementation of the new forms of support - financial instrument activation services in the form of Talon Career.

Balance of Competence included activities such as:

- $\quad$ Training / training by ABC Enterprise;

- Personal development training;

- Legal consultations on issues of employment and labour law;

- Consultations on the functioning of the labour market; and

- Pro-health consultation (geriatric doctor, physiotherapist, dietician, psychologist).

Source: Pracownia Badań Społecznych (PBS), 2012

These initiatives help not only to energise elderly workers to improve their skills and competencies in the labour market and encourage employers to undertake age management training, but also to combat the unfavourable perception of the characteristics of older workers from the labour market point of view. The most common of these perceptions are:

o older people want to retire early;

o older workers have trouble adjusting to rapid changes in job demands, as well as adjusting to new technological and foreign languages requirements;

0 it is difficult to persuade older workers to participate in training activities and new projects;

0 older workers are strongly limited in active participation in the labour market due to their mental barriers;

o older workers show low professional and spatial mobility; 
o older people want to develop knowledge but for their own reasons, i.e. mainly social purposes, not for professional reasons;

0 older workers quite often represent a demanding attitude; or

0 older workers aged 60 and $70+$ are the most difficult groups to mobilise in the labour market.

Another interesting initiative developed by the Polish Economic Society in the Pomorskie region was the "Wykorzystaj Nas! Pracownicy 45+ w Twojej Firmie" (literally: Make Use of Us! 45+ Workers In Your Enterprise) project, whose objective was increasing the awareness of ways to more effectively utilise the potential of workers aged $45+$, and also various means of adjusting their human resource policies to meet the changing demographic situation in the SME sector. The project was implemented in the years 2009-2010 and was co-financed by the European Social Fund (Box 2).

\section{Box 2 "Make Use of Us! 45 + Employees in Your Enterprise”}

The aim of the project was to identify opportunities for development of the human resources policies within Small and Medium Enterprises (SMEs), mainly through better understanding of the age management concept, to more fully exploit the potential of workers aged $45+$.

Quantitative and qualitative research constituted an integral part of the project, and was aimed at monitoring the situation within the labour market in the Pomorskie region, with particular emphasis on issues related to the employment of workers aged 45+. The studies were conducted among SME entrepreneurs, and 500 enterprises participated. Managers responsible for human resources policies in the investigated entities were the respondents in the survey.

The respondents evaluated elder workers quite positively, pointing to the loyalty of these workers, their respect for work, flexibility, diligence and experience. On the other hand, they evaluated as low their: ability to adapt to change; desire to undertake further education; and openness to innovations. The positive evaluation of workers aged $45+$, as well as declarations of the planned implementation of age-management-oriented policy draws quite an optimistic picture of $45+$ workers' employment prospects in the SME sector.

As a result of the project's outcomes, two publications were issued: a guide for SME employers entitled "How to successfully employ workers 45 +"; and a book entitled "45+ employees in an enterprise".

Source: Polskie Towarzystwo Ekonomiczne w Gdańsku, 2012

The initiatives mentioned above demonstrate that there is a consciousness in the region of the necessity to undertake actions related to demographic changes. The projects carried out thus far are in the nature of pilot studies and actions. Their main goal is to define the situation in the region and to seek good practice actions that will benefit companies in these new circumstances. Therefore, it is a strictly initial phase of adjusting the regional development to the new demographic situation.

The problem of how to extend the active working life of individuals is only one facet of the population ageing processes. The vast arena of issues connected with the existential needs of older people and the needs of older customers opens up new challenges and opportunities for silver and white economy development. The fields of competence and activities of both types of these new economies are very close to each other, and they often overlap.

The primary problems of the white economy that have been identified in the region are mainly connected with the following issues:

o underdeveloped and underfinanced health care system for older people; 
o particularly disadvantaged situation for the long-term care of older people;

o a lack of sufficient geriatric care and rehabilitation services;

o a lack of psychological support services for elderly people;

0 the growing number of foreign tourists requiring medical care creates a high demand for white economy services in the region, which stimulates white economy development, but also raises the costs of aged-care services, making them even less available for the local community.

The potential profits for the regional economy are connected with the development of the silver economy, which supplies the growing consumption demands of older customers. Among others, there are the needs connected with older people's free time management. Services which help to occupy their free time after retirement, including education, entertainment, tourism and recreation, are growing in demand. Another broad range of services required by the ageing population is connected with maintenance of independent dwellings (cleaning, shopping and care services), training in the use of high-technology household equipment, organisation of transportation services friendly to elderly people, and smart homes services, which help to equip apartments and homes with electronic systems enabling longer autonomy for inhabitants. The third type of services, which link silver and white economy fields of activity, is connected with health and beauty care services provided in spa, bath and sanatorium centres.

The natural environment of the Pomorskie region, including its seaside location, and long tradition as a spa and bath centre, create particularly favourable conditions for silver economy development. Provision of funding and training support for these fields under the regional policy framework should trigger resulting high activity in the regional small and medium enterprises. 


\section{CHAPTER 4: \\ SKILLS AND TRAINING ECOSYSTEM}

The Pomorskie region is the strongest educational centre in Northern Poland. There are 28 headquarters of higher education units situated in the region and 13 branches of higher education schools located outside the region. The region's higher education potential is created predominantly by state universities:

- University of Gdańsk - c.a. 30000 students

- Gdańsk University of Technology- c.a. 20000 students

- Medical University of Gdańsk - c.a. 5000 students

- and many others, such as: Gdynia Maritime University and the Naval Academy.

The TriCity agglomeration is one of the leading secondary education centres in Poland. A number of secondary schools in the region have been ranked as first quality schools over recent years. They therefore attract the best students from across the country. However, analyses of the educational careers of students reveal that the region's higher education system is unable to retain the most talented students, who prefer to attend the main higher education centres in Poland in Warsaw or Kraków, or who decide to study abroad (dispersed data provided by heads of secondary schools).

Local government expenditure on education can serve as an indicator of educational quality. Local government funds for education largely come from the state budget, from what are termed "educational subsidies". The funds allocated in the state budget are mainly designated for teacher's salaries under "current expenditure", while investment expenditure is covered by local government funds.

In the Pomorskie voivodeship, in the 2000-2010 period, overall expenditure on education rose by $79 \%$ ( $73 \%$ in Poland), current expenditure rose by $77 \%$ ( $73 \%$ in Poland) and investment-related expenditure rose by $101 \%$ ( $79 \%$ in Poland). Therefore, relatively speaking, more funds were invested in Pomorskie's educational infrastructure than in the rest of the country. However, the expenditure on investments, both in Pomorskie and in the rest of the country, amounted to only 6-7\% of total expenditure on education (Local Data Bank, CSO, 2012).

In the period discussed, the share of expenditure on education from municipalities' and city districts' budgets as a percentage of the total of all local and regional governments' expenditure on education rose visibly (from $83 \%$ in 2000 to $86 \%$ in 2010). The share of expenditure in rural districts dropped from $16 \%$ to $13 \%$. Regional administration expenditure amounted to only $1.3 \%$ in 2000 and $1 \%$ in 2010 of all local governments' expenditure on education. This expenditure does not cover higher education, which is funded independently from local government (Local Data Bank, CSO, 2012).

Calculating the share of adults that have received education and training, apart from defining the structure and changes in expenditure on education by different levels of local government, is important for defining the region's economic development potential. Among the 25-64 age group in the Pomorskie voivodeship, the percentage of people studying (including training etc.) rose from $4.5 \%$ in 2008 to $6.6 \%$ in 
2010 (compared to changes of $4.7 \%$ to $6.3 \%$ in Poland) (Eurostat, 2012). In Pomorskie, as in the rest of the country, women undertook education slightly more often than men.

Considering the population ageing issue and the changes in labour markets that originate from the post-industrial and postmodernist nature of economic systems, life long learning (LLL) plays a key role in forming skills and training ecosystems, and should be highlighted as a key regional strategy and supported by resources and funding.

Research that was undertaken as part of a project carried out for the Marshall's Office of the Pomorskie Voivodeship, co-financed by the European Special Fund, (Assessment of the conditions, 2011) showed that in a vast majority of households in the region (97\%), their members aged over 16 do not continue education as part of a LLL process. A 2006 Central Statistical Office study revealed that only 5.3\% of the region's inhabitants aged 24-64 participated in LLL. At the same time, only 18\% of household members younger than 16 years old participated in free extracurricular activities. For paid activities, this rate dropped to less than 9\% (Assessment of the conditions, 2011). Investment in children's and youth's additional education is strongly correlated, firstly, with the level of the parents' education, and secondly, with the level of their income. Among the paid education activities undertaken, households most frequently chose foreign languages classes. This could indicate that public availability of these courses may be poorly developed in the region. The research also showed that a significant number of households with children aged less than 6 do not use institutional care such as nurseries and kindergartens. This is another indicator that the preschool education system in the region is not attractive enough for parents in terms of accessibility and forms of service. It is worth noting that preschool education builds the basis for positive attitudes towards LLL.

The functioning of six Universities of the Third Age in the region is, beyond any doubt, a successful outcome of local policy initiatives. Three of them are situated in the TriCity area and three of them in sub-regional centres. The largest one was created by the University of Gdańsk and has continued to gain in popularity. The number of students is limited by the capacity of the school, rather than by a lack of interested people (Figure 19). The popularity of the Third Age Universities demonstrates the desire of older people to develop knowledge for their own purposes, such as for social reasons.

\begin{tabular}{|c|c|c|c|c|c|c|c|c|c|c|}
\hline \multirow[b]{2}{*}{$\begin{array}{c}\text { Academic } \\
\text { year }\end{array}$} & \multicolumn{3}{|c|}{ Lecturers } & \multirow{2}{*}{$\begin{array}{c}\text { Number } \\
\text { of } \\
\text { lectures }\end{array}$} & \multirow{2}{*}{$\begin{array}{c}\text { Classes - } \\
\text { number of } \\
\text { teaching } \\
\text { hours }\end{array}$} & \multicolumn{5}{|c|}{ Number of students } \\
\hline & professors & doctors & M.Sc & & & Gdansk & Kartuzy & $\begin{array}{c}\text { Pruszcz } \\
\text { Gd. }\end{array}$ & Pelplin & Total \\
\hline $2004 / 2005$ & 7 & 8 & 6 & 29 & 464 & 470 & - & - & - & 470 \\
\hline $2005 / 2006$ & 11 & 10 & 10 & 27 & 945 & 735 & - & - & - & 735 \\
\hline $2006 / 2007$ & 13 & 12 & 19 & 51 & 2378 & 770 & - & - & - & 770 \\
\hline $2007 / 2008$ & 9 & 16 & 17 & 50 & 2525 & 800 & 50 & 200 & - & 1050 \\
\hline $2008 / 2009$ & 17 & 10 & 26 & 52 & 2878 & 1250 & 70 & 220 & 180 & 1720 \\
\hline $2009 / 2010$ & 15 & 13 & 33 & 75 & 3033 & 1300 & 70 & 220 & 180 & 1770 \\
\hline
\end{tabular}

Figure 19 Gdańsk University of the Third Age

Source: based on http://www.ug.edu.pl

Another example of a successful third age university in the region is the Sopot University of the Third Age (self-government organisation), which carries out educational, cultural, creative and tourist activities (Box 3). 


\section{Box 3 Sopot University of the Third Age}

The University promotes active lifestyles and gerontological ageing processes prevention. Students are trained in one of the following areas:

- languages;

- historical;

- social;

- ecological;

- psychological; or

- preventative health.

Training cycles last two years, and the attendees can be any older person that is not professionally active. Classes are held regularly on a fixed weekly plan.

Sopot University of the Third Age is a partner in projects co-ordinated by the government of Sopot: "Bank of Good Practice" (working in partnership with local government representatives, Ozierska, from the Kaliningrad region) and "Sopot Time Bank", in which older people work in exchange for leisure time, thus helping other community members. Students also participate in medical programmes such as free flu vaccinations, blood tests, musculoskeletal research and circulation improvement, carried out by the doctors of the Medical University of Gdańsk, Sopot Ambulance, and Sopot Physical Activity Association.

Among other projects, the University-led "Eighteen, eighty, or how many links between early and late adulthood", subsidised by the Polish-American Freedom Foundation, works to break the different stereotypes of people concerning both earlyand late adulthood, as well as building an "intergenerational bridge." Meetings were conducted in four closely related areas:

- information technology;

- culture and art;

- ecology (designed to acquire the habit of caring for the environment and promoting physical activity and healthy lifestyles);

- psychology (designed to perpetuate positive relations via interpersonal communication between generations).

Another important project was: "e-Senior, the twenty-first century sage". The project aimed to develop skills in computer and Internet use by the elderly. A secondary goal was to change the perception of seniors within society - promoting the image of a senior who is actively working in today's information-driven society, and who communicates their knowledge and experience to others, especially the younger generation, using modern technology.

The project "Q-Ageing senior-friendly city", developed a comprehensive and transnational solution to issues arising from an ageing society. In Sopot, a map was created detailing the city's architectural barriers that hinder the elderly and the disabled. In several branches of the municipal library, "senior's corners" have been created, which contain computers with free Internet access, tailored to the needs of the elderly.

Source: Sopocki Uniwersytet Trzeciego Wieku, 2012

The demand for the Universities of the Third Age's services is increasing, in line with population ageing. Therefore, continued support, including provision of resources and funding, is essential in order to keep the universities growing and developing to meet the needs of the attendees. 


\section{CHAPTER 5: HEALTH SERVICES FOR SOCIAL TRANSFORMATION AND INCLUSION}

High accessibility to healthcare services positively influences regions' development. Such access allows people to maintain their health, which in turn enables them to remain economically active even at an older age.

In the years 2004-2010, the number of hospitals in the Pomorskie voivodeship rose from 39 to 41 . In spite of this, the accessibility - measured in the number of beds per 1000 inhabitants - decreased from 4.2 to 3.9. A similar decrease - from 4.9 to 4.7 - has been observed across the country as a whole. Unfortunately, in Pomorskie (as in the rest of the country), the number of doctors per 1000 inhabitants has also dropped - from 2.4 to 2.1. Accessibility to other medical personnel is also decreasing. In the 19992010 period, the number of nurses per 1000 inhabitants dropped from 4.7 to 4.1 (5.2 to 4.8 in Poland). Accessibility to midwives did not change throughout the discussed period, remaining at t0.5 per 1000 inhabitants (0.6 in Poland) (Local Data Bank, CSO, 2012).

The results of analysis of statistical data from the Pomorskie voivodeship show that accessibility to doctors has been slightly deteriorating. Data of the Central Statistical Office prove that the number of doctors per 1000 inhabitants dropped to as little as 1.9 in 2010. In spite of the absolute number of doctors shrinking, and the decrease of the per-1 000 inhabitant rate in the voivodeship, in some districts, accessibility rose. This is a result of the policy of having one doctor attend several different facilities. The highest accessibility rate is observed in the agglomeration cities where, in 2010 , this rate has surpassed 5 doctors per 1000 inhabitants (Figure 20). Constant improvements in accessibility are observed in Gdańsk and Gdynia (Figure 21). 


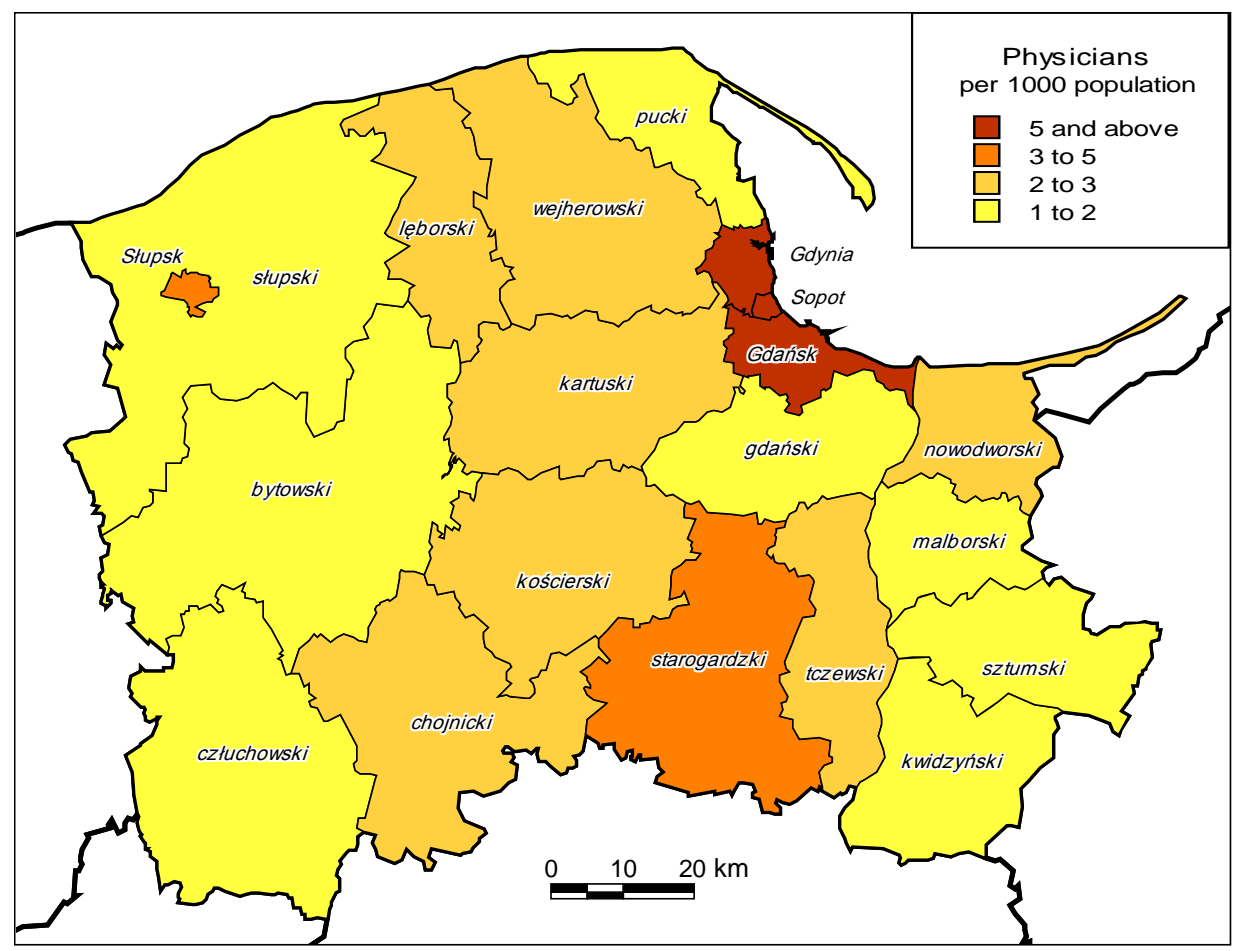

Figure 20 Physicians in LAU 1 of the Pomorskie Region, 2010

Source: maps produced from Local Data Bank, CSO, 2012

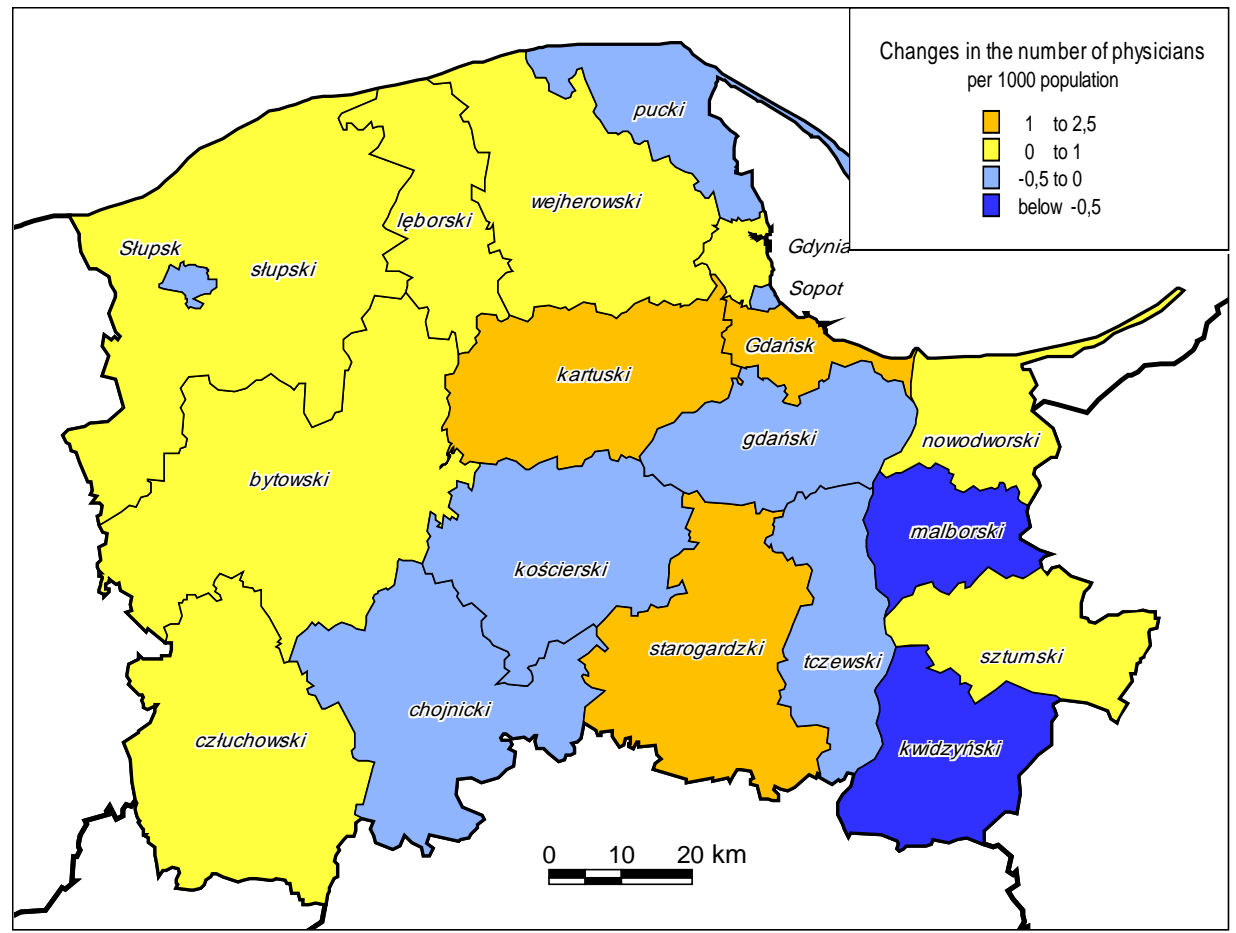

Figure 21 Changes in the number of physicians in LAU 1 of the Pomorskie region, 2006-2010

Source: maps produced from Local Data Bank, CSO, 2012 
The death rate in Pomorskie has increased in recent years, from 9.2 per 1000 inhabitants in 2005 to 11.3 in 2009 . This growth is associated with population ageing.

It is safe to assume that as the population ages, social welfare expenditure will grow. The state's and local government's expenditure, as well as the number of people subject to social welfare, are regulated by law. The legislator establishes the income threshold below which a person is entitled to receive social welfare benefits. Since 2004, these thresholds have not changed in Poland, in spite of inflation and changes in national average earnings. As a result, the number of people entitled to state social assistance benefits, which are distributed by local governments, is decreasing. This policy is intended to avoid rapid expansion in social expenditure.

The picture of the distribution of social assistance funds within the region clearly indicates that the peripherally located and economically most lagging LAU 1 territorial units are the ones with the highest social welfare expenditure (Figure 22). The high level of social assistance in one of the metropolitan core cities, Sopot, results from the city having the highest percentage of $65+$ inhabitants. This interpretation of social assistance distribution is yet more proof that stimulating socio-economic activity in a given territorial unit is the best tool for solving the problems of social exclusion. In the long-term, it is also a much more efficient solution than building up the social support funding system.

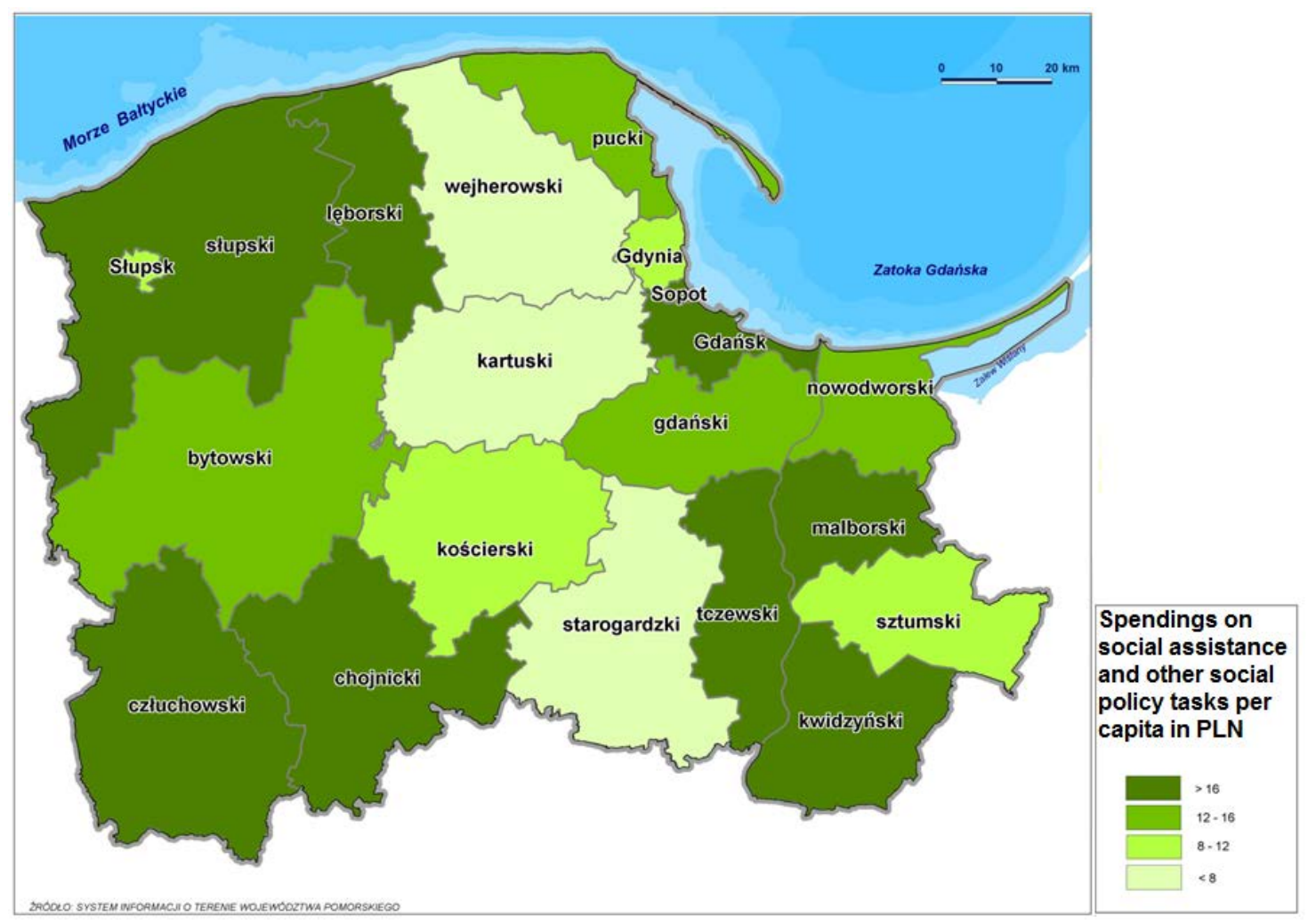

Figure 22 Social assistance in LAU 1 of the Pomorskie region, 2010

Source: Marshall's Office of the Pomorskie Voivodeship, 2011

In the 2004-2010 period, Pomorskie's government-based expenditure on social infrastructure (investment expenditure) rose by $88 \%$ (in Poland it dropped by $24 \%$ ). It should be noted that investment expenditure constituted only $0.5 \%$ of total current expenditure, i.e. the overall benefits paid in 2010 . The investment expenditure of districts has grown by $181 \%$ (by $55 \%$ in Poland), although it amounted to less than $5 \%$ of current expenditure. Municipalities' expenditure has grown by $287 \%$ (by $126 \%$ in Poland), 
although it amounted to slightly more than $1 \%$ of current expenditure at the local government level in 2010 (Local Data Bank, CSO, 2012).

In Pomorskie, current expenditure on social security was largely covered from municipalities' budgets ( $82 \%$ of total expenditure in 2010 ), to a lesser extent from districts' budgets $(16 \%)$, and even less from the voivodeship's budgets (ca. 2\%). In the 2004-2010 period, the share of the municipalities' percentage in overall expenditure did not change, however the districts' share decreased, while the voivodeship's share grew (Local Data Bank, CSO, 2012).

In 2010, 455000 of Pomorskie's inhabitants were receiving retirement payments and pension benefits (ex-farmers amounted to 9\% of this group). In the 1999-2010 period, the number of people receiving social security benefits dropped only by $0.1 \%$ (2.2\% in Poland), while the number of people receiving retirement payments and pension benefits from the Agricultural Social Insurance Fund dropped significantly - by $35 \%$ (by $29 \%$ in Poland). On the other hand, the number of people receiving retirement payments and pension benefits from the Social Insurance Fund grew by $6 \%$ (by 5\% in Poland). The following groups are among those receiving social security benefits from the Social Insurance Fund: retired persons; those incapable of working; and people receiving family pensions (e.g. due to the loss of a parent). In Pomorskie in the 1999-2010 period, the number of retired persons registered with the Social Insurance Fund grew by $51 \%$ (by $49 \%$ in Poland) up to 270000 people; the number of persons incapable of work and therefore receiving pension benefits dropped by 52\% (by 54\% in Poland) down to 67 000; and the number of people receiving family pensions grew by $5 \%$ (by $8 \%$ in Poland) up to 75000 . In general, the number of retired persons combined across both social security systems grew by $28 \%$ (by $21 \%$ in Poland), and reached 314000 (Local Data Bank, CSO, 2012).

This rate of growth of the retired population in Pomorskie, which is higher than the average for Poland, corresponds to an increase in growth of the elderly population in proportion to the working age population in the region. The elderly dependency rate (i.e. the number of $65+$ elderly people compared to those aged 15-64) in the 1991-2009 period grew from 13 to 17 persons of post-working age per 100 persons of working age (and from 16 to 19 in Poland overall). Therefore, the rate of population ageing in Pomorskie is higher than the Polish average, but the share of elderly persons in proportion to working age persons is smaller. In the period mentioned, the young dependency ratio (youth aged below 15 compared to those aged 15-64) also decreased. In Pomorskie, the rate dropped from 40 to 23 pre-working age persons (38.5 to 21.5 in Poland) per 100 persons in the working age group. The drop was similar to the rest of the country, although Pomorskie still maintains a higher number of young people in proportion to its working age population (OECD, 2012).

In the years 2003-2010, in the Pomorskie voivodeship as in the rest of the country, the number of people receiving pension benefits due to their inability to work and the number of unemployed have dropped. At the same time, the economically active population has grown. This has caused the economic dependency rate, measured as the share of the first two groups in proportion to the third one, ${ }^{1}$ to decrease. In the above-mentioned period, this rate dropped from 36 to 19 unemployed and/or receiving pension benefits per 100 economically active persons (32 to 18 in Poland). Thus, taking into account all the people who receive retirement payments, pension benefits, and the unemployed, the economic dependency rate in these years dropped from 74 to 61 (73 to 63 in Poland). In Pomorskie, this drop was caused mainly by a decrease in the number of unemployed, to a lesser extent, by a decrease in the number of those receiving pension benefits due to their inability to work, and also by a growth in the economically active population (CSO, 2012).

\footnotetext{
${ }^{1}$ Economic dependency (person in receipt of transfer benefits such as pensioners + unemployed/economic active persons)
} 
The increasing percentage of elderly people in society opens up new possibilities for nongovernment organisations (NGOs), which can provide support for those people in need of assistance. This results in a growth in the number of NGOs, some of them specialising in social assistance, while others focus mainly on organising various training activities for the elderly. The Central Statistical Office (2012) and the NGOs' Portal (2012) data indicate that in Pomorskie, in 2008, there were 3600 active organisations and 7700 in 2011. This shows a growth in rate from 16.4 to 34.2 NGOs per 10 thousand inhabitants (18.6 to 32.1 in Poland). Due to lack of data, it is impossible to establish the exact dynamics of growth in the number of NGOs that concentrate on social assistance exclusively for people aged 55 and above.

One of the more effective means of counteracting social exclusion and forming attitudes open to LLL is building a knowledge-based society. The level of households' computer equipment and broadband Internet connection access is a useful measure of progress in this aspect. In the case of Pomorskie, its level is among the highest in Poland. Fifty point six per cent of households in the region have a computer with Internet access, which is the highest percentage in the country, and an indication that an information society is forming. Forty-seven per cent of households have broadband Internet access, which is slightly more than the rest of the country $(46 \%)$; putting Pomorskie in the $4^{\text {th }}$ position in Poland. Wireless connections are one of the means of access to broadband Internet. Such solutions are more and more often implemented in many spots across the TriCity area. One of the projects related to wireless Internet access is "Wireless City Gdańsk", whose aim is establishing hotspots with free wireless Internet access around Gdańsk. In 2007, there were 123 hotspots in the voivodeship. Similarly, Trójmiejska Akademicka Sieć Komputerowa (TASK) is an initiative that aims to provide advanced IT services to the academic community and allows access to high-performance computers and scientific research software based in the Academic Computer Centre in Gdańsk (TASK) and other supercomputers in Poland (http://www.task.gda.pl/). One of the aims of TASK is to provide access to all the secondary schools in the TriCity area. However, it is not limited only to high schools - major companies, city councils, and the Marshall's Office have access to its network as well, and primary and junior high schools are also starting to participate in the network.

The characteristics of information technology usage in the region's enterprises are similar. In 2008 , Pomorskie ranked $2^{\text {nd }}$ in terms of the number of enterprises with computer access, $3^{\text {rd }}$ in the number of enterprises with their own websites, and $5^{\text {th }}$ in terms of the number of transactions performed via computer networks, and full e-administration services via the Internet. These figures illustrate a high potential of knowledge and innovations within the region's society.

The level of e-administration services is strictly related to the development of the information society. Many authorities in the Pomorskie voivodeship opened Internet portals to provide on-line services. Nevertheless, so far none of the public offices and institutions have become fully accessible via eadministration procedures. Most commonly, the actions consist of introducing electronic documents' processing, integrated office management systems, providing on-line access to services, investing in hardware infrastructure, computer networks and software, and creating public access points to the Internet. However, in terms of social inclusion policy, undertaking actions aimed at building e-administration accessibility for the public sector should constitute a priority for regional policy.

Evaluation of the information society's development is directly linked directly to another field of evaluation for the region, which is the social sphere. To fully evaluate the social capital of the region, it is essential to distinguish between bonding and bridging social capitals. The basic difference between these two capitals is the nature of interpersonal relationships within them. Bonding capital is the one that attracts people who already know each other very well, while bridging capital brings together persons or groups that have not met before. Bonding human capital is exclusive, introverted and aimed at building inner identities and the homogeneity of a group - closed local communities, ethnic and religious groups, and 
exclusive clubs may serve as examples. Bridging human capital, on the other hand, is inclusive and encourages building networks of contacts between people of different social statuses and backgrounds. Different societies and movements as well as numerous social initiatives are all examples of bridging human capital (Putnam, 2000).

Because of its tendency to limit connections only to a small social circle, bonding human capital decreases the inflow of information from the outside and thus limits the innovativeness and entrepreneurship among social groups. Nevertheless, a high level of trust within such groups, which may stimulate enterprises, is an advantage of this type of capital. Then again, the bridging social capital fosters openness in social connections, which increases the economic growth rate by allowing new economic or human capital resources. In spite of being less secure, because of their loose nature, bridging connections often provide otherwise lacking resources for closed groups. It has not been definitively settled which combination of these two types of social capital best benefits economic development. Observation research, in Italian regions among others, shows a combination of high bridging capital and a medium level of bonding capital most effectively stimulates development (Sabatini, 2005).

In the context of different forms of social capital, the Pomorskie region is divided into two distinctive areas: the TriCity area; and the rest of the region (Działek, 2011). The urban agglomeration has a low level of bonding capital and a high level of the bridging one. The rest of the region has a high level of bonding capital and a medium level of the bridging one. Therefore, in these terms, the region's potential should be seen as positive. The metropolitan area possesses a positive, pro-development social capital, while the region is not completely dominated by the more conservative bonding capital, since the bridging capital resources are at a medium level. Bridging social capital is a sort of "social" derivative of human capital resources. Thus, its high level in the TriCity area and a medium level in the region indicate a high potential of innovativeness and entrepreneurship that may serve as a solid base for building a knowledgebased and informative society.

In summary, doubtlessly the social sphere should be considered as being among the region's resources and constitutes its endogenous capital, whose capabilities should be considered in development scenarios. The described nature of the region's social capital helps in the development of attitudes and activities aimed at social inclusion and integration. Strong bonding social relations and human capital resources are conducive to NGOs' activities' social milieu. Regional policy should stimulate the development of NGOs focused on tasks related to population ageing. Their role in providing services devoted to the existential needs of older people may be crucial. Mobilisation of the NGOs to combat social exclusion processes should be strengthened by IT services development and availability. Considering the high level of households' computer equipment and broadband Internet connection access, the development of e-administration and e-governance more generally may significantly help to avoid social exclusion phenomena stemming from the low mobility caused by the age of the region's inhabitants. In this sphere, the roles of regional policy and local policy are pivotal. 


\section{CHAPTER 6: \\ GREEN REGIONAL ATTRACTIVENESS}

Improvement of the living environment can stimulate regional economic development. Applying green solutions (understood as innovative technologies to tackle climate change and new industries to drive long-term economic growth) positively influences the standard of living and draws foreign capital, from those interested in high-technology sector investments. This mechanism could also increase the number of workplaces that require high level qualifications.

There are several indicators that allow the evaluation of changes in the protection of the natural environment. One of these is the share of degraded and devastated ${ }^{1}$ land in the total region's area. In Pomorskie, in the 2002-2003 period, this share rose from $0.14 \%$ to $0.16 \%$ (in Poland it dropped from 0.23 to $0.20 \%$ ). Although the share of degraded and devastated land has risen, it is still smaller than the Polish average. At the same time, the share of the voivodeship's arranged green land ${ }^{2}$ rose from $0.58 \%$ in 2005 to $0.65 \%$ in $2010(0.68 \%$ to $0.73 \%$ in Poland). Pomorskie has a larger percentage of forest areas than the Polish average. Between 2002 and 2010 the percentage of forest area grew from 35\% to 37\%. During the same period, the land covered by areas qualified as recreational did not change. However, the data collected by the Central Statistical Office does not recognise the fact that the forests also have a recreational function. For example, many inhabitants of the Gdańsk agglomeration use the forests that belong to the TriCity Landscape Park, which are situated within the administrative limits of Gdańsk, Gdynia and Sopot.

The land use structure in the Pomorskie region points to a very high level of regional green attractiveness (Figure 23). The share of forest area in the land use structure of the region (37\%) is higher than the Polish average (30\%) and the European average (34\%).

\footnotetext{
${ }^{1}$ Land which lost partial or total utility value due to decreasing natural conditions or industry activities and due to improper agricultural cultivation.

${ }^{2}$ Parks, greeneries, municipal woods
} 


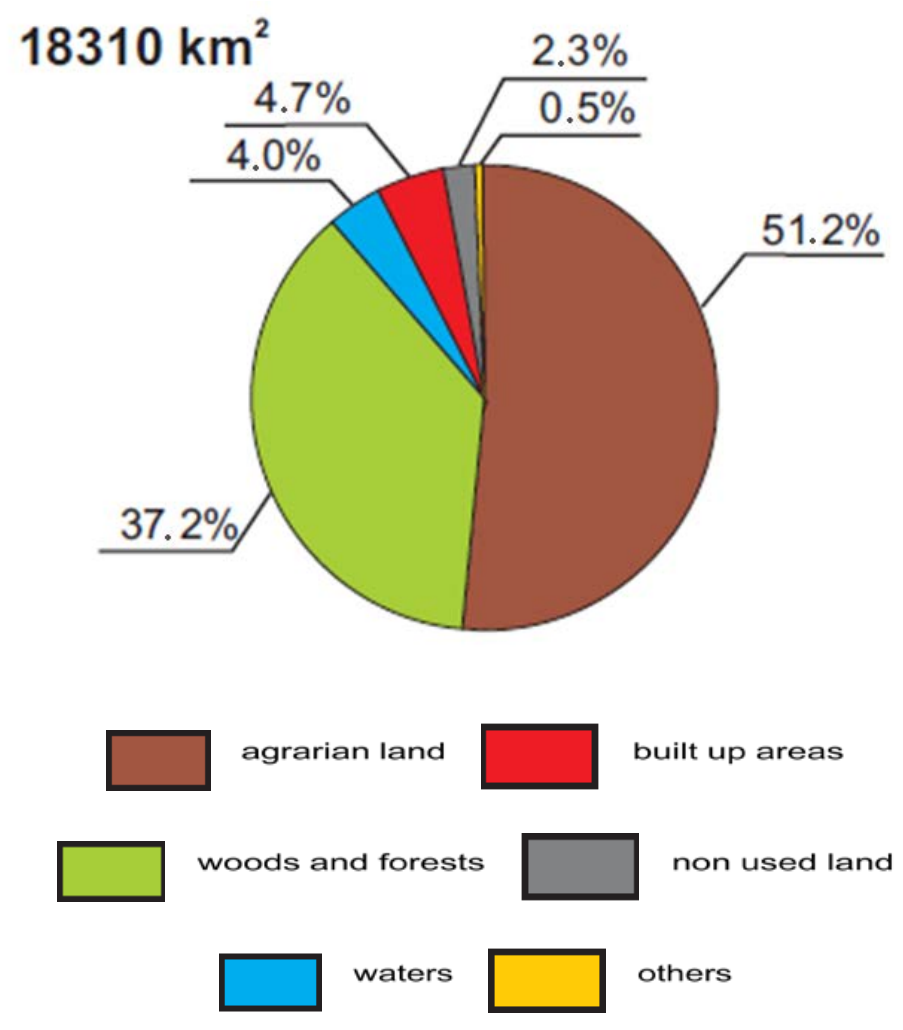

Figure 23 Land use in the Pomorskie voivodeship

Source: Marshall's Office of the Pomorskie Voivodeship, 2011

Public access to green amenities is high within the whole territory of the region (Figure 24). A very high accessibility to green spaces in the main metropolitan cities of the region is especially worth noting. This is the result of the afore-mentioned TriCity Landscape Park, protecting the forested moraine hills, which are situated within the administrative limits of Gdańsk, Gdynia and Sopot. 


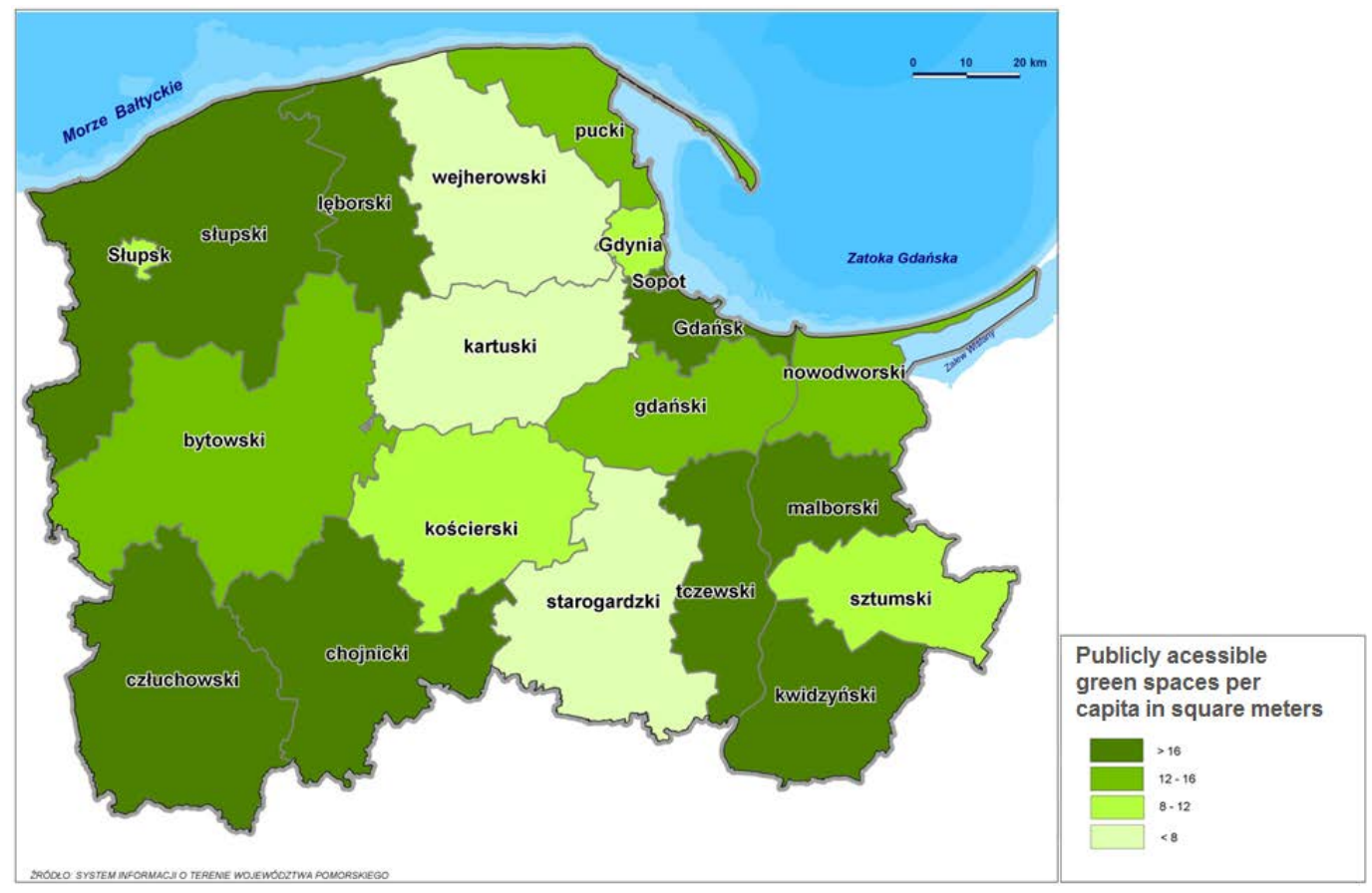

Figure 24 Publicly accessible green spaces indicator in LAU 1 of the Pomorskie region, 2010

Source: Marshall's Office of the Pomorskie Voivodeship, 2011

Apart from the measures that allow analysis of changes in land use, it is crucial to also focus on those measures that refer directly to the impact of human activities on the environment. One of these measures is the quantity of municipal waste produced by the region's inhabitants. In Pomorskie, in the years 2000-2009, this quantity grew in absolute numbers, but did not change per capita - throughout this period it remained at the level of $355 \mathrm{~kg} /$ person per year (in Poland it dropped from 320 to $316 \mathrm{~kg} / \mathrm{person}$ ). The quantity of recycled industrial waste grew noticeably from $0.38 \mathrm{~kg} /$ person in 2000 to $51 \mathrm{~kg} / \mathrm{person}$ in 2009 ( 0.34 to $37 \mathrm{~kg} /$ person in Poland). The quantity of waste designated as compost grew from 0.24 $\mathrm{kg} /$ person in 2004 to $13 \mathrm{~kg} /$ person in 2009 (3 to $18 \mathrm{~kg} /$ person in Poland). In general, in Pomorskie in 2005, $75 \%$ of waste was collected from the inhabitants; in 2009, the regional coverage rate of municipal waste collection grew to $86 \%$ (Eurostat, 2012).

Together with the development of industry comes the rise in the level of pollutant gas emissions from environmentally disruptive plants in the Pomorskie voivodeship. In the 1998-2010 period, the level of gas pollutants ${ }^{3}$ increased by $31 \%$ (as opposed to a $1 \%$ drop across Poland in the same period). This was mainly caused by the expansion of the Lotos oil refinery. In proportion to area, the emission of pollutant gases, in the discussed period, rose from 27 to $36 \mathrm{~kg} / \mathrm{sq}$. km per year. The growth of motorisation also leads to higher emissions. Between 1999 and 2009, the level of motorisation, measured in number of cars per 1000 inhabitants, grew from 244 to 435 . A similar increase occurred throughout the whole country. At the same time, the particulate pollution in Pomorskie, as in the rest of the country, decreased (from 0.07 in 1996 to $0.02 \mathrm{~kg} / \mathrm{sq}$. km in 2010) (Local Data Bank, CSO, 2012).

More inhabitants of Pomorskie have access to the sewerage system and this sewage is directed to treatment plants. In the 2002-2010 period, the share of the population using the sewage treatment plants was higher than the Polish average, and grew from $75 \%$ up to $80.5 \%$ (compared to an increase from $57 \%$

\footnotetext{
${ }^{3} \mathrm{SO} 2, \mathrm{NOx}, \mathrm{CO}, \mathrm{CO} 2, \mathrm{CnHm}$
} 
to $65 \%$ in Poland as a whole). There was also a significant increase in communal and industrial sewage treatment - from $93 \%$ to $99.5 \%{ }^{4}$ (91\% to $92 \%$ in Poland) (Local Data Bank, CSO, 2012).

The Pomorskie region is ranked as the region with the best living conditions in Poland (Kalinowski, 2006). The green attractiveness of the region plays a key role in its success within the rankings of the regions (Map of residential attractiveness, 2011). As a consequence, it positively influences the residential attractiveness of the region. In the context of the ageing population, the residential attractiveness creates favourable conditions for the future development possibilities of the region.

Positioning the Pomorskie region within the Baltic Sea Region's development strategies opens up new perspectives for economic growth. The development of competitive services in the Pomorskie region may extend its recreational, sliver and white economy activities to the whole Baltic Sea Region. However, this demands the active presence of the Pomorskie authority in common with the Baltic Sea Region's organisations, institutions and initiatives.

\footnotetext{
${ }^{4}$ Industrial and municipal sewage treated as a percentage of overall sewage that requires treatment
} 


\section{CHAPTER 7: \\ REGIONAL/LOCAL INITIATIVES AND POLICY ISSUES}

\subsection{Local initiatives}

The local and regional authorities, aware of the trends in demographic change, are attempting to adjust the local economy and the living conditions to meet the new types of needs and demands that stem from population ageing. In the Social Policy Strategy of the Pomorskie Voivodeship to 2013, developed in 2006, regional authorities considered the ageing population as a growing problem. The process of demographic ageing of the population was first defined as being the primary issue in the region's social diagnosis. Although the region's demographic structure is still relatively young, policy aimed at facing the fast-growing number of older persons are already under way.

Some of the projects initiated by the region's authorities, mentioned in the discussion above, such as "I work - I develop competence. An innovative model of support for workers 50+" or the "Make Use of Us! $45+$ Employees in Your Enterprise" project serve the purpose of diagnosing the situation in the region and developing practices of problem solving. The region is still in the initial phase of adjusting to the new demographic situation. It is to be noted that these actions are being taken at the right time and are of a preemptive nature.

Among others, the local authorities' initiatives are projects aimed at stimulating and prolonging the elder population's activity in the labour market, which is playing an increasingly prominent role. This tendency corresponds with the general policies of the state, best illustrated by decisions to equalise the retirement age of men and women, and to raise it to 67 years.

Another field of actions for local and regional authorities is building and adjusting educational offers to the life-long learning (LLL) model and encouraging older people to participate in overall education as well as in those areas intended to develop skills and competencies. The popularity of third age universities, which are an integral part of LLL, and which are actively supported by local and regional authorities, serves as an example of successful promotion of attitudes and lifestyle.

The third substantial field of actions is adjusting the health and social care systems to meet the changing and growing demands on their services. New forms of financial and non-financial assistance are being developed. The number of daytime nursing homes is growing. In response to the market's increasing demand, caused by the growing number of older persons, there are more places available in non-public daytime or round-the-clock nursing homes.

Family policy is the first priority in the strategy to adjust the region to better handle the new challenges brought about by demographic changes. Family lifestyle, and the character of the household constitute a basis for demographic changes. Elderly people's roles as providers and recipients of care in the family should be considered one of the key elements of family policy. Therefore, actions aimed at supporting families in carrying out this role are a vital aspect of local government policy initiatives. The change in the name of one of the institutions from the Municipal Social Assistance Centre in Gdańsk to the 
Municipal Family Assistance Centre illustrates one of the actions whose objective is to establish an integral approach to family policy and social assistance policy.

Population ageing not only delivers threats, but also creates opportunities for the region's economy. The growing number of older persons increases the demand in the white economy sector. There is the potential for white economy services development in the region. The Gdańsk medical and biotechnology research centres are among the highest ranking in the country. However, active support from regional policy is needed to build the knowledge economy based on the results of their work. A positive example in this area is The Baltic Centre for Biotechnology and Innovative Diagnostics BioBaltica. The initiative is a joint venture of three of the biggest universities of Gdańsk and regional and city authorities (Box 4).

\section{Box 4 Baltic Centre for Biotechnology and Innovative Diagnostics BioBaltica}

The Centre's mission is to create proper working conditions for scientists, universities and companies who will conduct research and implementation work in biotechnology and in the field of innovative diagnostics on a global level.

Its activity is focused on:

- executing individual research-implementation programmes;

- providing access to test and scientific instrumentation for companies and institutions from the biotechnology sector, as well as functioning as a business incubator;

- conducting research for external partners;

- selling services in biotechnology and in the innovative diagnostics field.

The strategy is concentrated on co-operation with industry in the sphere of development and implementation of new products and methods leading to an increase in the modernity of companies. Moreover, it is planned to assist and support academic initiatives.

The Centre's strategic goal is forming a strong and dynamic research-implementation centre in the field of biotechnology and innovative diagnostics, providing excellent laboratory facilities focusing on co-operation with industrial partners, as well as scientific centres located not only in Poland but also those in the Baltic Sea Region.

The Centre wants to achieve goals by:

- a more open approach of the scientific environment to co-operation with industry and directing research towards industrial needs;

- creating proper conditions for bio-economy development through commercialisation of RTD work results;

- building leading positions in the Baltic Sea Region - a centre of intensive research and the implementation of new techniques and diagnostic applications;

- co-operation with institutes and research centres of the international research group, ScanBalt.

Source: Bałtyckie Centrum Biotechnologii i Diagnostyki Innowacyjnej BioBaltica, 2012-06-15, http://biobaltica.pl

Deep territorial diversification is one of the most challenging problems for regional and local policy development in the Pomorskie voivodeship. The region has both one of the most developed municipalities in the country, as well as some that belong to the most lagging territories in Poland. Thus, $a$ policy based on strong cohesion becomes a strategic necessity, and the regional policy addressing demographic issues must take the inner regional differences into account. 
The TriCity agglomeration is a highly developed metropolitan area. As a highly urbanised area, it is most prone to suffer strongly from population-ageing-related problems. The number of registered 50+ unemployed persons is one of the indicators of the differences in the problems' intensity between urban and rural areas. Over $60 \%$ of the unemployed people belonging to this age group live in the cities (People above 50, 2011). Because of this, urban policy plays a key role in solving demographic problems.

\subsection{Small scale policy survey}

The clear message from small-scale policy survey results also provides a quite coherent view on regional and local demographic policy. Pomorskie's overall index for the Older Workers Friendly Places to Work (OLWOF) was 2.1, which categorises the region as having a poor OLWOF index (1 being poor, through to 5 indicating excellence). The basic elements of creating a friendly working environment for older people, such as the recruiting process, work culture and opportunities offered for older workers, training and skills systems, as well as company health and benefits offered for older workers were evaluated as not being provided at a satisfactory level (OLWOF index ranked between 2.2 and 2.6). The recruitment process was the lowest rated. The overall importance of OLWOF topics was rated high, at 4.1. Most of the respondents consider these elements as being highly important for the creation of older workers friendly places to work (Figure 25). Thus, the negative interpretation of the contemporary situation reflects a significant policy gap and requires deeper investigation.

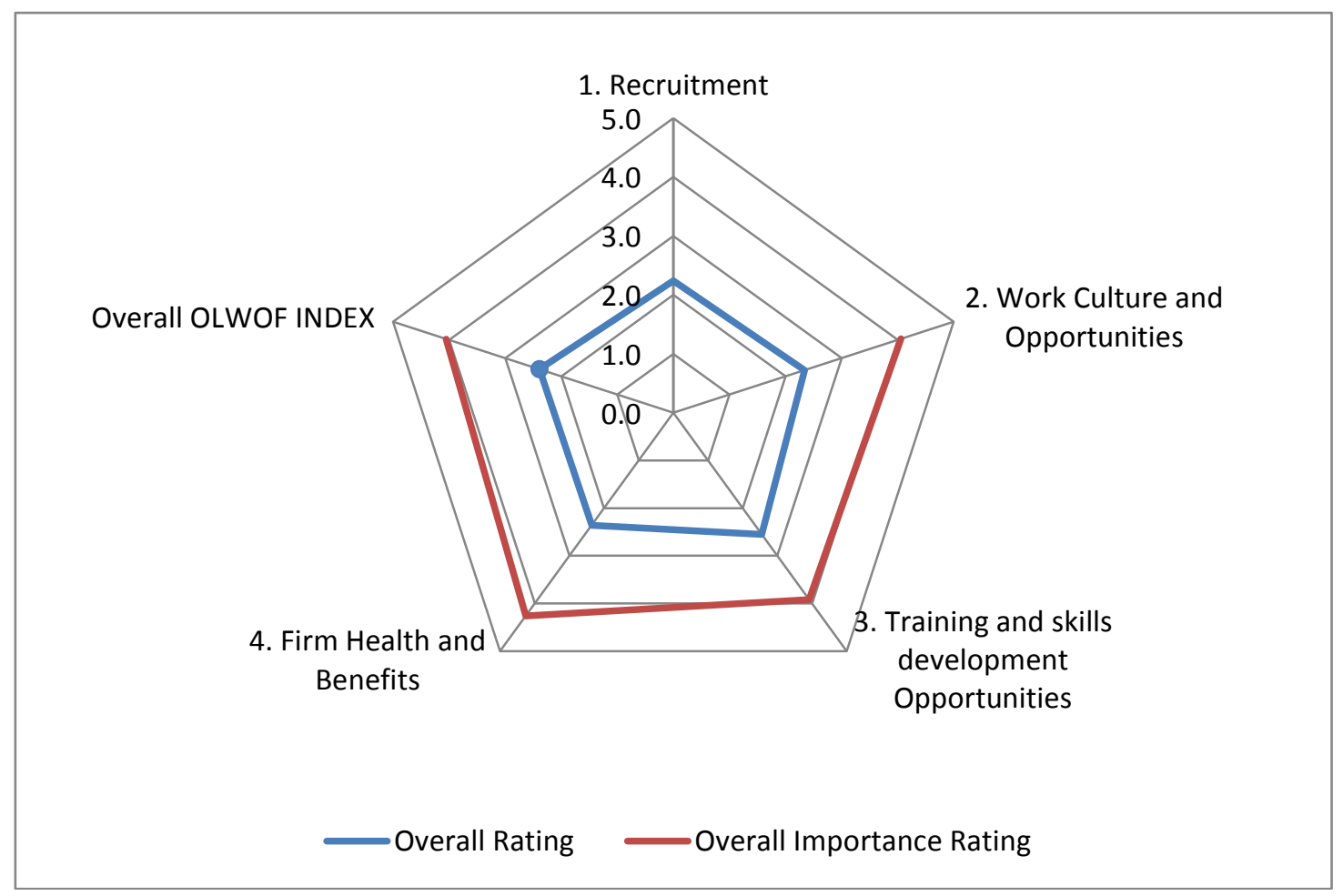

Figure 25 The evaluation and level of importance of specific areas of the OLWOF index in Pomorskie

Similar to the working milieu, the living space of elderly people was also rated low (Figure 26) in the Elderly Friendly Places to Live (ELFRI) index. The overall index is 2.4, which is just below the regional average as an elderly friendly place to live ( 1 is poor to 5 excellent). Urban space management, provision of services and the general level of inclusion of older people in the community's social life were 
all rated below the interviewees' expectations. The questionnaires' results clearly indicated the need for more intense actions and policy to meet the ageing population's expectations and requirements.

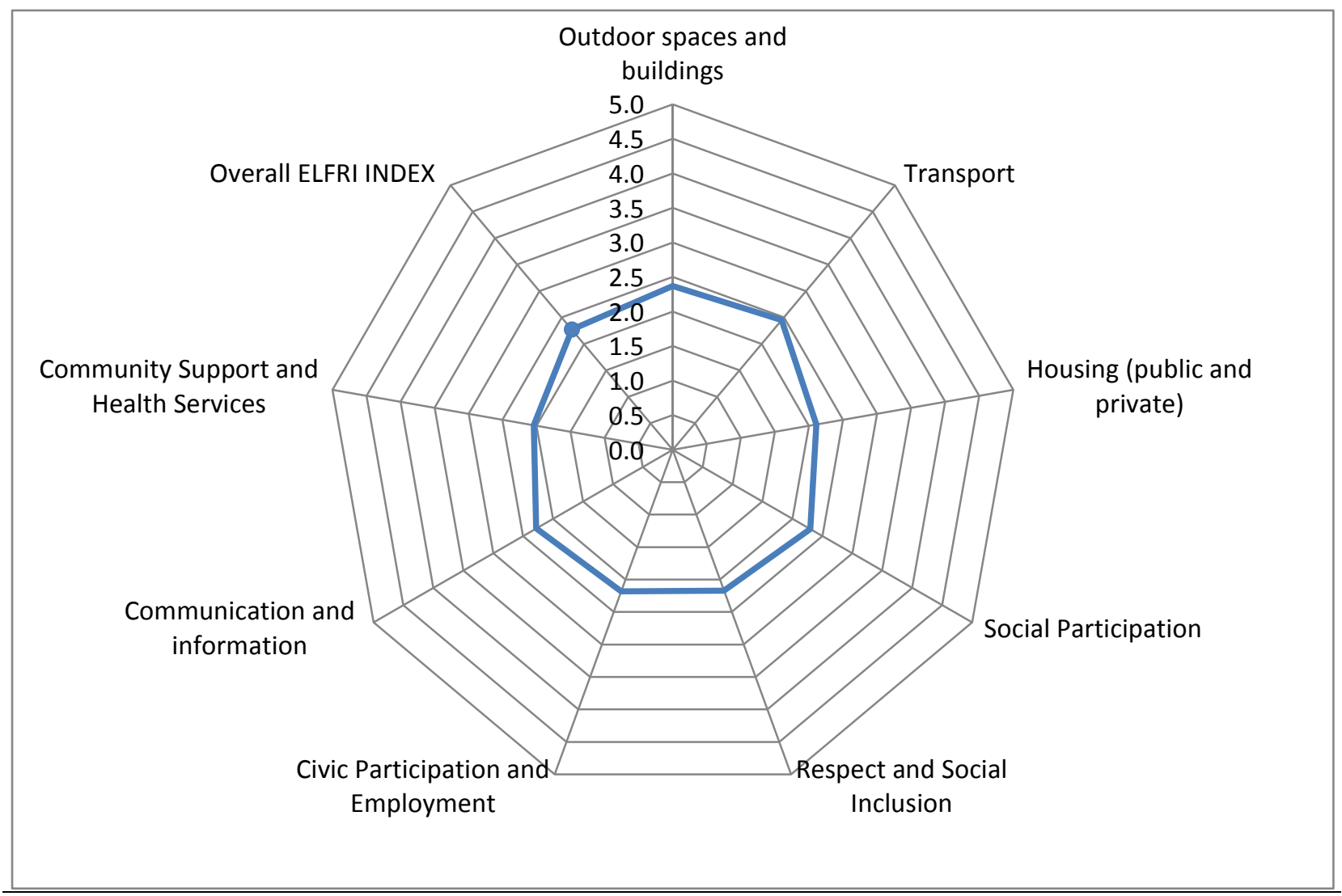

Figure 26 The evaluation of specific areas of the ELFRI index in Pomorskie

However, the results of these surveys have to be interpreted with care, as the number of participants was very low. For the ELFRI Index, there were only 22 questionnaires, while for the OLWOF Indexes, 20 questionnaires were completed. The sample was thus not a representative one. The participants of the workshop represented the group of active persons, involved in different public and non-government organisations. Although it was selected in a positive way, it was still a selective group. The significance of the results of this small-scale survey are that the respondents are active stakeholders and policy makers in the region and therefore are well aware of the regional services and the employment policy of companies in the region. Thus, the results reflect the opinion of a limited number of people, although they do represent the well informed and critical groups of respondents. 


\section{CHAPTER 8: KEY CONCLUSIONS AND RECOMMENDATIONS FOR POMORSKIE}

The demographic situation of the Pomorskie voivodeship places it among one of the few regions enjoying population growth in Poland. This is due to a positive value of both the basic components of real population increase being found in the region: natural increase; and net migration. Compared to the rest of the country, Pomorskie has a relatively young age structure and a low dependency ratio. Thus, the process of population ageing is still in the initial phase. However, this does not automatically mean that the growing percentage share of elderly people in the social structure of the region is not a problem. The current sound social structure is heading quite rapidly towards a less prosperous one, a trend that is aided by the rapidly decreasing number of people of pre-working age. An age pyramid (Figure 6) illustrates that the oldest age group (65+) within the region's population is rising abruptly. This age group requires large investments both in different types of infrastructure, and for those who require assistance and proper services. Preparing an adequate environment for the growing number of older inhabitants is one of the most difficult challenges for regional and local policy.

The Pomorskie voivodeship belongs to economically well-developed regions of Poland. The TriCity metropolitan area forms a very solid growth centre for the region. The post-industrial economic structure supplies a solid foundation for future dynamic development. To protect the positive economic trends, a policy challenging the negative demographic changes in the labour market is necessary. The domination of the services sector in the region's economic structure is most favourable in the face of population ageing. The services industry provides jobs that allow people to continue working to a very old age. The services' sector is also very attractive for women. Therefore, since women dominate in the elder age groups, having a vast number of workplaces in the region's services sector creates favourable conditions in which to carry out workforce-ageing-related policies effectively in the region. The employment rate among the 50+ population in Pomorskie is already one of the highest in Poland. In 2009 it was $31.7 \%$, which was higher than the national average of $29.9 \%$ (People above 50, 2011).

The development of the silver economy is one of the essential problems to be addressed within the region. However, it requires adjustment to legislation, flexibility among the institutions in which they are embedded, and a cultural change in social attitudes. This is a long-term process, which needs to start immediately. The skills and training ecosystem will play a critical role in these changes. Although some of the initiatives in the Pomorskie region such as the University of the Third Age, have been successful, these are single actions and not a systemic solution. The policy of instilling lifelong learning (LLL) attitudes among the inhabitants, which is one of the pre-requisites for a successful socio-economic transformation in the face of new challenges brought about by population ageing, will have to be initiated at a pre-school and primary school level. These first levels of education are crucial to the process of forming LLL-oriented attitudes, in preparation to undertake self-education and to meet the needs of the fast and constantly changing labour market, where workers are required to be flexible and adaptive. Thus, across the entire education system, and especially at the higher levels, the formation of generic skills is and will be of even more importance than ever before. Generic skills, much more so than the traditional vocational skills, form the basis for instilling entrepreneurial and innovative attitudes. 
Forming LLL-open and oriented attitudes is a far more complicated task than embedding them in institutions within which they can function. Even today, recruiting interested persons and candidates for various courses and training is more difficult than obtaining funds to carry out the courses themselves.

Accessibility to social services is one of inclusive social policy's challenges. Access to healthcare services is one of the most important factors influencing the quality of older people's lives. The ongoing systemic reform of healthcare in Poland, together with the shrinking number of medical staff and facilities, make improving healthcare services a challenge for regional policy. Considering the forecast dynamic growth of the oldest age groups, further development of social assistance and healthcare systems will be one of the most difficult tasks. The limited influence that regional policy has over the centrally-funded healthcare system is an additional obstacle. Therefore, the possibilities of implementing individual, regional solutions are minimal. However, support for social assistance is funded by the local authorities, so the amount of support is determined by the size of the local budget, which is established by the local and regional authorities, who have limited financial independence.

The Pomorskie region is located in an ideal environment in which to offer the innovative solutions that are necessary in green economy development. The environmental conditions, together with life science services development, create unique opportunities for the region's silver and green economy development. However, this requires long-term policy and investment. Thanks to environmental conditions, the region boasts a very high level of residential attractiveness and quality of life. These attributes also make it a desirable place to live for the elderly. The region's environmental advantages, seaside location, and land use structure with a high share of green amenities and forests, as well as human capital, including biotechnological potential, make it a very attractive area for health services, sanatoria, and recreation area for local and foreign clients. Ageing societies from neighbouring countries, such as Germany and Scandinavia, generate a high demand for services such as these, which are dedicated to older people. Thus, demographic changes can open up new possibilities for economic development in the region. It needs to be stressed that the regional authorities' development policies are strongly oriented towards preserving their environmental assets. Therefore, the development of the green economy is a natural consequence of the region's environmental assets possession.

Solving the problems that originate from demographic changes caused by population ageing should be a part of family policy. Actions are already visible, but still not as frequent as they ought to be, thus it would seem that more unconventional solutions to assist families in their caring and support role should be explored. Strong family norms and relationships, which are still present in Polish family culture, constitute a great potential for policy design focus. Ensuring the continuation of these cultural family traditions by assisting with the caring functions of the family unit should take place both at the economic level as well as at the organisational level. There is still much to be done in this field, however. It is necessary to change the working culture, organisation of social and institutional life, and the legislative systems, in order to allow the development of support for families in their functions.

Together with the socio-economic developments, there has been a tendency to change families' care systems. Family obligations are shifting from hands-on care to managing care arrangements. Again, this change opens up new possibilities for the development of a market for services that assist the family in its functions. Such a system is economically much more effective and socially beneficial than the taking over of these caring functions by public institutions and is therefore the direction the policy development should take.

It is of the utmost importance to take into account the deep socio-economic diversity of the region in any regional policy creation. Demographic problems have distinct natures and different levels of intensity in the strongly urbanised metropolitan area compared to the typically rural peripheral municipalities. Therefore, there is a need to develop and carry out almost two different strategies for 
policies with which to tackle the demographic issues. Due to the intensity of processes of demographic change in the metropolitan environment, the urban-focused policy should be in the vanguard of solving problems related to population ageing.

Regardless of the nature and scope of actions undertaken to counteract the undesired effects of demographic changes, the respective policy should be represented by long-term efforts, since demographic transitions themselves are long-term processes.

Analysis of the demographic changes affecting the Pomorskie region and the recommendations for policy development and strategic responses to these changes are outlined below.

- System-wide strategy: a regional strategy for demographic future challenges is needed. The demographic transition is a change in the basic elements of the whole socio-economic system and therefore needs a systemic approach in order to solve the problem comprehensively.

- Identification of the appropriate governance arena: to solve the demographic problems, the spheres of required interventions of governance, whether at the local, regional or national level should be identified. Some fields and scopes of competence among the hierarchical levels of the public authorities are overlapping, but there are also some gaps between them. For instance, regional and local potential to improve and develop the health system is very limited, as this falls under the umbrella of state regulations and funds. However, infrastructure development is undertaken by all levels of governance. The analysis of demographic change problems therefore need a full stock take, including identification of the "owner" of the problem and the application of appropriate measures by which to solve these problems.

- Local policies for local issues: in regard to demographic issues, the policy of devolution needs to be implemented more broadly. The territorially differentiated phenomenon requires the proper local or regional investigation and tailor-made policy. There are still too many issues in which regions and localities are powerless and the decision making remains centralised. The debate on this issue between the different levels of governance needs to be opened up.

- Co-operative initiatives: the partnership approach is necessary in order to meet the demographic challenges. This approach means forming a broad coalition of stakeholders. Involvement of any existing regional entrepreneurial sectors and social organisations could be essential. The bottom-up, community led initiatives stem from the local environment. They result from a unique combination of social, economic and morphological features of the local and regional environment. New instruments of public assistance for entrepreneurs or social organisations, as well as for individual families could trigger the grass-roots potential at the local level. Additionally, bottom-up initiatives are usually the most effective ones.

- Wider implications and considerations: regional policy aimed at demographic change should not be developed in geographical isolation or limited to the voivodeship boundaries. The interpretation of problems from the national as well as the international perspective is necessary. In today's world, the demographic condition of a region depends strongly on migration movements. For this reason, analysis and predictions of people's mobility, and the directions and intensities of their movements are essential. Additionally, the Pomorskie region should analyse the demographic opportunities and challenges in the context of being part of the Baltic Sea Region even more than the national opportunities and challenges. 


\section{REFERENCES}

Central Statistical Office (CSO), 2012-02-25, www.stat.gov.pl

Central Statistical Office, 2011, People over 50 years old in the labour market in 2009, Central Statistical Office, Warsaw.

Działek J., 2011, Social capital as an incentive of economic growth in regional and local scale. Wydawnictwo Uniwersytety Jagiellońskiego, Kraków.

Kalinowski T. (ed.), 2006, Development success of Polish voivodeships. The Gdańsk Institute for Market Economy, Gdańsk.

Marshall's Office of the Pomorskie Voivodeship, 2005, Development Strategy of Pomorskie Voivodeship, Marshall's Office of the Pomorskie Voivodeship, Gdańsk.

Marshall's Office of the Pomorskie Voivodeship, 2006, Social Policy Strategy of Pomorskie Voivodeship to 2013. Marshall's Office of the Pomorskie Voivodeship, Gdańsk.

Marshall's Office of the Pomorskie Voivodeship, 2009, Pomorskie Voivodeship Competitiveness, Pomorskie Regional Studies, Marshall's Office of the Pomorskie Voivodeship, Gdańsk.

Marshall's Office of the Pomorskie Voivodeship, 2010, Spatial Development Plan for Pomorskie Voivodeship, Pomorskie Regional Studies, Marshall's Office of the Pomorskie Voivodeship, Gdańsk.

Marshall's Office of the Pomorskie Voivodeship, 2011 Map of residential attractiveness of Pomorskie voivodeship, 2011, Marshall's Office of the Pomorskie Voivodeship, Gdańsk.

Marshall's Office of the Pomorskie Voivodeship, 2011 Assessment of the conditions and quality of life of Pomorskie voivodeship inhabitants and their perception of the future, Marshall's Office of the Pomorskie Voivodeship, Gdańsk.

Non Governmental Organizations, 2012-02-25, www.ngo.pl

Pracownia Badań Społecznych DGA, 2012, Project Implementation Strategy; I work - I develop competence. An innovative model of support for workers 50+. Pracownia Badań Społecznych DGA, Gdańsk

Putnam, R.D., 2000, Bowling alone: the collapse and revival of American community. Simon and Schuster, New York.

Sabatini F., 2005, Social capital as social networks. A new framework for measurement. Economics Working Paper Archive, Washington University of St. Louis, St. Louis.

Sagan I., Czepczyński M., Szmytkowska M., Masik G., Rzyski S., 2006, Balancing suburbanisation processes in TriCity metropolitan area. [in:] Pankau F. (ed.), TriCity metropolitan area studies. Pomeranian Region Studies, Marshall's Office of the Pomorskie Voivodeship, Gdańsk.

Szmytkowska M., Masik G., Czepczyński M., 2010, Trends in development and the quality of human capital evaluation in the Pomorskie voivodeship, Marshall's Office of the Pomorskie Voivodeship, Gdańsk. 
$54 \mid$ 8. KEY CONCLUSIONS AND RECOMMENDATIONS FOR POMORSKIE 


\section{ANNEX}

Annex 1 Inter-LAU 1 migrations of the Pomorskie region in 2002

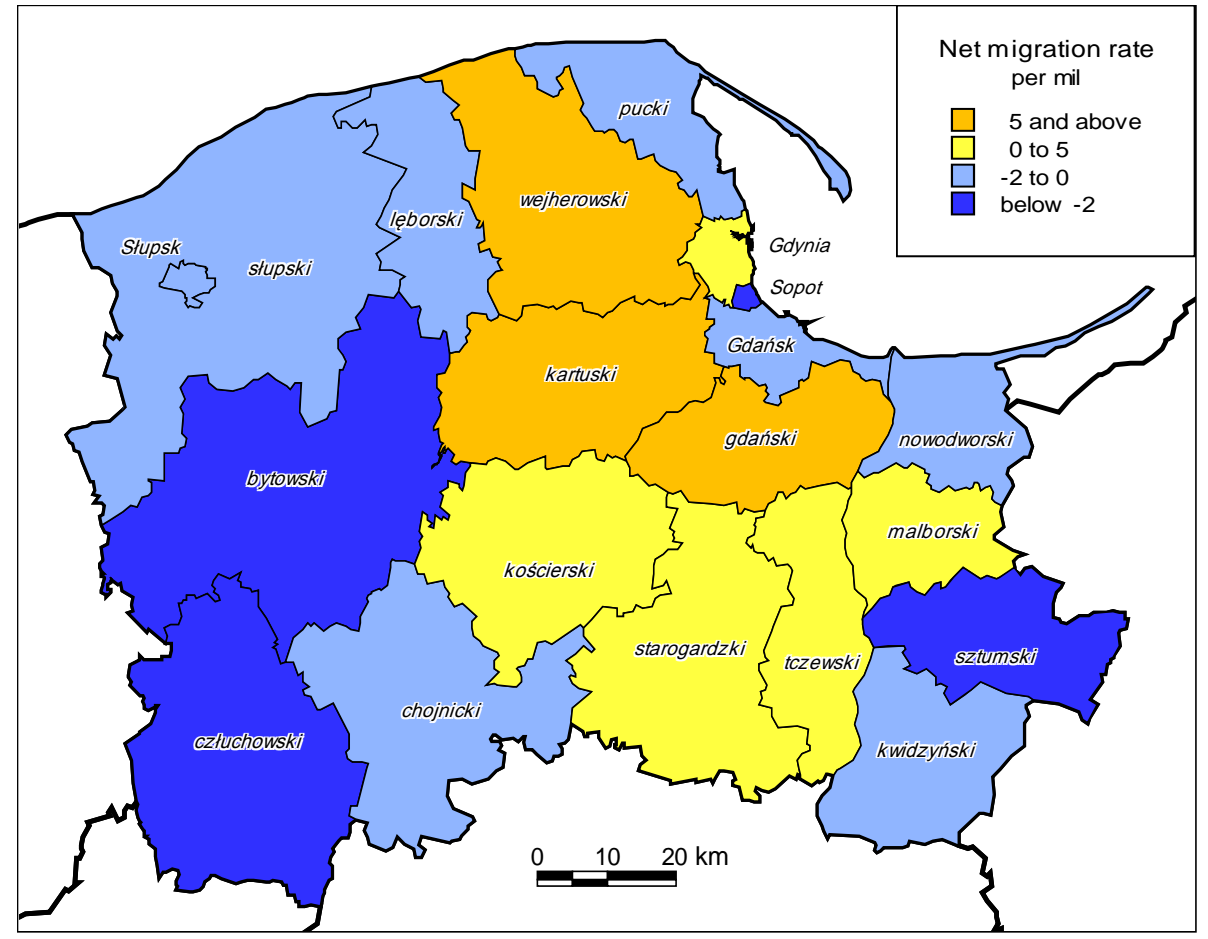

Source: map produced from Local Data Bank, CSO, 2012

Annex 2 Inter-LAU 1 migrations of the Pomorskie region in 2010 


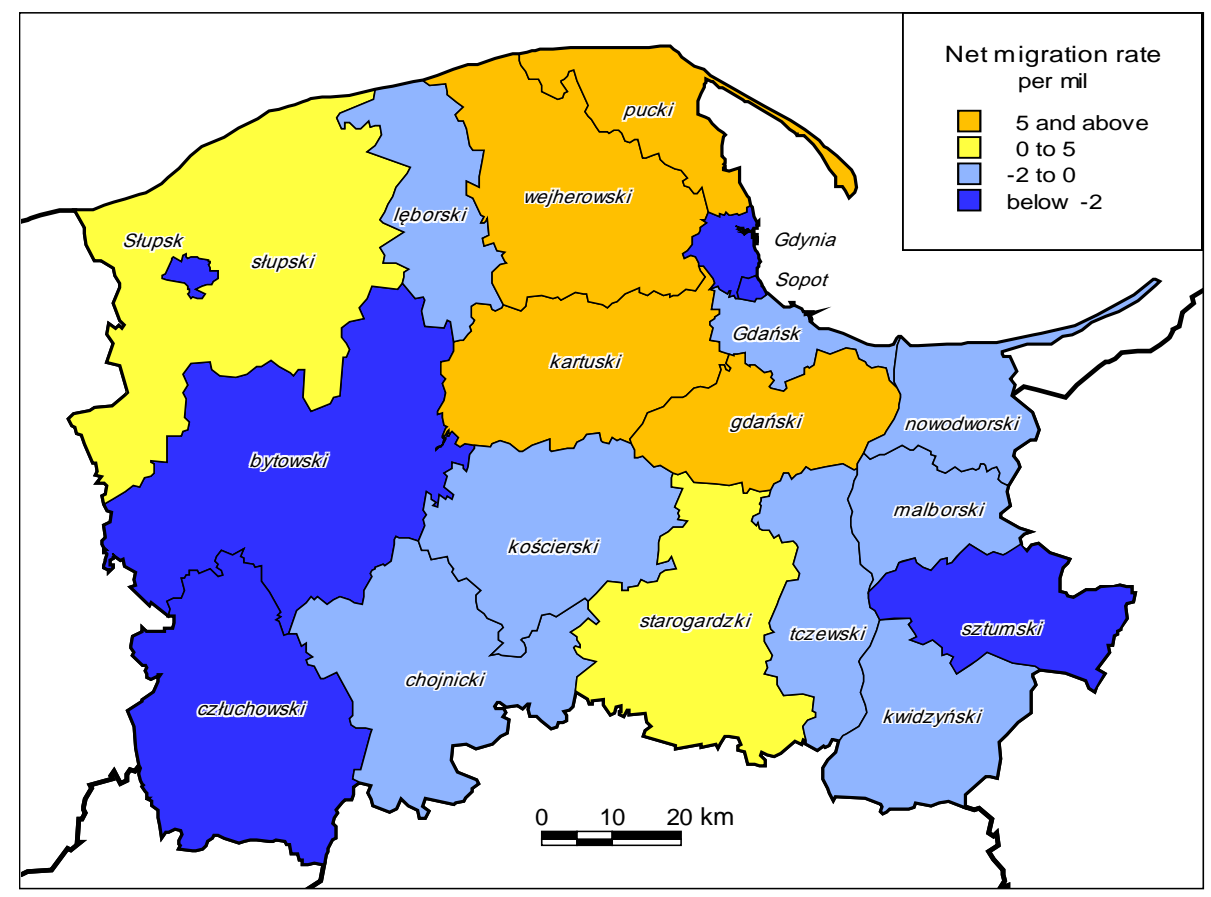

Source: map produced from Local Data Bank, CSO, 2012

Annex 3 Population density in LAU 1 of Pomorskie Region in 2010

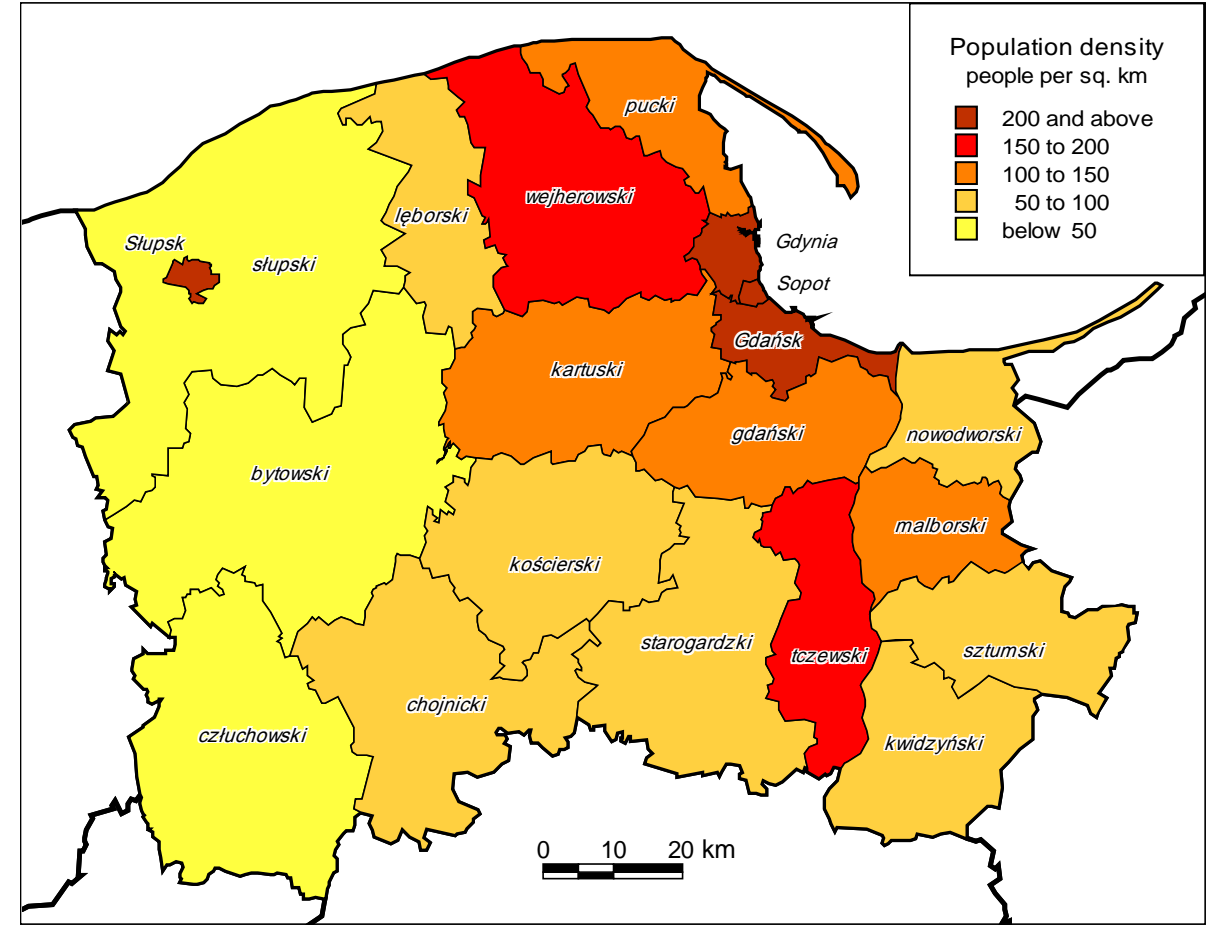

Source: map produced from Local Data Bank, CSO, 2012

Annex 4 Employment of women in LAU 1 of the Pomorskie region in 2010 


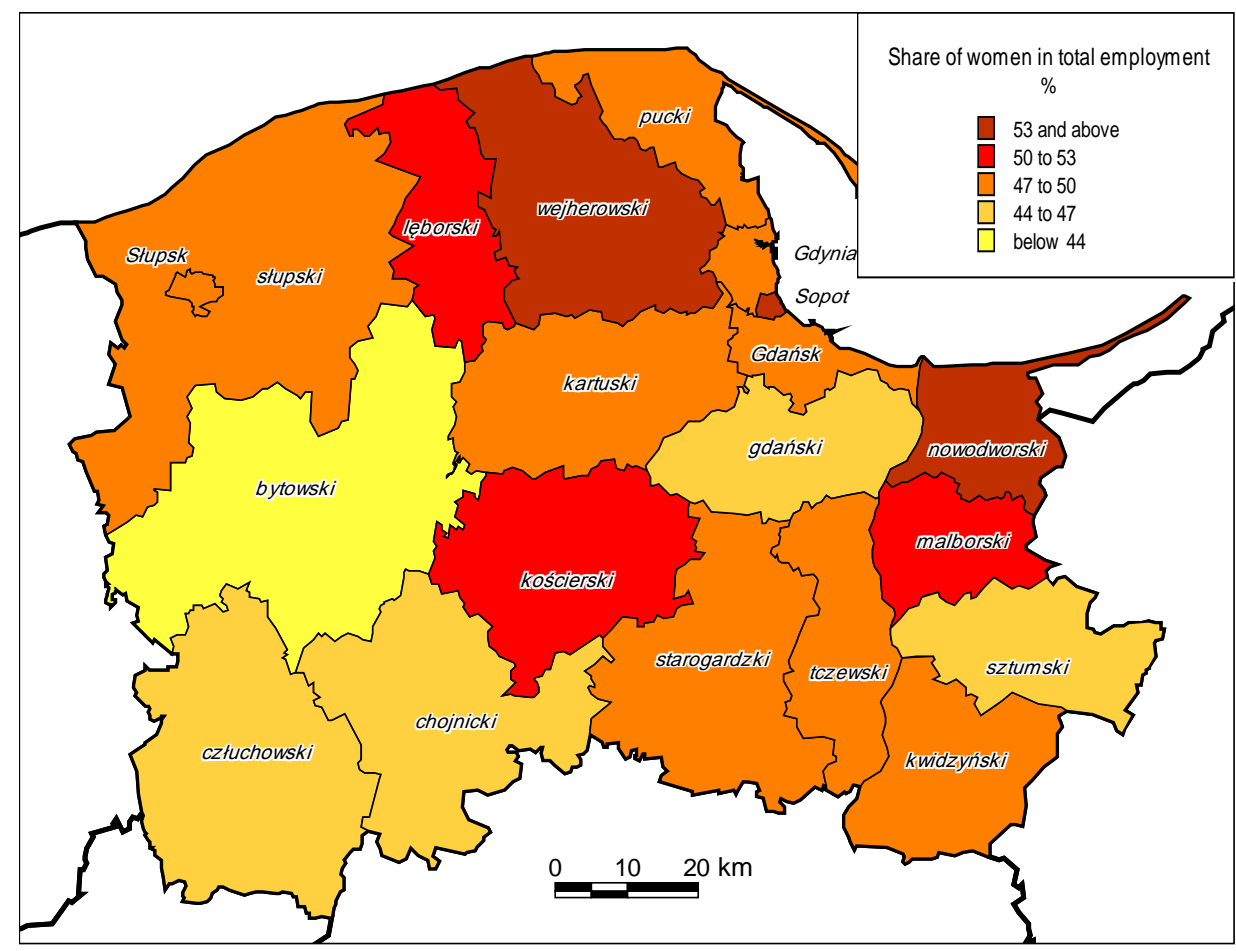

Source: map produced from Local Data Bank, CSO, 2012

Annex 5 Changes of female employment in LAU 1 of Pomorskie region in the years 2002-2010

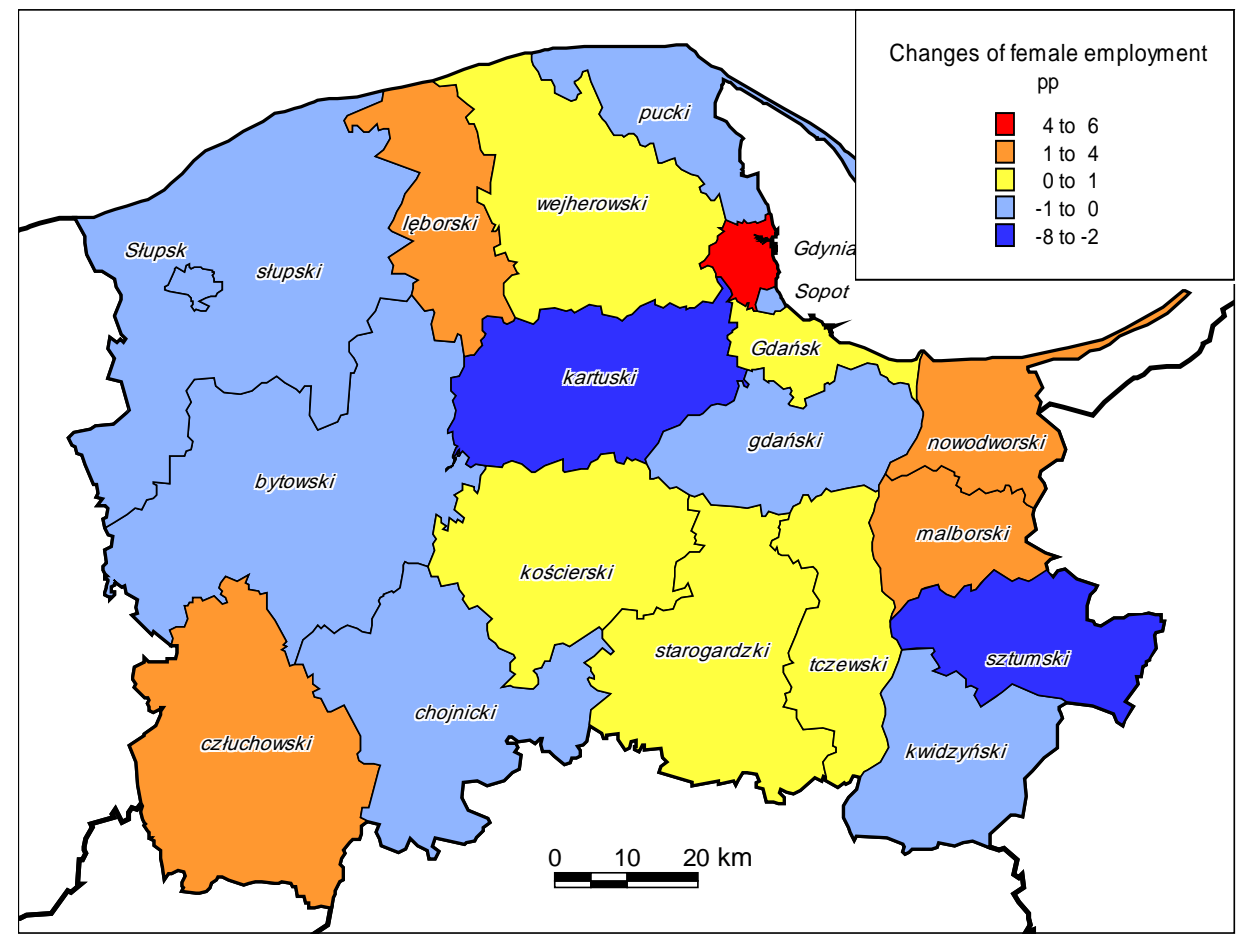

Pomorskie Region: Responding to Demographic Transitions Towards 2035 C OECD 2013 
Source: map produced from Local Data Bank, CSO, 2012

\section{Annex 6 Unemployment of women in LAU 1 of the Pomorskie region in 2010}

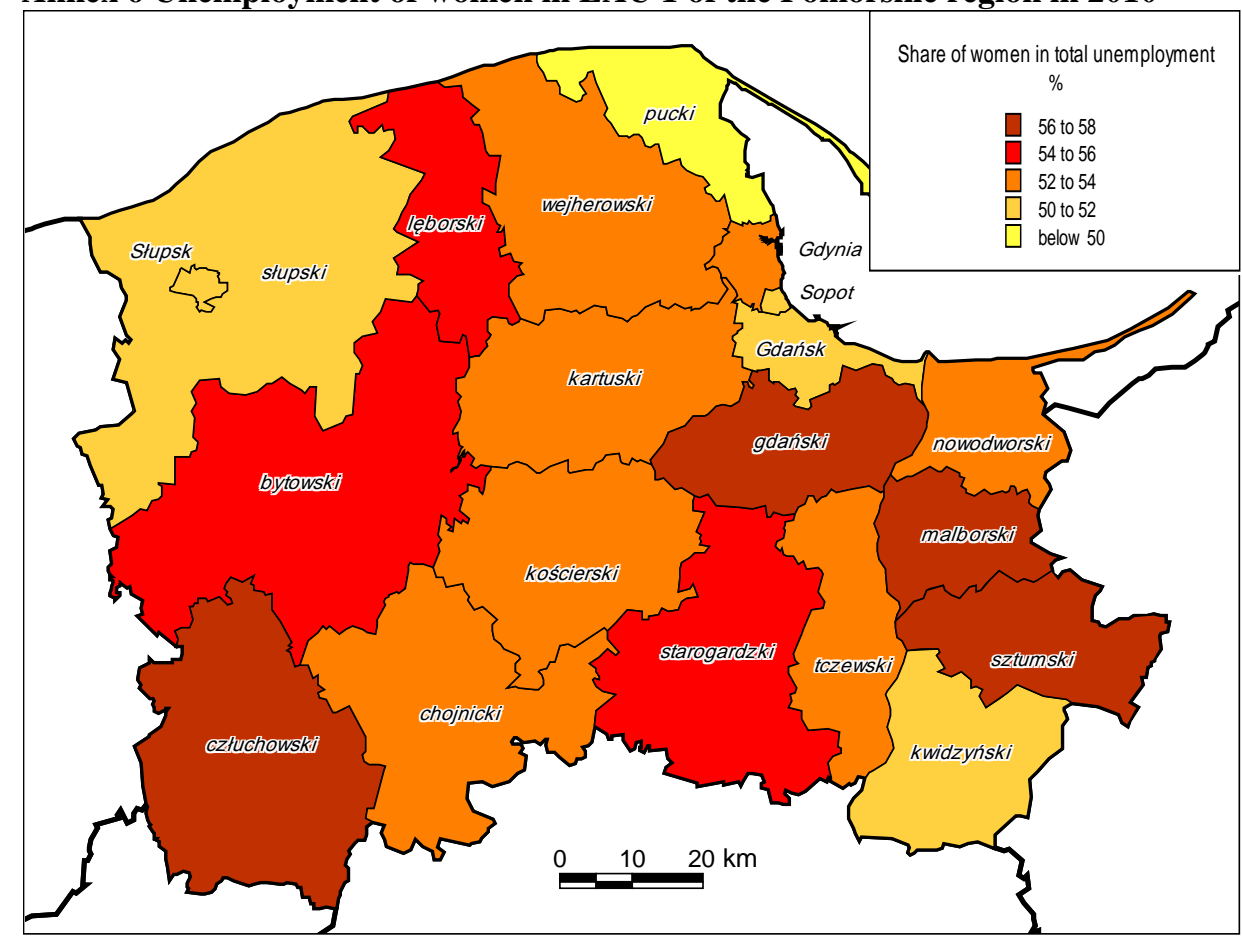

Source: map produced from Local Data Bank, CSO, 2012

Annex 7 Changes in female unemployment in LAU 1 of the Pomorskie region in the years 2003-2010

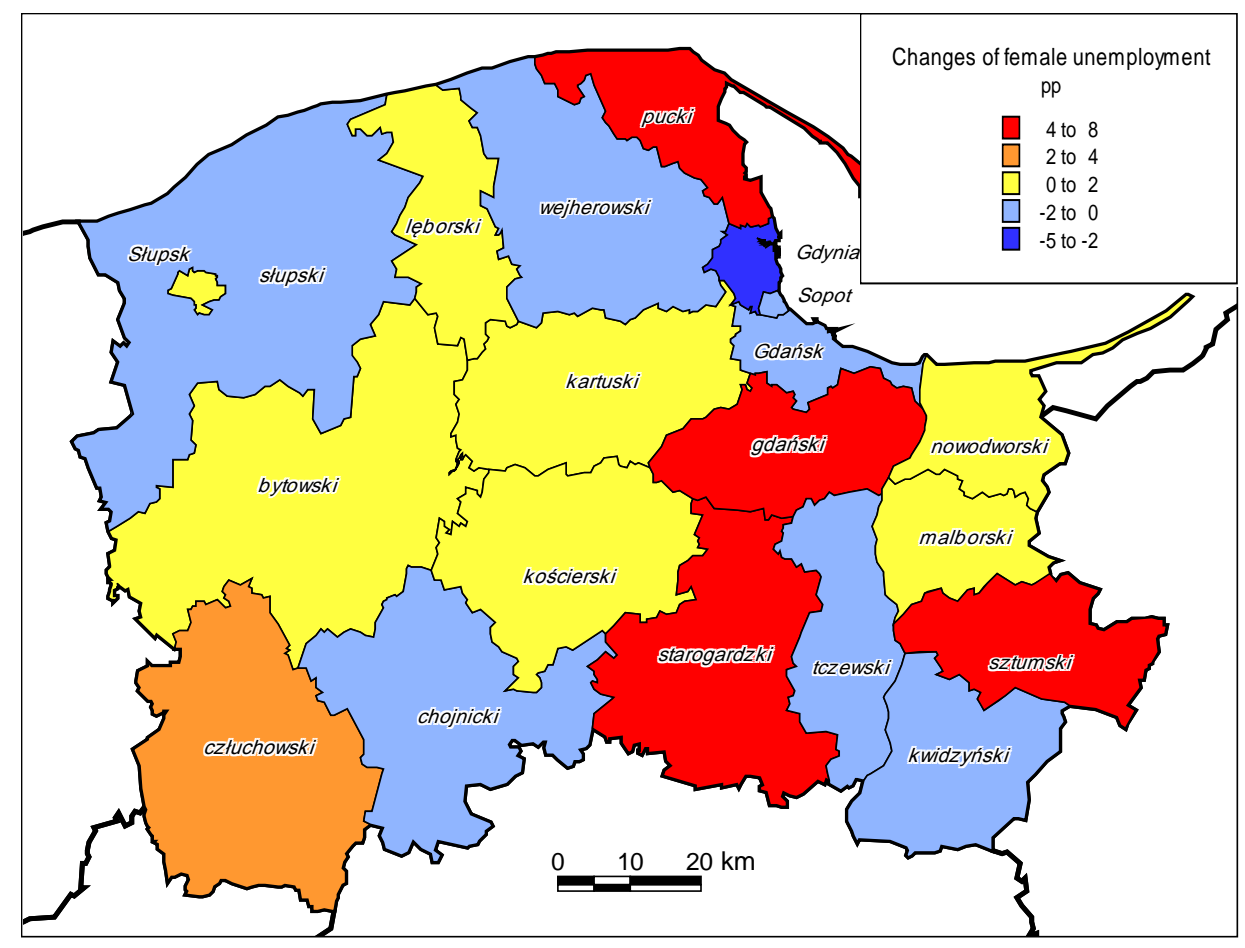

Pomorskie Region: Responding to Demographic Transitions Towards 2035 @ OECD 2013 
Source: map produced from Local Data Bank, CSO, 2012

\section{Annex 8 Pomorskie workshop discussion}

Pre-workshop discussion and study visits

The workshop was co-organised by the OECD LEED Programme, Poland Ministry of Regional Development and Marshall's Office of the Pomorskie voivodeship as a part of the activities of the 'Local scenarios of Demographic Change' project in March 2012.

The meeting was divided into two parts. The first part was dedicated to the introduction of OECD experts in the development problems of Pomorskie region. A background note was presented by the local expert. The following issues were widely analysed:

- socio-economic characteristics of the region;

- demographic trends;

- older workers and silver economy development;

- skills and training ecosystem in a region;

- social problems and changes in the white economy;

- green regional attractiveness of a region;

- regional/local policies and initiatives.

The field trip, which illustrated some of the discussed problems, followed the background presentation. The OECD experts visited selected inner-city districts, where the processes of demographic change influenced the urban phenomena such as social degradation, regeneration or gentrification of particular areas. The field trip included a visit to Partner in Business Strategies (PBS) research agency. PBS specialises in quantitative and qualitative research and offers services for both private and public entities. The agency carried out the project ' $I$ work - I develop competence. An innovative model of support for workers 50+'. The project was prepared at the request of the Marshall's Office of the Pomorskie voivodeship and was funded from regional European Social Fund sources. The aim of the project was to diagnose the situation of older workers in the regional labour market, to experiment with some innovative skill development training organised for some of them, and to develop an innovative instrument, supportive of the labour market policy.

\section{Gdańsk Workshop}

The second part of the visit involved a working meeting of OECD experts, local experts, and participants representing different social and professional groups. It consisted of plenary and thematic groups' discussions on the impact of demographic change on the present and future regional development. The meeting was opened by the Vice-Marshal of the Pomorskie voivodeship, who emphasised the meaning of the OECD LEED Programme for regional policy, and particularly for regional development strategy preparation. Dr Cristina Martinez-Fernandez provided the introduction to the project and local expert, Prof. Iwona Sagan, who presented the background note on the demographic changes in the Pomorskie region. The four focus groups followed the opening session.

FOCUS GROUP 1: Labour markets and older workers: organisational approaches by businesses and trade unions

During an intensive discussion, numerous issues were raised regarding the situation of older workers in the labour market. It was agreed that for employees 50+ some of the contemporary labour market conditions are especially difficult to meet. Among them are:

- job insecurity, intensified today by highly flexible labour markets;

- $\quad$ work skills, and ever growing individual performance efficiency expectations;

- spatial and professional mobility required in the labour market; 
- health limitations of older age.

All these challenges put older workers at a disadvantageous position in the labour market. All the same, the requirements mentioned above make employing older people economically unattractive for employers. Another problem is that the perceptions about older workers' limitations are quite often built on stereotypes rather than on verification of actual abilities.

During the discussion, the 'flattening' of the age of older workers was often raised as a specific problem. A 50 years old worker's physical and mental abilities cannot be compared to those of a 60 or 65 years old worker. It is quite surprising that so little attention is paid to the diversity of the inner structure of the strata generally called older workers. The unequal treatment of older male and female workers was noted as well. Finding a job is much more difficult for unemployed older women than for older men.

In the centre of the debate was the issue of skills and training possibilities for older workers. The lack of information on available programmes of support was often stressed. Also, the simple methods of verifying older worker's abilities, such as carrying out test works, are hardly present in the labour market practice. It was stressed that the engagement of employers in educational training of their workers is essential.

However, some positive trends were noticed. For older workers, one of the most promising examples of such tendencies is reorganising the labour market so that it focuses on projects rather than on institutions. The new approach is based first of all on qualifications, skills and experience not on formal employment structure. It creates new opportunities for older workers and in this case, the growing flexibility of labour market works to their profit.

\section{Box Some key emerging themes from the Focus Group 1}

- Ageing is not a stand-alone issue. Ageing, economic and other trends jointly demand new ways of thinking about work, the labour market, continuous development of human capital and policies.

- Working longer does not always mean working in the same job. Radical job changes can be difficult, but there is a need to think in creative ways to discover promising career opportunities. There is also a need to make sure that actions are not undermined by negative stereotypes - people encountering many difficulties lose self confidence after a while.

- The issue of ageing and difficulties in infrastructure are very much connected. It is very hard to expect ageing people to engage in a new job that requires a significant amount of travel to and from work.

- Labour market intelligence is a crucial tool to deal with the challenges of ageing. Although forecasting precise changes in the future is naturally problematic, there are tools that give some direction which are very useful. However, intelligence is not only something at the macro level, it also encompasses skill matching tools at the individual level. Such initiatives are already present in the region, and this is encouraging.

FOCUS GROUP 2: New business developments and entrepreneurship: the silver economy plus the white economy and the green economy

A very broad scope of problems was discussed during the meeting. The issues raised may be divided into several thematic groups.

- Unfavourable characteristics of older workers expressed by employers:

o older people want to retire early;

o older workers have trouble adjusting to quickly changing job demands as well as new technological and foreign languages requirements;

o it is difficult to persuade older workers to participate in trainings and new projects; 
o older workers are strongly limited in active behaviour on the labour market due to their mental barriers;

o older workers show low professional and spatial mobility, due to their financial limitations;

o older people want to develop knowledge but for their own, mainly social purposes, not for professional reasons;

o older workers are often treated in their work places as those who are finishing their professional careers;

0 older workers quite often present a demanding attitude;

0 older workers in the age $60+$ and $70+$ are the most difficult group to activate in the labour market.

It was noted that it is necessary to clearly distinguish between $50+$ and $60+$ and $70+$ workers, as these groups represent completely different generations, with varying development abilities, physical capabilities, and needs. These differences should be taken into account in the context of services and possible activation initiatives that may involve these groups.

- Problems of the white economy:

o health care systems for older people should be better financed and developed;

0 the long-term care for older people is particularly underdeveloped in the Pomorskie region;

0 there is a lack of sufficient geriatric care and rehabilitation services;

0 there is a lack of psychological support services for elderly people;

0 foreign older tourists requiring medical care or seeking medical retreats such as spas create a high demand for white economy services in the region; this stimulates white economy development, but also raises the costs of services, making them even less available for the local community.

During the discussion, the importance of the issue of financial accessibility to medical and other services such as sanatoria, and unconventional healing for older persons was stressed. The accessibility is often impeded by older people's lower incomes and, to a large extent, by the demand sof foreign tourist, who are in a better economic situation.

- Problems of the green economy:

0 the multidisciplinary and universal character of the green economy creates new possibilities of jobs for experienced older people - development of the green economy as a chance for employment of older people;

0 the future of green economy development is linked with the activity of the SMEs in this sector and a flexible, inclusive type of employment policy.

Nevertheless, the workshop participants do not consider the "green economy" to be directly linked to elder people activation. In their opinion, the "green economy" is related to new technological solutions (solar panels, wind turbines, etc.) which require quick and flexible learning, which does not necessarily coincide with the perception of older people.

- The role of the public and social sectors:

o development of a subsidies system to activate older people in the labour market;

0 the importance of the role of the NGOs in different care systems for older people; 
o development of the social economy as a means of older persons' professional engagement.

Additionally, during the discussion, participants proposed numerous means and ideas for professional engagement of older workers, for example:

- To build professional and non-professional activity awareness through local communities, local leaders, voluntary workers, and also media and social initiatives, that showcases active elderly people.

- Psychological assistance and coaching for older persons in their workplace.

- Substantial role of elder mentors and leaders.

- Education and services' adjustment to meet older people's needs.

\section{Box Some key emerging themes from Focus Group 2}

- Older workers have training and skills development nees that are not usually addressed by current programmes as they need to be customised (success of the third age university).

- There needs to be a change in mentality to increase participation of older workers in the labour market, as the previous regime did not provide incentives for people to stay longer in jobs.

- Developing the silver economy is challenging without public funding directed towads offer services for engagment of the elderly.

- The most challenging situation is regarding the development of the white economy, as care services are close to collapsing, with not many alternatives for caring for the aged. There is no funding for basic care services such as rehabilitation or for combating long-term-diseases. In fact, a new structure of care services is needed to address the rising high demand of new care environments such as nursing home based services, which for the moment are very expensive.

- The demand for new occupations is very high for medical care, rehabilitation, mental health therapists, but the supply does not exist. Indeed, a challenge for the white services ecosystem appears when people come to the region and pay for these services as there is restriction in what can be offered and limited supply.

- The green economy has a good prospect for developing in an ageing society because it can be learned quickly and it does not require high level skills or complex certification, as many of the skills can be learned on the job. In addition, many of the jobs in, for example, renewable energy, do not require a full time work load and jobs can be performed under flexible working conditions.

- Public funding is needed to raise public awareness of the new silver era and what it means to be ageing in an active society, but programmes and advertising campaigns need to be specific not generic, in order to promote cultural change and higher acceptance of the aged. For example, the media could be used to promote fitness courses for the aged and to promote older leaders that keep active and can act as role models for others. In particular, promoting fitness needs a large scale national campaign to change from an over consumption of medicines as promoted by the pharmaceutical companies. Fitness programmes can also be promoted in the workplace and organised by firms specifically targeting senior workers.

FOCUS GROUP 3: Sustainable local development models: the urban form and social \& financial implications of an elderly society

The general conclusions helped to draw a picture of living conditions of older people in urban areas. They also pointed out some key issues of demographic change, which are important from an urban policy point of view.

The increasing number of older people in the region reveals the intensive growth of demand for two types of services:

- leisure, spa and recreational services; the demand created by older people significantly extends the tourist season in the region, otherwise limited only to two summer months;

- educational services, specially the university type courses dedicated to older people. 
Gdańsk city is concerned with a growing problem of elderly inhabitants. 'Programme for Seniors 2020' is under preparation. A Supervisor for Seniors' Problems position at the Gdańsk City Council has been created. The Municipal Centre of Family Support (MCFS) plays a very important role in urban policy regarding the issues of older people. Its activity covers, among others, such areas as:

- older peoples' housing issues (creating family retirement homes, nursing homes, health care centres, home care);

- initiatives activating older people in the social, cultural and educational sphere (creating seniors' clubs, daytime retirement homes and designating funds for removing architectural barriers);

- creation of social assistance centres to address the different types of needs of older people.

An animated discussion developed around the question of the role that urban gardening plays in improving the quality of life of older people. The long tradition of locating allotments within the city limits, still very alive in Poland, has a great potential for making urban space attractive and friendly not only for older inhabitants, but for others as well.

The issue of communication with older people was raised during the discussion. The quite common problem of their exclusion from the new means of social communication, such as the Internet, results in the absence of this group in social dialogue.

\section{Box Some key emerging themes from Focus Group 3}

- The city/regional infrastructure development and maintenance should take into account the ageing trend, for example: 1) avoid massive developments outside of the city centre as the older population will be less mobile than the younger population, and at the same time, efforts should be made to reduce environmental footprints; 2) allocate building permits carefully today to ensure accessibility and availability of public transportation systems and various services for the older population in the future.

- A number of initiatives, including cost-effective measures for dealing with the ageing society - different types of services according to different life stages (e.g. 55+/ 75+) - were mentioned and their potential seemed to be worth further investigation:

- Establishment of "senior clubs" in the neighbourhood (funded by the municipality and run by NGOs) to keep up mental and physical well-being of seniors so that people could stay longer at their home. This was presented as being a more cost-effective option (approximately one-tenth) compared to nursing homes that would offer care 24/7 but are more costly.

- Establishment of physician co-operatives that are intended to cater to low-middle income clients due to long waiting lists for receiving state health care services and private sector services that are too expensive.

- Promoting home care or group housing, as opposed to more costly nursing homes.

- In order to ensure cost reduction in the long-run, it is also important to look at reducing the environmental footprint of different sectors. For example, air pollution is said to have a greater impact on the older population. Greening of the industry is likely to create green job opportunities in the short-term and contribute to reducing medical expenditure in the long-term.

- Both the private sector and NGOs are currently bidding to provide services for public facilities (e.g. clubs for the elderly). In the future, educational institutions may also be actively included in such processes.

- Cost reduction may also be achieved through better utilisation of older people, in the form of volunteering or part-time employment. It seems that there is sufficient time for the region to develop mechanisms that could utilise human capital in Pomorskie.

- The region has good potential for further developing the tourism industry as part of the silver economy. The spa town of Sopot is already attracting some tourists. Such spa resorts may be further developed, in combination with the existing natural (e.g. forests) and historical assets in the region, by improving accessibility to the older population. Wealthy international clients (e.g. Scandinavian countries) may be targeted.

- Use of existing but underutilised urban gardens may be revisited for promoting urban agriculture, but also as a means for older people to have access to green space, as they are less mobile than younger people. 
- Limiting the public discussions and debate to new methods of communication (e.g. utilisation of IT) may exclude the older generation from decision-making processes. From a sustainable development point of view, it is important to ensure that those that are less privileged do not get excluded, therefore, other means of communication should also be utilised (e.g. town meeting/newsletters) in ensuring that community decisionmaking processes include adequate stakeholder participation.

- Collaboration amongst different stakeholders in discussing challenges associated with demographic change are so far limited, and further dialogues may be encouraged (e.g. collaboration between the social services department and urban development department).

FOCUS GROUP 4: Social transformations: dynamics of social inclusion, family development and intergenerational solutions

The discussion concentrated on the following issues:

- homelessness of people aged 50+;

- the difficulties with professional engagement of older homeless people;

- the policy of supporting and strengthening intergenerational links as a system of caring for elderly people; proposed idea of creating multigenerational neighbourhoods;

- financial barriers as one of the main problems for engaagement of older people;

- the growing number of older people whose children emigrated for work, who are left without any family support or access to other social forms of care;

- the multi-fold role of education for older people and the necessity of life-long learning educational programmes development;

- solutions that allow combining professional and family life (flexible terms of employment, lowering employers' costs in case of persons who raise children and work shorter hours, creating nurseries/kindergartens in the work place)

During the discussion, the role of local and regional pro-family policy was highlighted. The critical meaning of local authorities in the creation and maintaining of nurseries and kindergartens was emphasised. It was also stated that new and much more innovative methods of financial support for families should be implemented. The positive role of different campaigns promoting family life was discussed. One of them, 'You have a baby - you are a good worker' was cited as an example of good practice. The campaign was aimed at both young women having babies and at employers. It encouraged flexible forms of employment tailored to the individual situations of young mothers.

\section{Box Some key emerging themes from Focus Group 4}

- Reference was made during the focus group to the university of the third age, this clearly attracts elderly people, with a good level of education and social skills, and seems to be a good initiative in terms of intergenerational dialogue.

- Reference was also made to a "care giver act" to be soon approved by the Parliament but this seems to be controversial. Would be good to have some information on this.

- The focus group mentioned that youth are also at risk of social exclusion and this is even worse for young women.

- There is a need to reduce red tape and the administrative burden to allow civil society initiatives to develop, for instance social economy entities could organise kindergartens

\section{Summary of the workshop}

The closing plenary session started with the brief reports of four focus groups reporters. They presented key points from each working group discussion. Summarising notes of OECD experts, who participated in the workshop, were the main focus of the closing plenary discussion. Experts 
interpreted the issues raised during the focus groups working meetings on the basis of their international experience.

Some attempts to categorise the problems were made. One of the most inspiring approaches to systemising the challenges is based on places in which regional and local demographic policy might be implemented. They are:

- places of work;

- family;

- civil society with its social, nongovernmental organisations;

- social economy and social entrepreneurs.

The experts suggested ways of categorising the demographic policy actions in regard to these places, understood as spatially located social milieus, which seems to be a highly functional proposition for regional/local policy practice.

The necessity to treat the demographic processes in an holistic way was one of the important concluding remarks. It is not possible and it is not appropriate to separate the problems of older people from the low fertility rates, younger people's unemployment or other family issues. Thus, demographic policy must be applied to all dimensions of the process simultaneously because they are interrelated - otherwise, the policy will not be effective. It was emphasised that policy aimed at older people's problems dominated the discussion and the broadly defined family policy was not satisfactorily treated during the workshop.

The deep interlinking and connecting demographic policy problems that were put into the agenda of the workshop discussions were reflected in the very similar conclusions and recommendations worked out during separate focus groups meetings. Such issues as the lack of sensitivity to the diversity of the inner structure of the demographic group generally described as older workers, or to the potential present in families, or in self-helping groups of older people to solve many their problems were noted as recommendations for local policy development by the majority of the focus group reporters and workshop participants. 
Annex 9 Workshop participants

\begin{tabular}{|c|c|}
\hline Name & Title and Organisation \\
\hline Aldert de Vries & $\begin{array}{l}\text { Ministerstwo Spraw Wewnętrznych Holandii (Ministry of Interior and } \\
\text { Kingdom Relations of the Netherlands) }\end{array}$ \\
\hline Byczkowski Wiesław & $\begin{array}{l}\text { Wicemarszałek Województwa Pomorskiego } \\
\text { Urząd Marszałkowski Województwa Pomorskiego }\end{array}$ \\
\hline Herman Przemysław & $\begin{array}{l}\text { Naczelnik Wydziału Ewaluacji, Departament Zarządzania Europejskim } \\
\text { Funduszem Społecznym } \\
\text { Ministerstwo Rozwoju Regionalnego }\end{array}$ \\
\hline Martinez-Fernandez Cristina & $\begin{array}{l}\text { Senior Policy Analyst/Project team leader } \\
\text { CFE/ LEED }\end{array}$ \\
\hline Naoko Kubo & $\begin{array}{l}\text { Expert sustainable Development/Consultant } \\
\text { CFE / LEED }\end{array}$ \\
\hline Noya Antonella & $\begin{array}{l}\text { Senior Policy Analyst } \\
\text { CFE / LEED }\end{array}$ \\
\hline Puckowska-Pociask llona & $\begin{array}{l}\text { Kierownik Referatu Wyboru Projektów i Informacji Departament } \\
\text { Europejskiego Funduszu Społecznego } \\
\text { Urząd Marszałkowski Województwa Pomorskiego }\end{array}$ \\
\hline Sagan Iwona Dr Prof. & $\begin{array}{l}\text { Professor } \\
\text { Uniwersytet Gdański }\end{array}$ \\
\hline Siwak Kamila & $\begin{array}{l}\text { Z-ca Dyrektora Departamentu Europejskiego Funduszu Społecznego } \\
\text { Urząd Marszałkowski Województwa Pomorskiego }\end{array}$ \\
\hline Strauss Robert & Komisja Europejska (European Commission) \\
\hline Sułkowski Michał & $\begin{array}{l}\text { Wydział Ewaluacji, Departament Zarządzania Europejskim Funduszem } \\
\text { Społecznym } \\
\text { Ministerstwo Rozwoju Regionalnego }\end{array}$ \\
\hline Van Loo Jasper Dr & $\begin{array}{l}\text { Senior Expert } \\
\text { CEDEFOP }\end{array}$ \\
\hline Żmudzińska Katarzyna & $\begin{array}{l}\text { Kierownik Referatu Planowania, Analiz i Sprawozdawczości, Departament } \\
\text { Europejskiego Funduszu Społecznego } \\
\text { Urząd Marszałkowski Województwa Pomorskiego }\end{array}$ \\
\hline Hildebrandt Anna & $\begin{array}{l}\text { Instytut Badań nad Gospodarką Rynkową; Katedra Geografii Rozwoju } \\
\text { Regionalnego, Instytut Geografii UG }\end{array}$ \\
\hline Jankiewicz Małgorzata & PBS DGA Sp. z o.o. \\
\hline Krzywosiński Zbigniew & $\begin{array}{l}\text { Z-ca Dyrektora } \\
\text { Departament Zdrowia UMWP }\end{array}$ \\
\hline Mariusz Lewandowski & ADMAL \& Energia Odnawialna \\
\hline Masik Grzegorz Dr inż. & $\begin{array}{l}\text { Katedra Geografii Ekonomicznej na Wydziale Oceanografii i Geografii } \\
\text { Uniwersytetu Gdańskiego w Gdańsku }\end{array}$ \\
\hline
\end{tabular}




\begin{tabular}{|c|c|}
\hline Name & Title and Organisation \\
\hline Meisner Barbara & MOPS Sopot \\
\hline Michalak Marek & LM Consulting \\
\hline Mirotta-Murawska Izabela & Departament Rozwoju Gospodarczego UMWP \\
\hline Rzyski Stanisław & $\begin{array}{l}\text { Mgr, Katedra Geografii Ekonomicznej na Wydziale Oceanografii i Geografii } \\
\text { Uniwersytetu Gdańskiego w Gdańsku }\end{array}$ \\
\hline Sikorska Ludwika - & $\begin{array}{l}\text { Pełnomocnik JM Rektora UG } \\
\text { Gdański Uniwersytet Trzeciego Wieku }\end{array}$ \\
\hline Wójcikiewicz Krzysztof & Powiatowe Centrum Zdrowia So. Z o.o. NZOZ w Malborku \\
\hline Dziewiątkowska - Seroka Kinga & Departament Programów Regionalnych UMWP \\
\hline Liedtke-Jarema Janina & $\begin{array}{l}\text { p.o. Dyrektora } \\
\text { Miejski Ośrodek Pomocy Społecznej w Gdańsku }\end{array}$ \\
\hline Majewski Dariusz & $\begin{array}{l}\text { Pomorski Urząd Wojewódzki } \\
\text { Wydział Polityki Społecznej }\end{array}$ \\
\hline Pankau Feliks & $\begin{array}{l}\text { Zastępca Dyrektor } \\
\text { Departament Rozwoju Regionalnego i Przestrzennego UMWP }\end{array}$ \\
\hline Rogocz Maciej & Biuro Rozwoju Miasta Gdańska \\
\hline Weremko Katarzyna & Regionalny Ośrodek Polityki Społecznej UMWP \\
\hline Maja Grabkowska & $\begin{array}{l}\text { Uniwersytet Gdański } \\
\text { Katedra Geografii Ekonomicznej }\end{array}$ \\
\hline Brzoskowska Alicja & „MORPHE” Pracownia Architektoniczna \\
\hline Burczyk-Dobrysiak Marta & Routermedia \\
\hline Bystry Wojciech & $\begin{array}{l}\text { Prezes } \\
\text { Towarzystwa Pomocy im. Św. Brata Alberta Koło Gdańskie }\end{array}$ \\
\hline Dominiczak Krystyna & $\begin{array}{l}\text { Dyrektor } \\
\text { Regionalny Ośrodek Polityki Społecznej UMWP }\end{array}$ \\
\hline Jakubowska Julita & $\begin{array}{l}\text { Dyrektor } \\
\text { Miejski Ośrodek Pomocy Społecznej w Tczewie }\end{array}$ \\
\hline Jarosz Anna & $\begin{array}{l}\text { Dyrektor } \\
\text { Miejski Ośrodek Pomocy Społecznej w Sopocie }\end{array}$ \\
\hline Podgórniak Maria & $\begin{array}{l}\text { Pełnomocnik ds. osób niepełnosprawnych } \\
\text { Urząd Miejski w Gdańsku }\end{array}$ \\
\hline
\end{tabular}




\section{Annex 10 Note on contributors}

Professor Iwona Sagan is the Head of Department of Economic Geography, University of Gdańsk, and o-ordinator of the RECOURSE Centre of Excellence - "Research and Education Centre for Urban SocioEconomic Development". Her primary research areas include: urban and regional governance, transformation of the post-socialist cities, theory and methodology of regional studies. She is a Head of the Metropolitan Experts' Board of the Pomorskie Marshall's Office as well as an advisor in both Regional and City of Gdańsk Urban and Architecture Commissions. She is a research affiliate of the Martin Prosperity Institute, Rotman School of Management, University of Toronto.

Dr. Cristina Martinez-Fernandez is a Senior Policy Analyst on Employment and Skills, Green Growth and South-East Asia at the Organisation for Economic Co-operation and Development (OECD), Local Economic and Employment Development (LEED) programme. She works on issues related to the challenges of skills and training systems for SMEs, entrepreneurial and innovation activities; industrial policy, climate change and the transformation of labour markets into the low-carbon economy; the challenges of demographic change and an ageing society for skills and employment development. Cristina also manages the OECD/LEED Initiative on Employment and Skills Strategies in Southeast Asia (ESSSA). Before joining the OECD she was an Associate Professor at the Urban Research Centre, University of Western Sydney in Australia where she led the Urban and Regional Dynamics Programme which analyses industry change, urban performance and socio-economic development within the frameworks of innovation, globalisation and the knowledge economy.

Dr. Tamara Weyman works as a contracted expert for the OECD, working on various projects involving employment and skills, SMEs development, South-East Asia, territorial development policy, and demographic change and sustainability. Recently Tamara has been involved in publications such as 'Martinez-Fernandez, C.; I.Miles; T.Weyman (2012) The Knowledge Economy at Work: Skills and Innovation in Knowledge Intensive Services Activities, Edward Elgar; Martinez-Fernandez, C.; P.Chorazy; T.Weyman; and M.Gawron. (2011), The Territorial Dimension of the European Social Fund: A Local Approach for Local Jobs, OECD; OECD (2012) Skills development and Training in SMEs, OECD publishingOECDpublishing; Martinez-Fernandez, C.; N.Kubo; A.Noya; and T.Weyman (2012), Demographic Change and Local Development: Shrinkage, Regeneration and Social Dynamics, OECD; and a chapter in a forthcoming book Schatz, L.; D.Leadbeater; C.Martinez-Fernandez; and T.Weyman (2013), 'From "up north" to "down under": Dynamics of shrinkage in mining communities in Canada and Australia' in Stories of Tough Times: International perspectives and policy implication in shrinking cities, Routledge. Tamara worked as a Research Associate at the Urban Research Centre, University of Western Sydney (UWS) and completed her PhD on Spatial Information Sharing for Better Regional Decision Making in 2007 at UWS. Since 2009, Tamara has been involved in the COST Action TU 0803 "Cities Regrowing Smaller". 


\section{POMORSKIE REGION:}

RESPONDING TO DEMOGRAPHIC TRANSITIONS TOWARDS 2035 